\author{
UNIVERSIDADE DE SÃO PAULO \\ ESCOLA DE ENGENHARIA DE SÃO CARLOS \\ DEPARTAMENTO DE ENGENHARIA MECÂNICA
}

\title{
Sistema Para Medição de ErRo de Planicidade
}

RItA de CÁssia AlVes de MAGAlhães

Dissertação apresentada à Escola de Engenharia de São Carlos da Universidade de São Paulo, como parte dos requisitos para obtenção do título de Mestre em Engenharia Mecânica

OrientAdor: Prof. Dr. Benedito Di Giacomo

\section{São Carlos}

2006 
Ficha catalográfica preparada pela Seção de Tratamento da Informação do Serviço de Biblioteca - EESC/USP

M188s Magalhães, Rita de Cássia Alves de Cássia Alves de Magalhães. -- São Carlos, 2006.

Dissertação (Mestrado) -- Escola de Engenharia de São Carlos-Universidade de São Paulo, 2006.

Área: Engenharia Mecânica.

Orientador: Prof. Dr. Benedito Di Giacomo.

1. Metrologia. 2. Metrologia dimensional. 3. Desvio de planicidade. 4. Técnicas de separação de erros. I. Título. 
Aos meus pais Anna e João (in memorian).

Com todo o meu amor. 


\section{Agradecimentos}

Ofereço meus sinceros agradecimentos ao Prof. Dr. Benedito Di Giacomo por ter sido professor, estudante, amigo e companheiro. Obrigada pela paciência e dedicação para me transmitir seus conhecimentos e experiências. Pelas lições que não podem ser encontradas em livros.

Aos colegas de pós-graduação Alessandro, Fabrício, Marcela, Alexandre, Rosenda, Márcia, Eraldo, Juliana, Enzo, Alessandra, Roberto e Andréa por terem tornado os anos de pós-graduação tão agradáveis.

Ao Prof. Dr. Roberto Hideaki Tsunaki pelo incentivo à pesquisa científica e por todas as discussões que ajudaram o desenvolvimento deste trabalho e o meu aprendizado.

Ao Luiz Carlos Neves pelas brincadeiras e amizade. Obrigada, pela ajuda na montagem dos experimentos, coletas de dados e pelo apoio dado durante a fase em que estive ausente de São Carlos.

Ao Alessandro Marques pela amizade e ajuda no desenvolvimento dos programas computacionais.

Ao MSc. José Cláudio P. De Azevedo pela ajuda no desenvolvimento das interfaces eletrônicas, pela amizade e por estar perto quando precisava de ajuda.

Aos funcinários de oficina Adão S. Bolsan, José C Botelho e José C. Risardi pelo apoio técnico e incontáveis visitas à oficina.

À minha mãe e ao meu pai (in memorian) que, mesmo com todas as dificuldades e limitações, não pouparam esforços para me educar. Obrigada pelo amor e carinho que têm por mim.

Aos meus irmãos Fátima, Ângelo e Joana por nunca me faltarem. Pelas risadas e lágrimas. Pelas longas conversas 'filosóficas'.

Aos meus sobrinhos Carol, Laura, Lívia, Caio, João Victor, João Gabriel e José Gabriel por me darem tantas alegria e me fazerem passar horas rindo de suas peraltices.

Às amigas Priscila, Laura e Ana Carolina, com quem compartilho minhas alegrias e aflições.

Ao Gil por me fazer sonhar.

A Deus por sempre me acompanhar e me dar forças.

A todos aqueles que de uma forma ou de outra contribuíram para a realização deste trabalho. 


\section{Sumário}

LISTA DE FIGURAS IV

LISTA DE GRÁFICOS VI

LISTA DE TABELAS VII

RESUMO VIII

$\begin{array}{ll}\text { ABSTRACT } & \text { IX }\end{array}$

CAPÍTULO 1: INTRODUÇÃO 1

CAPÍTULO 2: DEFINIÇÃO E MÉTODOS DE MEDIÇÃO DO 4 DESVIO DE PLANICIDADE

2.1 Definição para Planicidade e Tolerância de Planicidade 6

2.2 Princípios de Geração e Medição de Superfícies Planas 8

2.3 Superfícies de Referência e outros Métodos de Medição de 19

Desvio de Planicidade

2.4 Instrumentos mais Utilizados na Medição de Desvio de 25

Planicidade

2.5 Evolução dos Algoritmos para Cálculo do Desvio de 30

Planicidadade

CAPÍtUlo 3: FERRAMENTAS MATEMÁticas PARA O 32 ESTUdo E ANÁlise DO DESVIO DE PLANICIDADE E CÁlCULO DA INCERTEZA DE MEDIÇÃo

3.1 Técnicas Históricas de Separação de Erros 33

3.1.1 Teste de Três Planos 34

3.1.2 Reversão do Nivel 35

3.2 Técnicas Atuais de Separação de Erros 36

3.2.1 Reversão da Régua Padrão 36

3.2.2 Método "Sequential-Two-Points" (TSP) 38 
3.2.3 Método "Sequential-Three-Points" (STRP) 40

3.2.4 Método Combinado ( Kiyono e Gao, 1994) 42

3.2.5 Método com Três Apalpadores ( Gao et al, 2002) 44

3.3 Método Matemático para Determinação do Desvio de 46 Planicidade

3.3.1 Método dos Mínimos Quadrados 46

3.3.2 Método dos Mínimos Desvios Proposto por Huang et al 49 (1993)

3.3.3 Método de Otimização para Determinação do Desvio de 53 Planicidade

3.4 Conceitos Estatísticos Básicos para Tratamento de Dados 55 Experimentais

3.4.1 Incerteza Padrão $\quad 57$

3.4.2 Incerteza Padrão Combinada 60

$\begin{array}{ll}\text { 3.4.3 Incerteza Expandida } & 61\end{array}$

CAPÍtulo 4: SISTEMA PARA MEDIÇÃo DE ERRO DE 63 PLANICIDADE

4.1 Desenvolvimento das Interfaces entre Máquina, Computador 64

e Operador

4.2 Método de Tomada de Dados 65

4.3 Método Matemático 66

4.4 Avaliação do Sistema Múltiplas Sondas $\quad 67$

4.5 Cálculo da Incerteza de Medição 67

CAPÍTULO 5: DESENVOLVIMENTO DO SISTEMA PARA 68 MEDIÇÃO DE ERRO DE PLANICIDADE

5.1 Desenvolvimento da Interface entre Máquina e Computador $\quad 69$

5.2 Método de Tomada de Dados $\quad 72$

5.3 Algoritmo para Cálculo o Desvio de Planicidade 73

5.4 Avaliação do sistema Múltiplas Sondas 80

5.5 Cálculo da Incerteza de Medição 81

5.5.1 Incerteza no cálculo das alturas $\mathrm{u}^{2}(\mathrm{z}) \quad 82$ 
5.5.2 Cálculo de $u^{2}\left(\beta_{0}\right), u^{2}\left(\beta_{1}\right)$ e $u^{2}\left(\beta_{2}\right)$

CAPÍTULO 6: TESTES EXPERIMENTAIS, RESULTADOS E 89 DISCUSSÃO

6.1 Medição do Erro de Retilineidade 90

6.1.1 Resultados Obtidos com o Método Combinado Proposto 90 por Kiyono e Gao, 1994

6.1.2 Resultados Obtidos com o Método Utilizando Três 93 Apalpadores Proposto por Gao et al, 2002

6.1.3 Resultados Obtidos com o Método "Sequential-Three- 97 Points" (STRP)

6.1.4 Resultados Obtidos com o Método "Sequential-Two- 99 Points" (TSP)

6.1.5 Verificação da Repetibilidade dos Métodos de 101 Separação de Erros

6.2 Medição de Erro de Planicidade 103

6.3 Cálculo da Incerteza de Medição 103

6.3.1 Cálculo da Incerteza Relativa às Alturas Z medidas 103

6.3.2 Cálculo de $u^{2}\left(\beta_{0}\right) u^{2}\left(\beta_{1}\right)$ e $u^{2}\left(\beta_{2}\right) \quad 105$

6.3.3 Cálculo de $\mathrm{u}^{2}(\operatorname{Max}($ dist $))$ e $\mathrm{u}^{2}(\operatorname{Min}($ dist$)) \quad 107$

CAPÍTULO 7: CONCLUSÕES E SUGESTÕES PARA 107

TRABALHOS FUTUROS

$\begin{array}{ll}\text { REFERÊNCIAS BIBLIOGRÁFICAS } & 110\end{array}$ 


\section{Lista de Figuras}

Figura 2.1. Tolerância de planicidade segundo ASME $\quad 7$

$\begin{array}{ll}\text { Figura 2.2. Tolerância de planicidade segundo ABNT } & 7\end{array}$

Figura 2.3. Zona de tolerância de planicidade 8

Figura 2.4. Máquina de 'Polimento 10

Figura 2.5. Plano Ótico 12

Figura 2.6. Sistema PBSS para medição de erro de planicidade 13

Figura 2.7. Conversão de ângulo em altura 14

Figura 2.8. Princípios de medição de forma 3D através de franjas 15

de moiré

Figura 2.9. Medição por triangulação 16

Figura 2.10. Sistema de medição de panicidade sem contato 18

$\begin{array}{ll}\text { Figura 2.11. Máquina de serrar granito } & 21\end{array}$

Figura 2.12. Repeat-o-meter_ instrumento para medição de 21

planicidade em desempenos

Figura 2.13. Espelho normal ao eixo ótico 22

Figura 2.14. Espelho inclinado 22

Figura 2.15. Esquema de um autocolimador 23

Figura 2.16. Medição de planicidade com régua padrão e blocos 23 padrões

Figura 2.17. Medição de planicidade de desempeno 24

Figura 2.18. Medição de ângulos 25

Figura 2.19. Ópticas para medição angular 27

Figura 2.20. Montagem para medir planicidade 27

Figura 2.21. Nivel de bolha 28

$\begin{array}{ll}\text { Figura 2.22. Nivel eletrônico } & 29\end{array}$

Figura 3.1. Teste de três planos $\quad 34$

Figura 3.2. Esquema para inversão do nivel 35

Figura 3.3. Esquema de montagem para medição de erro de 37 retilineidade 
Figura 3.4. Princípio do método STP 38

Figura 3.5. Desalinhamento entre sensores (Tanaka e Sato, 1986) 39

Figura 3.6. Princípio do método STRP (Tanaka e Sato, 1986) 41

Figura 3.7. Princípio do Método Combinado (Kiyono e Gao,1994) 43

Figura 3.8. Método com três apalpadores (Gao et al,2002) 44

Figura 3.9. Desalinhamento entre os sensores (GAO et al,2002) 45

Figura 3.10. Comparação entre MMQ e Mínimo Desvio 48

Figura 3.11. Determinação do modelo 1-1 50

Figura 3.12. Rotação dos planos de Controle para formar 50 modelo2-1

Figura 5.1.Representação da máquina de medir a três $\quad 70$ coordenadas do tipo ponte móvel

Figura 5.2. Garra de medição 70

Figura 5.3. Esquema do sistema de medição 71

Figura 5.4. Método das linhas diagonais 72

Figura 5.5. Union jack $\quad 72$

Figura 5.6. Método de grades retangulares 72

$\begin{array}{ll}\text { Figura 5.7. Linhas para coleta de dados } & 72\end{array}$

Figura 5.8. Tela do programa computacional 73

Figura 5.9. Fluxograma para coleta de dados 74

Figura 5.10. Fluxograma dos métodos de separação de erros com 75

2 e 3 sensores propostos por Tanaka e Sato (1986)

Figura 5.11. Cálculo do desvio de planicidade 78

Figura 5.12. Medição da peça teste com nivel eletrônico 80

Figura 5.13. Foto da medição da peça teste com interferômetro a 81 laser 


\section{Lista de Gráficos}

Gráfico 6.1: Comparação entre os resultados obtidos com cada uma das combinações de sensores.

Gráfico 6.2: Comparação entre os resultados obtidos com cada 92 uma das combinações de sensores desalinhamento eliminado

Gráfico 6.3-a Erro de retilineidade régua de aço com 93 desalinhamento

Gráfico 6.3-b Erro de retilineidade régua de aço sem 93 desalinhamento

Gráfico 6.4: Erro de retilineidade régua de granito calculado com método proposto por GAO et al,2002.

Gráfico 6.5: Resultados do desvio de retilineidade da superficie 96 idealizada

Gráfico 6.6: Erro de retilineidade régua de aço calculado com método proposto por GAO et al,2002.

Gráfico 6.7: Desvio de retilineidade determinados através do 97 método STRP

Gráfico 6.8-a: Desvio de retilineidade régua de granito usando método TSP com desalinhamento

Gráfico 6.8-b: Desvio de retilineidade régua de granito usando método TSP sem desalinhamento

Gráfico 6.9-a: Desvio de retilineidade régua de aço usando método TSP com desalinhamento

Gráfico 6.9-b: Desvio de retilineidade régua de aço usando método TSP sem desalinhamento

Gráfico 6.10: Resultado do experimentos realizados para verificar 100 repetibilidade dos métodos de separação de erros

Gráfico 6.11 : Erros de planicidade medidos utilizando diferentes 102 sistemas de medição 


\section{Lista de Tabelas}

Tabela 2.1. Exemplos de aplicação de desempenos 19

Tabela 3.1. Comparação entre os métodos ( Weber et al, 2002) 54

Tabela 3.2. Fator de abrangência e seu respectivo nível de 59

confiança assumindo uma distribuição normal (gaussoana)

Tabela 6.1. Leitura dos sensores A, B e C em sistema idealizado 95

Tabela 6.2. Leitura dos sensores A, B e C em sistema sem 95

desvios geométricos e com sensores desalinhados

Tabela 6.3. Equações usadas para separação de erros com 98

método de TSP

Tabela 6.4. Comparação entre sistemas de medição 102

Tabela 6.5. Incerteza no cálculo de $\beta_{0}, u\left(\beta_{0}\right) \quad 104$

Tabela 6.6. Incerteza no cálculo de $\beta_{1}, \mathrm{u}\left(\beta_{1}\right) \quad 104$

Tabela 6.7. Incerteza no cálculo de $\beta_{2}$, u( $\left.\beta_{2}\right) \quad 104$

Tabela 6.8. Incerteza no cálculo de Máx(dist), u(Máx(dist)) 105

Tabela 6.9. Incerteza no cálculo de Mín(dist), $u($ Mín(dist)) 105

Tabela 6.10. Incerteza do resultado da medição de desvio de 106 planicidade 


\section{Resumo}

MAGAlHÃES, R.C.A.. Sistema para Medição de Desvio de

Planicidade. Dissertação (Mestrado). Escola de Engenharia de São Carlos. Universidade de São Paulo.2005.

A acuracidade dos processos de medição e de montagem que utilizam os desempenos como referência depende principalmente da planicidade dessas superficies. Se a referência está fora das especificações é inútil utilizar instrumentos sofisticados e de alta acuracidade.

Neste trabalho é apresentado um sistema para medição de desvios de planicidade de desempenos. O sistema é constituído por dois transdutores de deslocamento do tipo LVDT fixados no eixo $z$ de uma Máquina de Medir a Três Coordenadas (MM3C).

Durante a medição a intenção é avaliar apenas os desvios da superfície, no entanto os mancais das MM3C não se deslocam perfeitamente e as leituras obtidas são as componentes dos desvios da superficie e do movimento dos mancais. Para eliminar os componentes de erros da máquina dos dados medidos, pode-se usar as técnicas de separação de erros, e então, o desvio da superficie pode ser determinado.

O sistema de medição proposto possui uma interface eletrônica que possibilita a aquisição dos sinais da régua óptica da MM3C e dos transdutores de deslocamento do tipo LVDT. Possui, também, um programa computacional que utiliza as técnicas de separação de erros para determinar o desvio de planicidade do mensurando.

O sistema desenvolvido foi utilizado para medir o desvio de planicidade de uma superficie. Para verificar a eficiência do mesmo foi realizada uma comparação entre os valores de erro de planicidade obtidos através de medição com o sistema proposto e aqueles obtidos com interferômetro a laser e nível eletrônico.

Palavras Chaves: Metrologia Dimensional, Desvio de Planicidade, Técnicas de Separação de Erros. 


\section{Abstract}

The accuracy of measurement and assembly process using surface plates depends mainly on these surfaces flatness. If the surface plate does not meet the flatness specification, it is ineffective to apply high technology instruments of measurement.

This research proposes is to develop a flatness measurement system for surface plates using two electronic comparators attached to the Coordinate Measuring Machine (CMM).

During a measurement process, the purpose is to evaluate the workpiece profile. However, the signals picked up by sensors include the workpiece profile and component motion error. In order to separate these errors, error separation techniques can be applied.

The proposed measurement system has an electronic interface to collect data from the CMM optical scale and from the electronic comparators. The collected data are sent to a computer prepared with an algorithm for applying the error separation equations and for compute the flatness error.

A surface was measured using the proposed measurement system. To evaluate its efficiency, the results were compared to the measurements made using electronic level and laser interferometric system.

Keywords: Dimensional Metrology; Flatness; Error Separation Technique. 


\section{INTRODUÇÃO}

A economia capitalista mundial, caracterizada pelo dinamismo do ambiente competitivo tem acelerado o desenvolvimento de tecnologias ligadas diretamente à produtividade industrial. É a necessidade cada vez mais premente de aumentar a produtividade, melhorar a qualidade e de reduzir custos dos produtos manufaturados que leva os países a investirem na procura de novas tecnologias e na automatização dos processos de fabricação e inspeção.

Das diversas fases da manufatura de um produto, uma das importantes é o controle de qualidade, nesta fase as dimensões das peças são medidas e comparadas aos valores especificados no projeto. Os erros de forma, orientação e posição também são medidos e 
comparados aos valores especificados para garantir o bom funcionamento do produto final e muitas vezes a intercabiabilidade.

O controle dos erros de forma e em especial o de planicidade se faz necessário em vários casos e os mais diferentes como, por exemplo, dar conforto e segurança às pessoas que utilizam rodovias e pistas de pouso de aeroportos. Um outro aspecto é o econômico, já que aumentar a qualidade de um produto implica em torná-lo mais competitivo. Isto pode ser verificado, por exemplo, no processo de laminação, uma das áreas do setor siderúrgico. A partir de diversas intervenções tecnológicas ganhos de produtividade foram conseguidos e garantiram o diferencial do produto, colocando a siderurgia brasileira dentre as mais competitivas do mundo. A melhoria da planicidade dos laminados permitiu atender aplicações criticas, especialmente nos setores de eletrodomésticos, móveis de aço, construção civil e etc.

Outros casos em que se deseja controlar a planicidade que podem ser mencionados são o encaixe de peças, o contato de superfícies, em mesas de montagem, diversos elementos de máquinas, instrumentos de medição mecânica, instrumentos óticos utilizados na medicina, odontologia, astronomia entre outros. Os limites de imperfeição do plano são de grande interesse, também, na construção de máquinas ferramentas onde o assento de carros e caixas de engrenagens sobre guias prismáticas ou paralelas e mesas de fixação das peças têm grande influência na precisão exigida da máquina.

A acuracidade dos processos de medição e de montagem que utilizam os desempenos como referência depende principalmente da planicidade dessas superficies. Se a referência está fora das especificações é inútil utilizar instrumentos sofisticados e de alta acuracidade.

Assim, diante do exposto, este trabalho tem por objetivo apresentar um sistema para medição de desvios de planicidade de desempenos. $O$ sistema de medição possui uma interface eletrônica que possibilita a aquisição dos sinais da régua óptica da MM3C e dos transdutores de deslocamento do tipo LVDT e uma interface computacional que utiliza 
os sinais adquiridos para calcular o desvio de planicidade de uma superficie.

O sistema desenvolvido foi utilizado para medir o desvio de planicidade de uma superfície. Para verificar a eficiência do mesmo foi realizada uma comparação entre os valores de erro de planicidade obtidos através de medição com o sistema proposto e aqueles obtidos com interferômetro a laser e com nível eletrônico.

Para um melhor entendimento, uma breve descrição dos capítulos do trabalho encontra-se na seqüência.

No capitulo dois são descritos uma série de sistemas de medição de desvio de planicidade desenvolvidos ao longo do último século. Além disso, é apresentada a definição de desvio de planicidade de acordo com as normas técnicas. Uma parte do capítulo é dedicada à descrição dos processos de fabricação e medição de desempenos.

No capítulo três são apresentadas as técnicas de separação de erros do sistema de medição e do mensurando e os algoritmos para cálculo do desvio de planicidade.

No capítulo quatro, é apresentado o sistema proposto para medição de desvio de planicidade.

No capítulo cinco, o sistema proposto é descrito detalhadamente. A interface entre máquina e microcomputador e o algortimo para cálculo do desvio de planicidade são apresentados. Por último, são introduzidas as equações para cálculo da incerteza das medição realizadas com o sistema proposto.

No capítulo 6 os resultados obtidos nos testes experimentais e uma discussão serão apresentadas.

As conclusões e as sugestões para trabalhos futuros estão apresentadas no capítulo 7 . 


\section{Capítulo 2}

\section{DEFINIÇÃO E MÉTODOS DE MEDIÇÃO DO DESVIO DE PLANICIDADE}

As fontes de erros são atribuídas normalmente à presença de forças de corte no processo de usinagem, aos erros nas guias das máquinas, à variações térmicas durante o processo de usinagem, à falta de rigidez da máquina e a deformações devido ao próprio peso da peça (Day e Marples, 1972).

Os desvios de forma são definidos como o grau de variação das superficies reais com relação às geometrias ideais que as definem e podem ser divididos em desvio de retilineidade, circularidade, cilindricidade e planicidade. O bom desempenho de sistemas mecânicos 
está ligado ao grau de conformidade das formas reais com suas geometrias euclidianas equivalentes, isto é, dentro das tolerâncias estabelecidas. A necessidade de avaliar o erro de planicidade justifica-se em muitas aplicações. A seguir estão apresentadas algumas dessas aplicações e para facilitar a apresentação, as superficies estão classificadas de acordo com suas dimensões. Segundo essa classificação as superfícies estão divididas em muito grandes, grandes, médias e pequenas.

As pistas de pouso de aeroportos, rodovias, pisos de depósitos e de fábricas são chamadas de superficies muito grandes. As normas do ACI (American Concrete Institute) especificam os métodos de medição e as tolerâncias de planicidade e de nivelamento para tais superficies.

Desempenos, guias e mesas de máquinas ferramentas utilizados durante fabricação de peças, medições e montagem de conjuntos são consideradas superfícies grandes e a medição do erro de planicidade pode ser feita com o auxílio de transdutores de deslocamento do tipo LVDT, de autocolimador, de interferômetro laser, de nível eletrônico ou de nivel de bolha.

Peças como selos mecânicos, blocos de motores e discos de embreagem são classificadas como peças médias. A medição dos erros de planicidade dessas peças pode ser realizada com a utilização de LVDT, régua padrão ou MM3C (Máquina de Medir a Três Coordenadas). Em peças médias o desvio de planicidade deve ser controlado, por exemplo, para melhorar o contato entre superficies. O contato imperfeito entre a face superior do bloco de motores e a face inferior do cabeçote pode, por exemplo, causar vibrações e perda de potência. Os selos mecânicos, utilizados em bombas hidráulicas, tampas de redutores e cárteres, têm a função de vedar e devem permitir o contato pleno para impedir o vazamento de fluidos. As faces de contato entre volante de motor e disco de embreagem devem ter baixo desvio de planicidade para garantir a transmissão adequada de potência 
Blocos padrões e sapatas de contado de micrômetros são classificadas como peças pequenas. A inspeção do desvio de planicidade em tais superficies é feita com paralelos ópticos ou planos ópticos.

O maior tamanho da superfície não implica em tolerâncias maiores para o desvio de planicidade como pode ser visto nos desempenos que possuem tolerâncias na faixa de $8 \mu \mathrm{m}$ e são classificados como superficies grandes. Já a face superior do bloco de motor, classificado como superficie média, possui tolerâncias por volta de $30 \mu \mathrm{m}$. Portanto, o valor tolerado é determinado a partir da aplicação da superfície.

Este capítulo apresenta uma ampla revisão bibliográfica sobre desvio de planicidade, definição de desvio de planicidade e algumas considerações sobre instrumentos de medição do desvio de planicidade.

\subsection{DefiniçÃo Para Planicidade E TOlerÂncia de PLANICIDADE}

Para definir um plano são necessários três pontos não colineares, ou um ponto e uma reta, ou duas retas. Por esta definição um plano não possui espessura e, portanto, não possui vales nem picos, sendo perfeito para ser utilizado como referência nas medições e nos processos de fabricação. No entanto, não se consegue fabricar tal plano e por isto tolerâncias são especificadas para os pontos que ficam fora do plano ideal, devendo existir um limite para o quanto fora eles estão. A seguir são apresentadas algumas definições para o erro e para tolerância de planicidade segundo ASME, BSI, JIS e ABNT.

De acordo com a BSI (British Standarts Institution) a zona de tolerância de planicidade é limitada por dois planos paralelos e a distância entre eles é o valor tolerado.

Segundo a JIS (Japanese Institution for Standarts) a planicidade de uma superfície de trabalho é expressa pela dimensão do intervalo mínimo entre dois planos paralelos. 
Segundo a ASME (The American Society of Mechanical Engineers) planicidade é a condição de uma superficie com todos os seus elementos em um plano. A tolerância de planicidade é definida por dois planos paralelos, distantes de $t$, entre os quais a superficie deve pertencer, Figura 2.1.

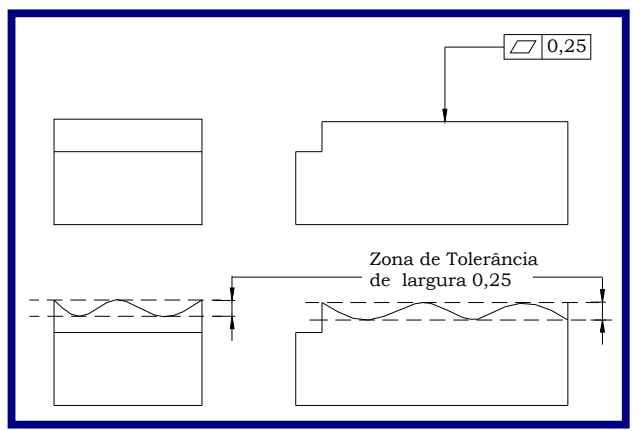

Figura 2.1- Tolerância de planicidade segundo ASME

Conforme a ABNT (Associação Brasileira de Normas Técnicas) o campo de tolerância é limitado por dois planos paralelos, distantes de 't', entre os quais deve estar situada a superficie em consideração, Figura 2.2.

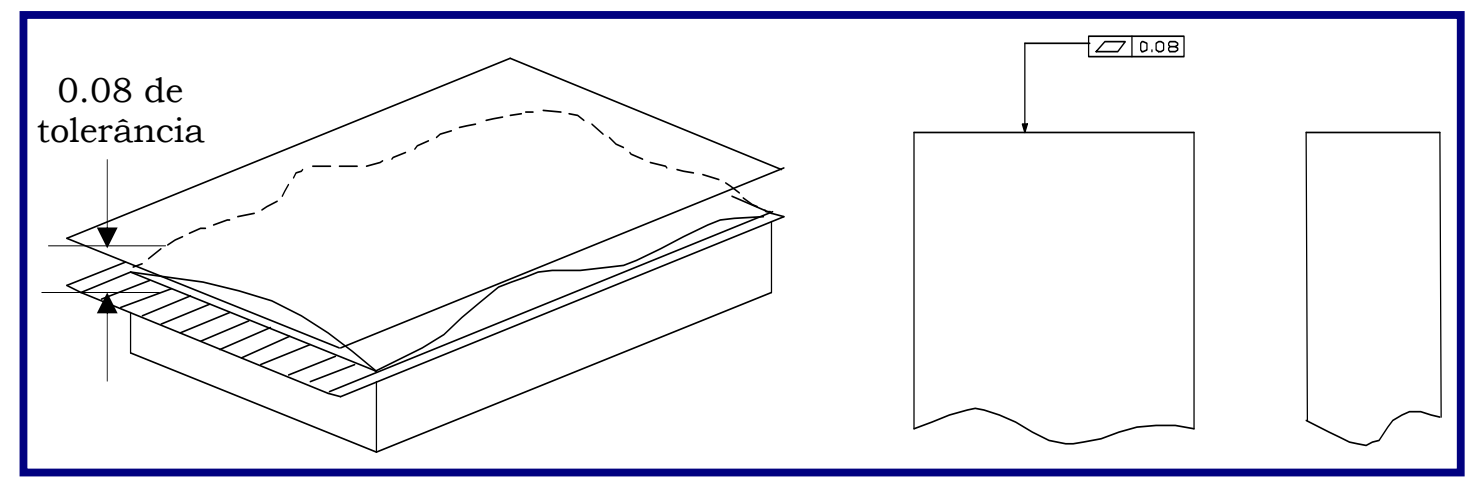

Figura 2.2- Tolerância de planicidade segundo ABNT

As normas citadas acima foram escritas quando, apenas blocos padrões eram usados para inspeção, causando ambigüidades quando vários pontos sobre a superficie passaram a ser tomados para caracterizar a superficie (Carr e Ferreira, 1995). Esse problema levou os 
membros das comunidades de normalização a desenvolver uma definição matemática para tolerâncias geométricas. As definições foram documentadas na norma ANSI Y14.5.1M-'Draft: Mathematical Definition of Dimensioning and Tolerancing Principle' no ano de 1993. De acordo com essa norma, zona de planicidade é um volume em que todos os pontos, $\vec{P}_{i}$, satisfazem a condição:

$$
\left|\hat{T} *\left(\vec{P}_{i}-\vec{A}\right)\right| \leq \frac{t}{2}
$$

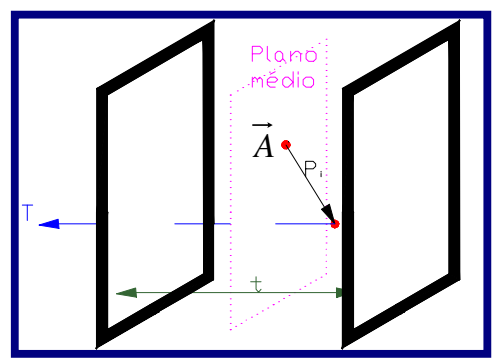

Figura 2.3- Zona de tolerância de planicidade

Sendo, T o vetor direção dos planos paralelos que definem a zona de tolerância; $\vec{A}$ o vetor posição localizado no plano médio da zona de tolerância e $\mathrm{t}$ a distância entre os dois planos paralelos que contêm todos os pontos medidos, como mostrado na Figura 2.3.

\subsection{PRINCÍPIOS DE GERAÇÃo E MEDIÇÃo DE SUPERFícIES PLANAS}

Em 1817 Richard Roberts inventou a plaina possibilitando a fabricação de superficies planas e paralelas com maior produtividade (Busch, 1988). Essas superfícies possuíam, porém, baixa acuracidade. 
Mas quem poderia garantir acuracidade se ainda não existiam instrumentos precisos de medição nem planos de referência?

Joseph Whitworth, há 150 anos, já sabia da importância dos plano de referência. Percebendo que não poderia existir manufatura precisa sem medições precisas, e que não poderiam existir medições precisas se não existissem planos de referência, Whitworth desenvolveu o método das três chapas para gerar um plano de referência. Esse método utiliza três peças de ferro fundido e consiste na anulação dos erros da superficie de cada plano combinando-as duas a duas, colocando suas superficies em contato e movendo-as uma contra a outra. Obtendo assim, três superfícies com baixo erro de planicidade (Busch, 1988).

Desde então, o homem começou a estudar métodos para a medição de desvios de planicidade de superficies de referência e também de superficies onde a planicidade deve ser controlada para garantir sua funcionalidade.

Em 1962, Gale e Wilson desenvolveram uma máquina para medir desvio de planicidade em superfícies com dimensões máximas de $95 \mathrm{~mm}$ x 95mm x 19mm. O princípio de funcionamento da máquina é simples. A peça a ser medida é colocada sobre três parafusos de regulagem no desempeno da máquina. Ajustando os parafusos gera-se um plano de referência e as alturas da superficie são medidas pneumaticamente. A vantagem desse tipo de medição é a ausência de carregamento sobre a peça. O desempenho da máquina foi verificado através da medição de um plano óptico. A acuracidade conseguida foi de $38 \mu \mathrm{m}$.

Uma máquina de polimento com prato de $305 \mathrm{~mm}$ de diâmetro foi usada por Dickinson em 1968 para fabricar superficies ópticas com baixo erro de planicidade. Os desvios de planicidade do prato eram modificados por três anéis posicionados junto ao prato, como pode ser visto na Figura 2.4. Movendo os anéis para dentro ou para fora do prato a forma da superfície é modificada de côncava para convexa. Entre essas condições existe uma posição dos anéis em que o prato permanece plano. Encontrada a posição adequada dos anéis, a máquina está pronta para trabalhar e novos ajustes raramente são 
necessários. Superfícies de $101 \mathrm{~mm}$ de diâmetro foram polidas com essa máquina e o erro de planicidade foi menor que $0,6 \mu \mathrm{m}$.

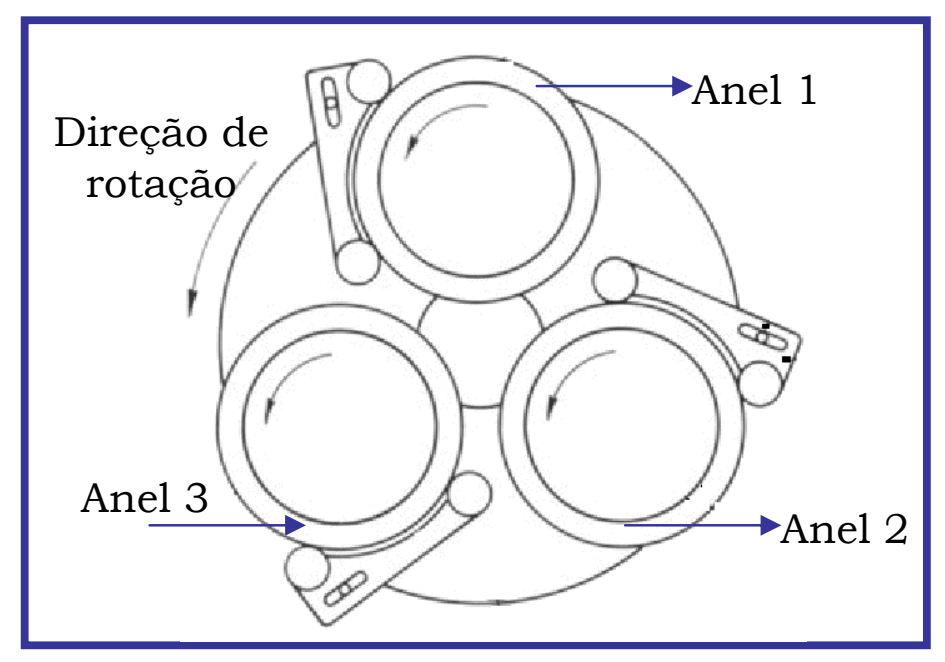

Figura 2.4- Máquina de polimento

Day e Marples fizeram, em 1972, adaptações no instrumento Talylin de medição de rugosidade de forma a habilitá-lo a medir desvios de planicidade. O Talylin possui um plano óptico que opera como referência sobre a qual corre uma guia de nylon. Qualquer movimento da agulha, fixado na guia de nylon, é medido com relação à linha de referência. Quando a agulha usada possui ponta com raio de curvatura bastante grande a resposta à rugosidade é minimizada, aparecendo apenas as ondulações com maiores comprimentos de onda, ou seja, os desvios de forma.

Para habilitar o Talylin para medir planicidade, uma mesa de referência, ajustável através de três parafusos de regulagem, foi construída e montada sobre a mesa rotativa. Mesa de referência, mesa rotativa e peça foram centralizadas, assim, a agulha percorre o mesmo raio quando a mesa rotativa gira $180^{\circ}$. A guia de nylon permite a medição de vários raios sobre a peça.

Os erros de batida da mesa rotativa e os desvios de retilineidade da guia de nylon diminuem a acuracidade das medições. A acuracidade foi verificada substituindo a mesa de referência por um plano óptico com 
erro de planicidade de 0,025 $\mu \mathrm{m}$ e feitas medições com o Talylin. O erro

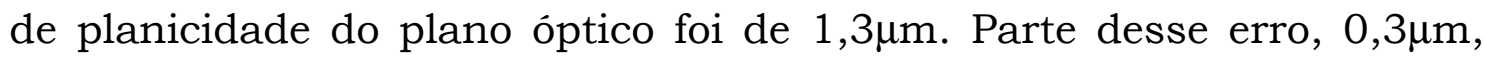
deve-se ao desvio de retilineidade da guia de nylon e $1 \mu \mathrm{m}$ de erro surge devido a inacuracidade do giro da mesa rotativa. O autor sugeriu para separar os erros causados pela mesa rotativa a utilização de métodos de reversão.

Medições de erro de planicidade auxiliadas por computador foram feitas por Birch em 1976. Para examinar a superficie de interesse foram feitos vários interferogramas e esses foram correlacionados usando um programa computacional desenvolvido por Birch e Cox (1973). O autor fez medições do desvio de planicidade de um espelho e os resultados demonstraram a eficiência da associação de interferômetro de incidência obliqua com microcomputador. Além disso, o autor verificou o comportamento da superfície de acordo com o tipo de apoio utilizado. Durante a medição o mensurando foi colocado sobre três tipos diferentes de suportes: três suportes igualmente espaçados em uma circunferência de raio $0,95 \mathrm{R}$, onde $\mathrm{R}$ é o raio do espelho medido; três suportes eqüidistantes no raio de 0,70R e seis suportes igualmente espaçados no raio de 0,70R. A forma da superficie foi modificada em cada uma das configurações e foi atribuída à ação da gravidade e à força dos suportes, como já havia sido discutido por Dew em 1966.

Nomura et al utilizaram, em 1992, o interferômetro de Fizeau para medição de erros de forma durante o processo de fabricação. Verificaram que o interferômetro não pode ser usado durante a fabricação devido a vibrações e gradientes de temperatura no ambiente. No entanto, afirmaram que se a máquina ficar parada por dez minutos as medições podem ser feitas com o interferômetro sem influências externas. A vantagem é que a peça não precisa ser retirada da máquina.

Continuando o trabalho de medição de erro de forma durante a fabricação de superfícies planas, Nomura et al apresentaram, em 1993, um sistema de medição usando o interferômetro com sistema óptico tridimensional montado em uma máquina de usinagem de alta precisão. Foi feita a medição do erro de espelhos girando a 900rpm e em 
velocidades menores. Os resultados foram os mesmos para várias velocidades e concordaram com os valores estáticos, obtidos com o interferômetro de Fizeau.

O objetivo da medição de plancidade é determinar o desvio de uma superficie com relação a outra plana padrão. Para esse tipo de medição comparativa pode ser usada projeção de luz, como no interferômetro de Fizeau. O interferômetro de Fizeau constitui de uma superficie de referência, uma fonte de luz colimada e monocromática e um visor para observar as franjas de interferência e é usado para medir desvio de planicidade. A superficie de referência usada nesse tipo de interferômetro é a face de planos ópticos.

Planos óticos para aplicações metrológicas são normalmente feitos de quartzo, podem ter várias dimensões e sua superficie é acabada de forma a se ter uma superfície próxima de um plano perfeito. Quando o plano ótico é colocado sobre uma superficie refletora com um pequeno ângulo de inclinação e luz monocromática incide sobre o plano ótico são formadas as franjas de interferência.

A Figura 2.5 apresenta o caminho percorrido pelo feixe de luz. O raio quando atinge a superficie A é refratado para a superficie B com um certo ângulo de inclinação. Na superficie $B$, parte do raio é refletida para $\mathrm{C}$ enquanto a outra parte atinge a superfície $\mathrm{E}$, onde é refletido percorrendo o caminho BEF. Um observador em DH verá a combinação destes dois raios.

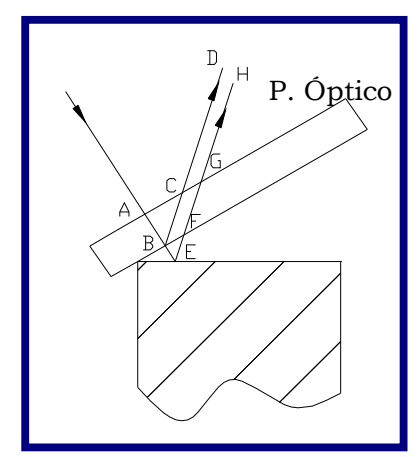

Figura 2.5: Plano Ótico 
$\mathrm{O}$ caminho adicionado $\mathrm{BEF}$ pode causar uma diferença de fase entre os dois raios. Se essa diferença é igual a um número ímpar de metades do comprimento de onda o resultado da combinação de raios será um escuro, pois ocorre o fenômeno de interferência destrutiva, caso contrário, um número par de metades do comprimento de onda, o resultado visivel será um claro, isto é interferência construtiva (Sardinãs, 1986).

Em 1997, Fan e Shiou descreveram o sistema desenvolvido em Taiwan para medição sem contato de erro de planicidade de superficies de tamanho médio, como lâminas de metal e superficies de vidro. $\mathrm{O}$ sistema consiste em fonte laser He_Ne com boa estabilidade, ópticas montadas em uma plataforma que pode ser rotacionada para modificar a direção do raio laser, lente colimadora para converter os raios laser divergentes em paralelos, uma estação linear para movimentar a peça para a posição de medição, uma tela para projetar os raios refletidos pela superficie de teste, câmera para capturar a imagem projetada e unidade de processamento de imagem para digitalizar a imagem projetada. O esquema do sistema PBSS (parallel beam scanning system) pode ser visualizado na Figura 2.6.

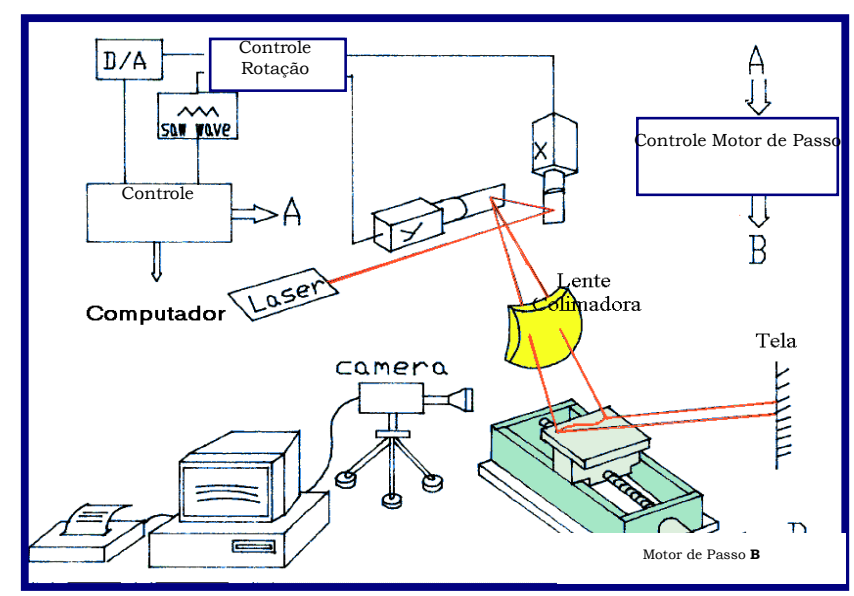

Figura 2.6: Sistema PBSS para medição de erro de planicidade 
O sistema PBSS faz medição do ângulo de inclinação de cada parte da superficie e os ângulos são convertidos em altura, como pode ser verificado na Figura 2.7.

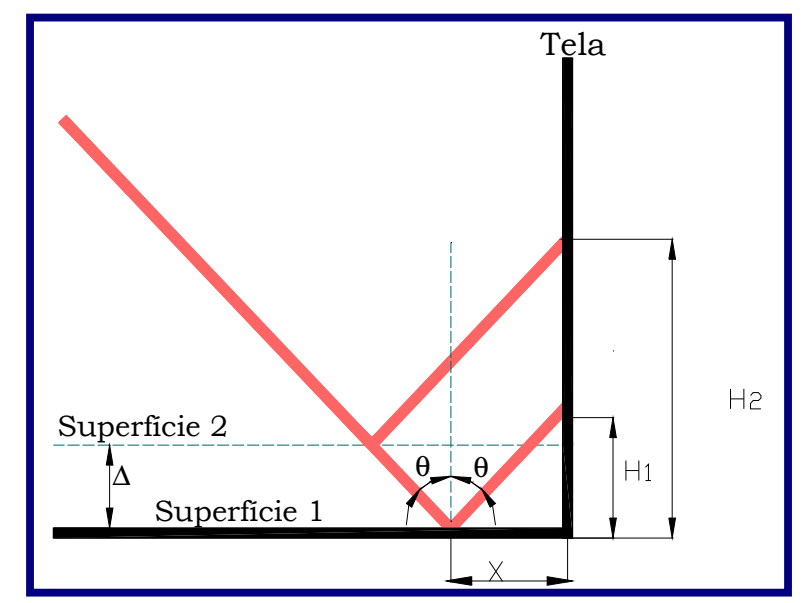

Figura 2.7: Conversão de ângulo em altura

Os autores fizeram medição de uma mesma peça com o sistema PBSS e com a MM3C e os resultados foram $117 \mu \mathrm{m}$ e $122 \mu \mathrm{m}$, respectivamente.

Durante a fabricação de chapas, os rolos de laminadores são imperfeitos e não exercem pressão uniforme sobre a chapa. Em conseqüência, o incremento no comprimento não será o mesmo em todos os pontos da secção da chapa. Essas variações de comprimento geram tensões internas na chapa, produzindo deformações, chamadas desvios de planicidade (Garcia et al, 1999).

Paakkari, Ailisto e Kopola (1998) mediram desvio de planicidade de chapas de aço laminados com 3,5m de largura e comprimentos que podem variar de $4 \mathrm{~m}$ a dezenas de metros. O sistema deveria cobrir $100 \%$ da chapa enquanto essa se desloca na linha de produção e as chapas possuíam desvio de planicidade na faixa de $6 \mathrm{~mm}$ por metro. A medição de planicidade foi feita usando princípio de Moiré. Uma câmera observa as franjas formadas e envia os dados para o microcomputador.

A Figura 2.8 ilustra o princípio de medição de formas 3D por franjas de moiré. Uma grade, formada por uma série de linhas finas, 
retas e paralelas impressas em uma placa de vidro, é obliquamente iluminada e projeta sua sombra sobre a superficie a medir. Uma câmera digital observa frontalmente a superficie a medir através da grade. O encontro entre as sombras na chapa e as próprias linhas da grade dá origem a regiões claras e escuras denominadas de franjas de moiré.

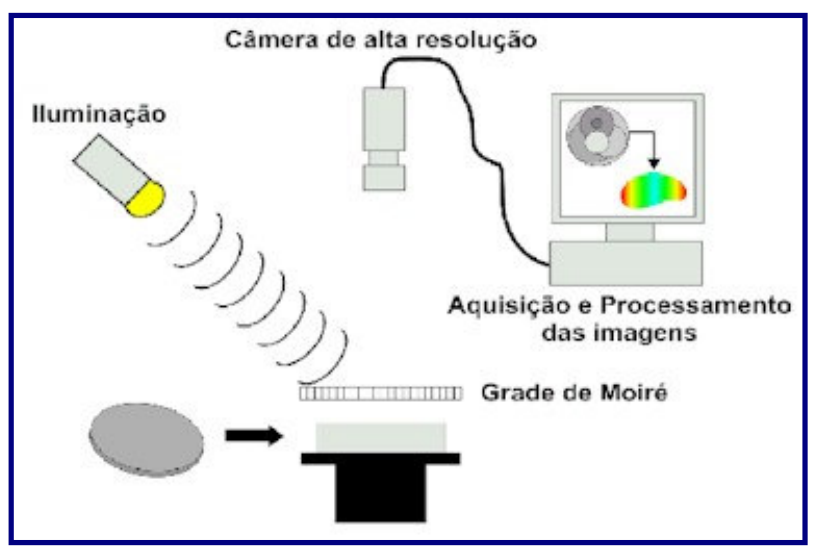

Figura 2.8: Princípio de medição de forma

3D através de franjas de moiré

Garcia et al (1999), também preocupados com a qualidade dos laminados, desenvolveu um sistema integrado ao processo de laminação para inspecionar o desvio de planicidade. O sistema possui 5 ópticas, um diodo laser e uma câmera. As variações de altura da chapa são medidas em posições igualmente espaçadas através de técnica de triangulação óptica. Foram feitos testes em diferentes elementos com desvios conhecidos. O erro relativo foi pequeno, chegando a $3,75 \%$ no pior caso. A acuracidade desse sistema é de $0,1 \mathrm{~mm}$.

Medições usando método de triangulação são tão antigas quanto as pirâmides do Egito. Quando usada em conjunto com laser e fotodiodo é uma poderosa ferramenta metrológica (Slocum, 1992). Nesse método a unidade laser envia um raio de luz monocromático para a superficie, onde é refletido para uma câmera. A Figura 2.9 mostra que se a altura da chapa variar $\triangle \mathrm{h}$ o caminho da luz é modificado. 


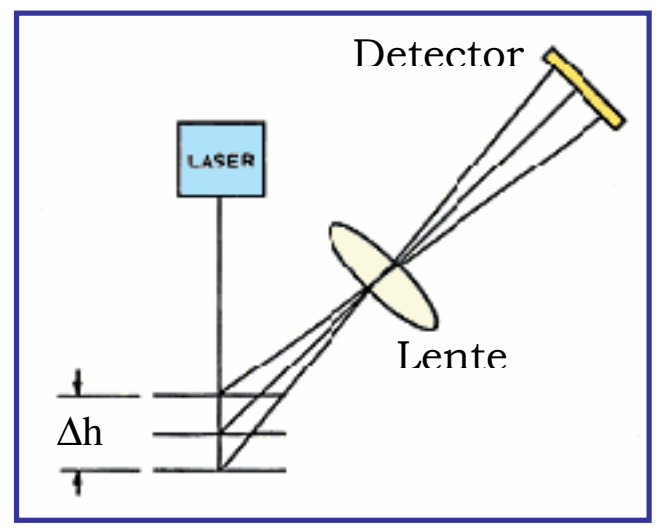

Figura 2.9: Medição por triangulação

$\mathrm{Na}$ indústria metal-mecânica o processo de retificação é usado para conseguir superfícies com bom acabamento e tolerâncias estreitas. No entanto, deflexões mecânicas associadas à peça e à ferramenta impedem que, em um só passe, tolerâncias apertadas sejam conseguidas (Hekman e Liang, 1998).

No processo de retificação a força é proporcional à taxa de remoção de material, de forma que, se a profundidade de corte é reduzida, a força decresce. Outros fatos que influenciam a força de retificação são propriedades do material, área de contato entre o rebolo e a peça e velocidade de rotação do rebolo. Como a área de contato e a taxa de remoção de material modificam durante a usinagem, a força também é modificada. Essas variações causam deflexões na máquina reduzindo a capacidade de geração de superficies planas. Para aprimorar a planicidade de superfícies usinadas em retificadoras verticais, Heckman e Liang manipularam a profundidade de corte para compensar as deflexões mecânicas que indiretamente influem na planicidade da superficie.

Para medir a força de usinagem vertical, um dinamômetro foi colocado entre a mesa da máquina e a peça, possibilitando o cálculo da deflexão relativa entre rebolo e peça. Um controlador foi usado para verificar a tendência de deflexão do rebolo e manipular a profundidade de corte, minimizando, portanto, o erro. A qualidade da superficie foi melhorada em 5 vezes no melhor caso e em 2 vezes no pior caso. 
Para aumentar a qualidade de filmagens, feitas por astrônomos, detectores CCD de 2048 x 4096 pixels quadrados são montados lado a lado para se ter detectores de 16384 x 16384 pixels quadrados. Para ser usado sem comprometimentos, os detectores devem ser montados com desvio de planicidade máximo de $30 \mu \mathrm{m}$ (Ströbele, 2001). Ströbele desenvolveu um instrumento para medir os desvios de planicidade dessas placas de detectores. A superficie a ser medida é colocada sobre uma mesa x-y controlada por motor de passo. No eixo vertical é colocado um sensor de triangulação. Os dados do sensor e dos motores são enviados para um microcomputador preparado com programa computacional para determinar o valor do desvio.

Gao et al desenvolveram, em 2002, uma sonda bi-dimensional com resolução de 0,01 arc-segundo para medir planicidade de placas de silício (silicon wafers) com diâmetro entre 300 e $500 \mathrm{~mm}$ usadas para montagem de componentes eletrônicos. A sonda usa o princípio do autocolimador para detectar as duas componentes de inclinação de um ponto da superficie. O sistema constitui de uma unidade sensora com duas sondas angulares bidimensionais movimentadas por uma guia linear na direção radial da placa, que é rotacionada por um eixo. De acordo com Gao o perfil de planicidade da superficie pode ser avaliado a partir das saídas das sondas sem as influências dos desvios de movimentação da guia e do eixo.

Nos anos 30 foi desenvolvido um protótipo de um interferômetro para medição de bloco padrões. Baseado nesse protótipo foi feito o projeto final e a construção de um interferômetro no NPL (National Phisical Laboratory) em Londres. As fontes de iluminação eram lâmpadas de cádmio e mercúrio. Franjas de interferência eram formadas pelo encontro da luz refletida do plano óptico e do mensurando. Observando as franjas de interferência, através de um visor, o desvio de planicidade podia ser estimado (Howick et al, 2003). No ano de 2003, foi feita, na Nova Zelândia, a automação desse interferômetro. A lâmpada de cádmio foi substituída por fibra óptica 
alimentada por radiação laser. Uma câmera foi usada para filmar as franjas e enviar a imagem para o microcomputador.

Com a máquina automatizada o tempo de medição caiu significativamente. Com o interferômetro original demorava-se 2 horas e 30 minutos para medir 10 blocos padrões, agora, gasta se 30 minutos. No sistema original a incerteza de medição era de 0,07 franja. A incerteza de medição com a máquina semi-automática, sem a câmera CCD, foi de 0,005 franja. Com a colocação da câmera CCD, a incerteza aumentou para 0,028 franja.

Foi publicado, em outubro de 2003, um sistema para medição de planicidade sem contato de superficies de até $2,6 \times 0,5 \mathrm{~m}^{2}$. Pavageau et al descreveram o sistema que consiste de duas guias movidas por motores, sendo uma das guias responsável pelo movimento vertical e a outra pelo movimento horizontal. No eixo vertical, laser e câmera CCD foram fixados para medir a distancia até a placa medida. A cada posição (x,y) ao longo da chapa são coletadas as medições. Como as guias não são retilíneas, dois raios laser foram usados para gerar a referência, como pode ser visto na Figura 2.10.

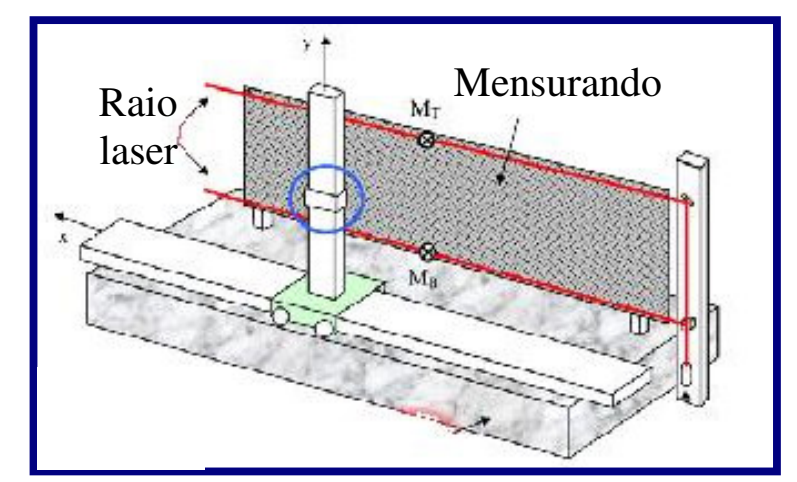

Figura 2.10: Sistema de medição de planicidade sem contato 


\subsection{SUPERFÍCIES DE REFERÊNCIA E OUTROS MÉTODOS DE MEDIÇÃO DE DESVIO DE PLANICIDADE}

A percepção de planicidade na indústria metal mecânica está amplamente associada às superficies de referência. Os desempenos representam os meios mais utilizados para estabelecer planos de referência, para os mais diversos tipos de medição dimensional mecânica. A Tabela 2.1, a seguir, apresenta algumas das aplicações mais comuns.

Tabela 2.1: Exemplos de aplicações de desempenos

\begin{tabular}{|c|c|c|}
\hline Tipo de medição & Dispositivos & Diagrama \\
\hline \multirow{3}{*}{ Paralelismo } & $\begin{array}{c}\text { Bupos para } \\
\text { indicador }\end{array}$ \\
\hline \multirow{2}{*}{ Distância linear } & $\begin{array}{c}\text { Traçador de } \\
\text { altura e } \\
\text { apalpador }\end{array}$ \\
\hline \multirow{2}{*}{ Comprimento } & Blocos padrão e \\
apalpador
\end{tabular}


Pode-se dizer que o desvio de planicidade é a principal característica funcional dos desempenos. A falta de planicidade nessas superficies afeta diretamente as medições nele realizadas.

Os desempenos podem ser fabricados em granito, ferro fundido e aço. As vantagens dos fabricados em granito são a elevada dureza e o fato de não oxidarem. Além disso, são termicamente estáveis, resistentes ao desgaste, fáceis de limpar e não magnéticos.

O granito tolera bem a água. Por isso são fáceis de limpar, não oxidarem nem são corroídos. Os desempenos de ferro fundido, ao contrário, não só se enferrujam como induzem a ferrugem nas peças que repousam sobre ele. Para diminuir esse problema, a superficie de trabalho deve ser lubrificada. No entanto, óleo atrai poeira, acrescentando erros na medição e acelerando o desgaste.

Os desempenos de ferro fundido sofrem interferência até do calor gerado por pessoas à sua volta. Já os desempenos de granito possuem grande estabilidade térmica. Fato que também pode ser uma característica negativa, pois demoram a atingir a temperatura ambiente. Quando a umidade é alta, vapor se condensa sobre a superficie enquanto o equilíbrio térmico não é atingido. Fazendo com que as superficies de aço sobre o desempeno oxidem (Busch, 1988).

A fabricação de desempenos exige controle rígido de qualidade. Quando fabricados em granito, as pedras são cortadas em fatias grossas. Na Figura 2.11 pode-se visualizar uma máquina para serrar granito. Algumas das peças serradas são selecionadas e polidas até possuírem desvio médio da ordem de micrometros. As operações seguintes são feitas em câmeras climatizadas. As superficies são medidas usando um equipamento chamado "repeat-o-meter" e as áreas com irregularidades são polidas.

O repeat-o-meter possui duas partes: uma móvel e outra fixa. A fixa é colocada sobre a parte do desempeno tomada como referência. A móvel, bem mais leve que a parte fixa, desloca-se de acordo com o desvio da superficie. Como pode ser visto na Figura 2.12, o apalpador é 
fixado numa extensão da parte fixa e sua ponta encosta na parte móvel e, assim, os desvios da superfície são medidos.

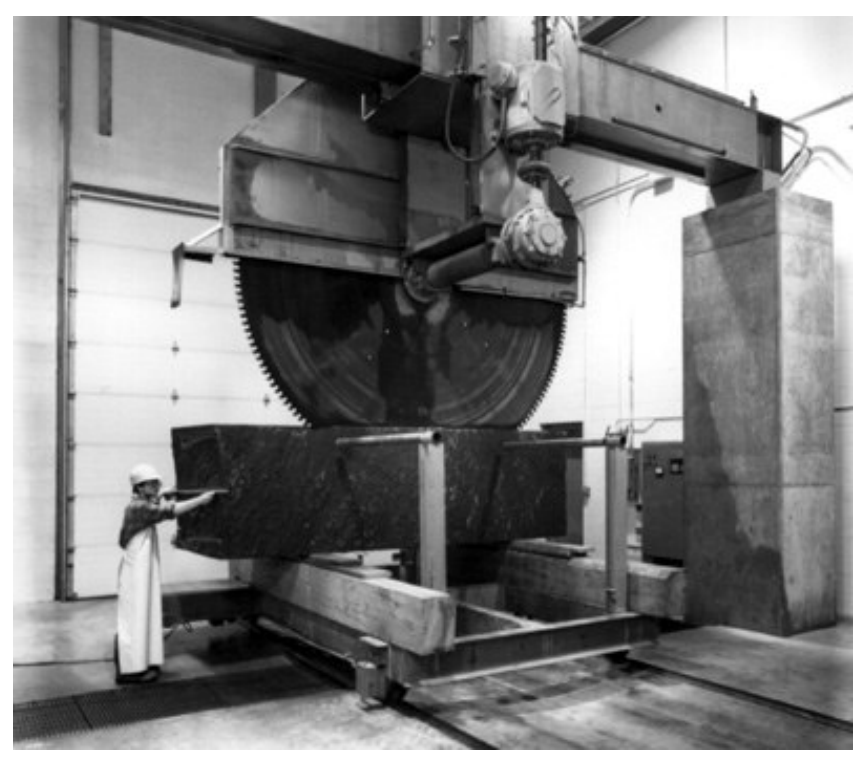

Figura 2.11: Máquina de serrar granito

O repeat-o-meter é usado apenas para medições grosseiras. Quando a superficie atinge limites mais finos de planicidade as medições passam a ser feitas com autocolimador.

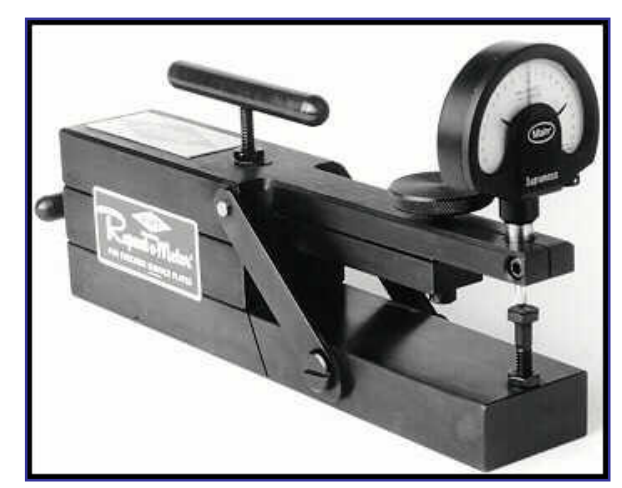

Figura 2.12: Repeat-o-meter_ instrumento para medição de planicidade em desempenos 
O autocolimador é usado para medição de pequenos ângulos. Sua aplicação é possivel devido à possibilidade de colimar os raios de luz, como ilustra a Figura 2.13.

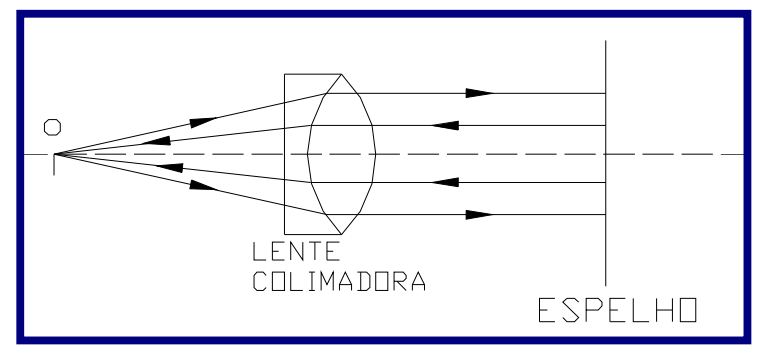

Figura 2.13: Espelho normal ao eixo ótico

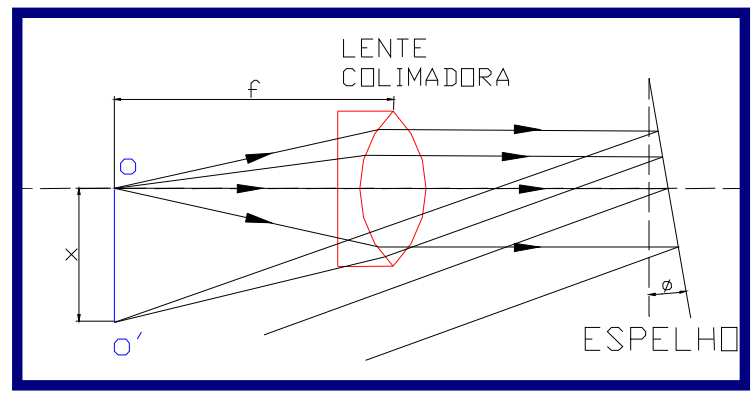

Figura 2.14: Espelho Inclinado

Se uma fonte de luz, O, é colocada no foco de uma lente colimadora os raios de luz serão projetados paralelamente, como mostra a Figura 2.13. Se os raios paralelos forem refletidos por um espelho em posição normal ao eixo ótico estes retornarão ao foco, posição inicial O. Se o espelho refletor estiver inclinado de um certo ângulo $\theta$, Figura 2.14, os raios paralelos serão refletidos com ângulo $\theta$ e convergirão para uma posição diferente do foco, $\mathrm{O}^{\prime}$, no plano focal a uma distância $\mathrm{x}$ de O.

$x=\theta \times f$, onde f é a distância focal.

Os autocolimadores utilizam o principio de funcionamento acima explicado e o esquema de um autocolimador pode ser visto na Figura 2.15. Pode-se observar que a distância entre o espelho e a lente não afeta o valor de $\mathrm{x}$. Para se ter sensibilidade, isto é, um grande valor de $\mathrm{x}$ para um pequeno desvio angular $\theta$ basta aumentar a distância focal da lente. 
O esquema da Figura 2.15 apresenta um autocolimador comercial onde a luz emitida pela fonte é desviada de $90^{\circ}$ do eixo do telescópio por uma lente de $45^{\circ}$ e passa pela objetiva iluminando um espelho parcial (P), com o desenho de duas linhas cruzadas em O. As linhas cruzadas estão localizadas no plano focal da objetiva, portanto sua imagem pode ser vista no infinito. No entanto, se um plano refletor é colocado na direção de projeção a luz é refletida para o autocolimador e a imagem das linhas cruzadas ficará no plano focal. Se o refletor for inclinado de um certo ângulo a imagem se moverá proporcionalmente a este ângulo, como explicado anteriormente. Para saber qual o deslocamento da imagem utiliza-se um micrômetro incorporado ao sistema (Galyer e Shotbolt, 1981). Atualmente, os sinais do autocolimador podem ser transferidos para o microcomputador dispensando o uso do micrômetro.

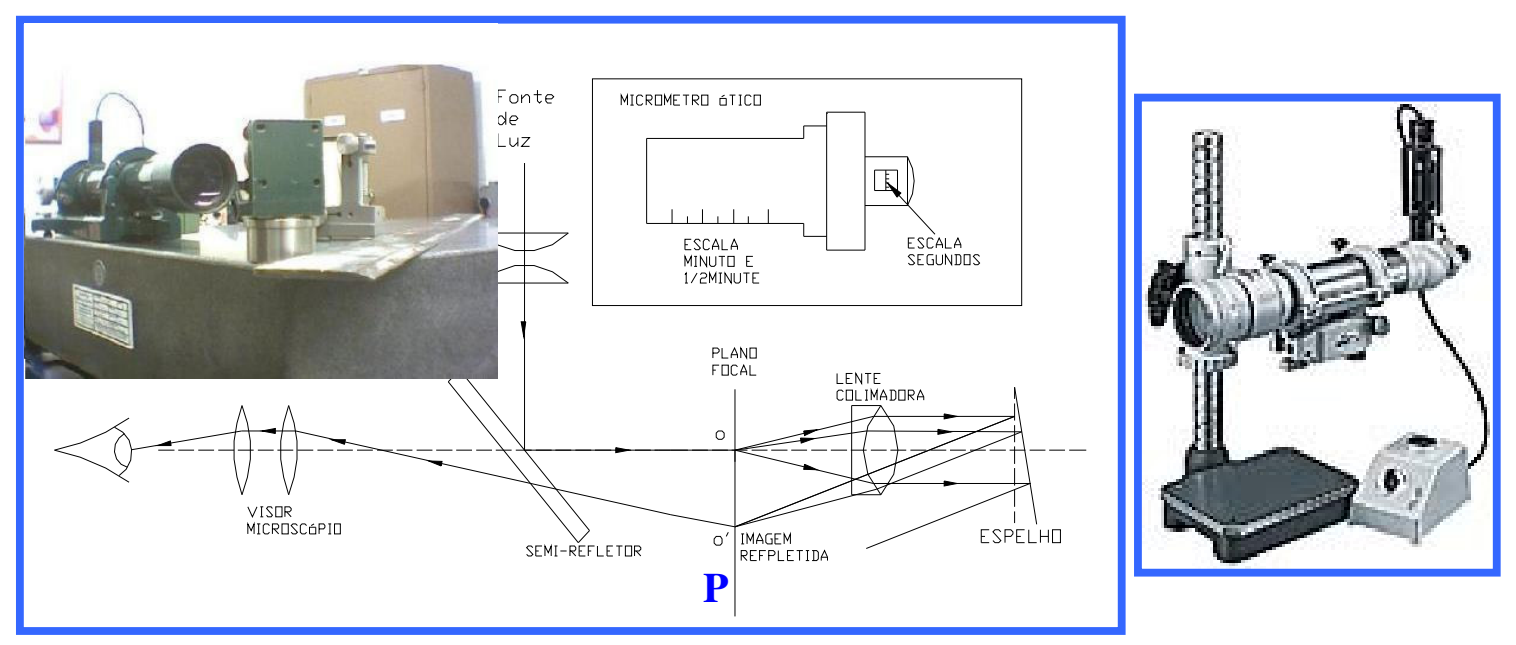

Figura 2.15: Esquema de um autocolimador

Outro método utilizado na medição do desvio de planicidade de desempenos utiliza régua padrão e blocos padrões. Três pontos $\mathrm{a}, \mathrm{b}$ e c sobre a superficie são escolhidos, como indica a figura, para gerar o plano de

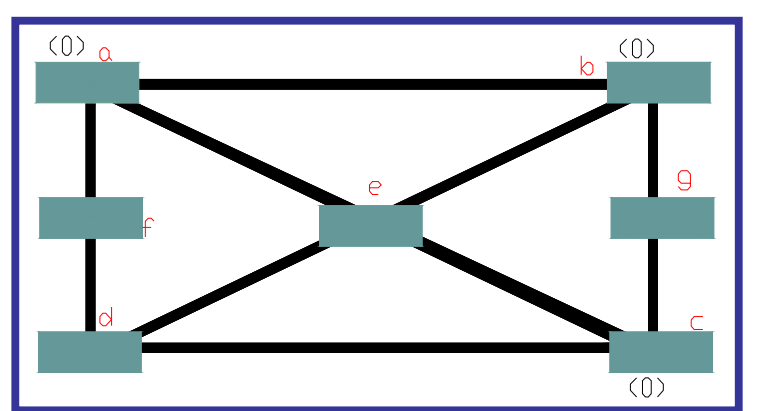

Figura 2.16: Medição de planicidade com régua padrão e blocos padrões 
referência teórico onde são colocados os blocos de mesma altura. Dessa forma, o plano que passa pela face superior dos blocos é o plano de referência. A régua padrão é colocada sobre os blocos 'a' e 'c' e um bloco padrão de altura ajustável é colocado no ponto 'e'. A altura é ajustada até que a face do bloco encoste na régua padrão. A régua é agora colocada sobre 'b' e 'e' para encontrar o desvio do ponto 'd', em seguida colocada sobre 'a' e 'd' para encontrar o desvio de 'f'. Os desvios dos pontos entre 'b' e 'c' são encontrados da mesma forma.

Nivel de bolha, relógio comparador e régua padrão também são muito aplicados para medição de desvio de planicidade. Nas medições com esses intumentos, o plano de referência é definido por duas réguas padrões colocadas paralelamente sobre o desempeno, como mostra a Figura 2.17. As duas réguas $\mathrm{R}_{1}$ e $\mathrm{R}_{2}$ são colocadas sobre os calços ' $a$ ', 'b', 'c' e 'd', um deles de altura ajustável, de forma que as faces das réguas fiquem paralelas e pertençam, portanto, ao mesmo plano. $\mathrm{O}$ nivel de bolha é usado para esse ajuste.

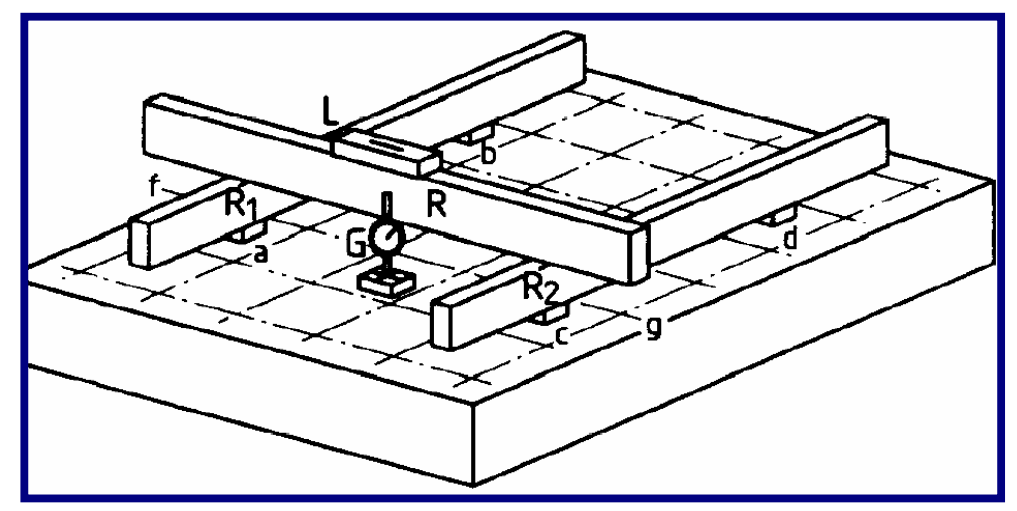

Figura 2.17: Medição de planicidade de desempeno

A régua $R$ é ajustada perpendicularmente sobre as outras duas e as alturas são lidas através de relógio comparador. A régua deve ser rígida o suficiente para não haver interferência de deslocamentos causados por flexão. 
Medição de planicidade pode também ser feita através de uma série de medições angulares tomadas enquanto o instrumento de medição adotado caminha sobre a superficie, como pode ser visto na Figura 2.18 .

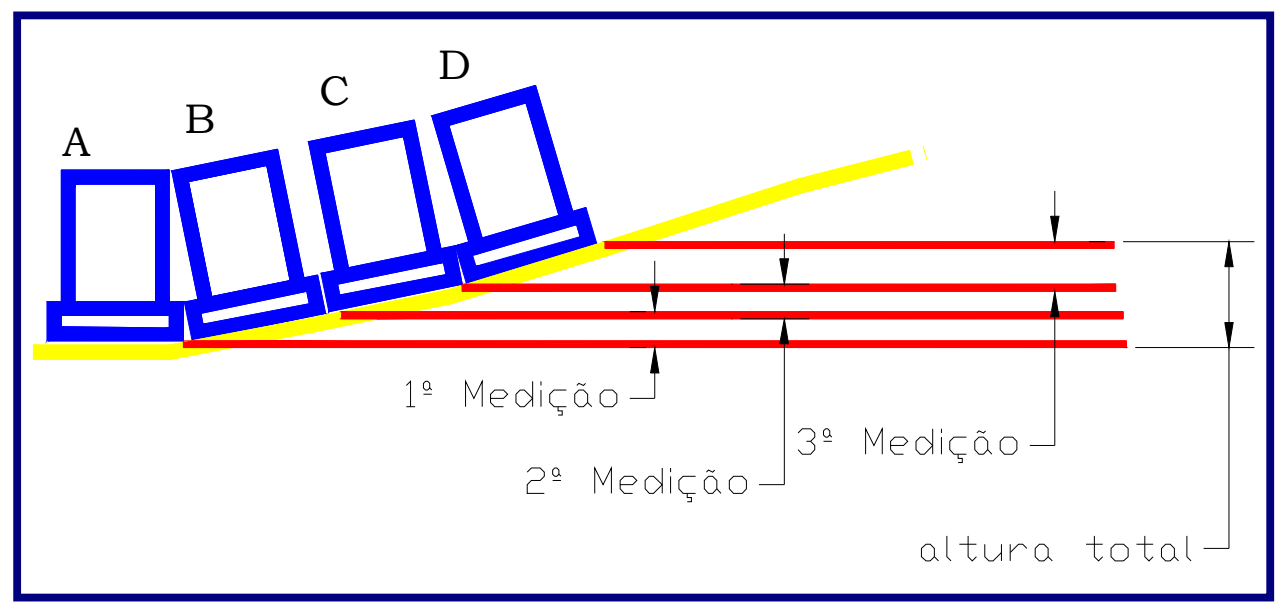

Figura 2.18: Medição de ângulos

A posição 'A' é chamada de referência, ou seja, possui altura zero. A posição 'B', cuja distância de 'A' é igual ao comprimento da base do instrumento utilizado, possui altura determinada através do ângulo medido e do comprimento da base do instrumento (HewlettPackard,1988). Similarmente, a altura dos demais pontos é calculada e relacionada à referência 'A'.

\subsection{INSTRUMENTOS MAIS UTILIZADOS NA MEDIÇÃO DO DESVIO DE PLANICIDADE}

Instrumentos como autocolimador, nível eletrônico, nivel de bolha e interferômetro laser são empregados para medição de ângulos e podem ser aplicados para medir planicidade. $\mathrm{Na}$ sequência são abordados os principais instrumentos. 
- INTERFERÔMETRO LASER

O sistema de medição a laser, freqüentemente chamado de interferômetro, consiste nos seguintes componentes:

- unidade laser;

- tripé sobre o qual o cabeçote laser é colocado;

- sensor que temperatura, umidade e pressão barométrica da atmosfera de medição;

- interferômetro que divide os feixes de luz e depende do tipo de medição a ser feita e

- espelho refletor.

As medições com o interferômetro laser são afetadas pela variação de temperatura, umidade e pressão barométrica. Estes parâmetros afetam a velocidade da luz e, portanto afetam o comprimento de onda da luz. O comprimento de onda do laser pode variar uma parte por milhão para cada variação de $1^{\circ} \mathrm{C}$ na temperatura; $2,5 \mathrm{~mm} \mathrm{Hg}$ na pressão barométrica e 30\% na umidade relativa.

Normalmente, o interferômetro laser vem equipado com sistemas de medição capazes de detectar a variação dos parâmetros citados. Estas informações são utilizadas para alterar os valores das medições, compensando as variações no comprimento de onda do raio laser nas condições atmosféricas do ambiente.

As ópticas utilizadas na medição de deslocamento angulares são mostradas na Figura 2.19. O feixe laser é dividido em dois feixes paralelos de freqüências $F_{1}$ e $F_{2}$, no interferômetro angular. A distância entre os dois caminhos percorridos pelos feixes é conhecida e inicialmente o ângulo entre o interferômetro e o refletor é assumido nulo. Se o interferômetro ou o refletor é movimentado, o comprimento relativo entre os dois caminhos irá mudar. O sistema de medição calcula o ângulo baseado na variação das distâncias entre os espelhos. 


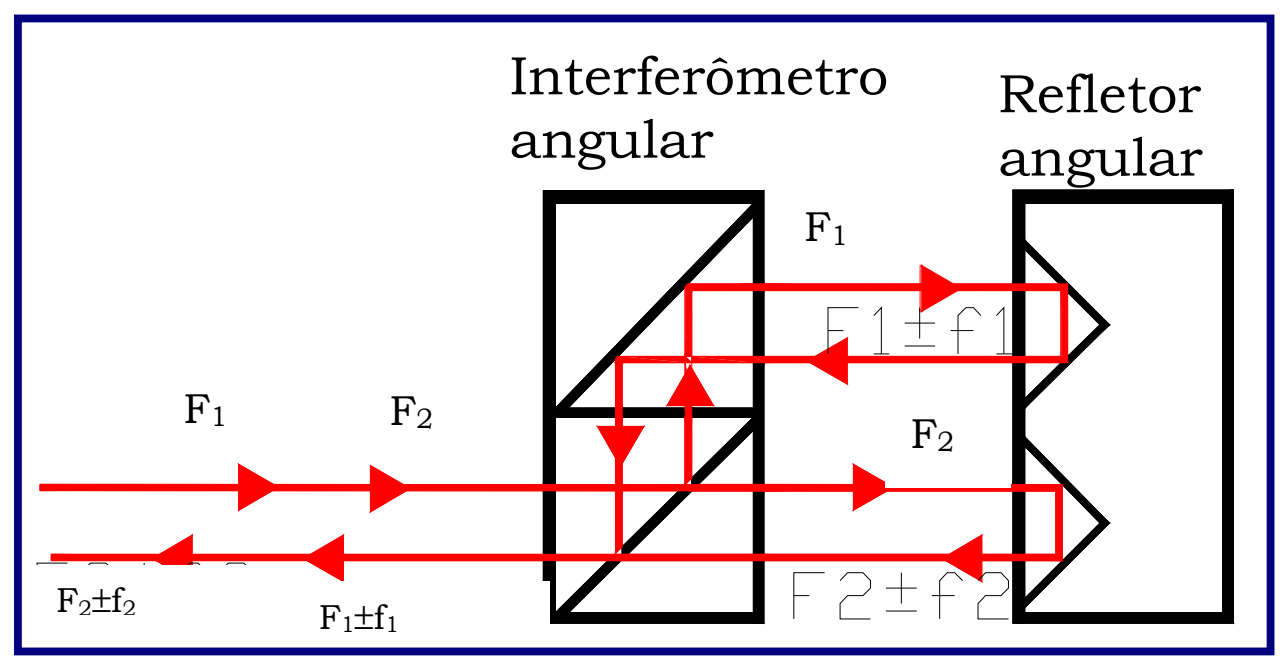

Figura 2.19: Ópticas para medição angular

O desvio de planicidade pode ser medido utilizando canhão (1), interferômetro (2), refletor (3), régua (4) e espelho para desviar o feixe (5). O esquema de montagem para esta medição pode ser visto na Figura 2.20.

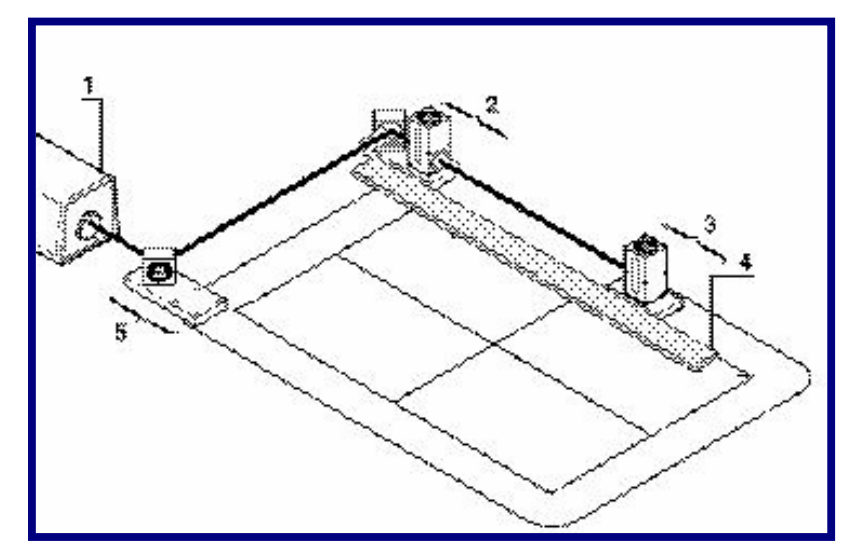

Figura 2.20: Montagem Para Medir Planicida

- NÍVEL DE BOLHA:

Esse instrumento é constituído por um tubo de vidro, na forma de um arco, fechado e quase cheio com um líquido de baixa viscosidade, por exemplo: álcool. O pequeno espaço que não é preenchido com o líquido forma uma bolha que sempre ficará no ponto mais alto do arco. 
A Figura 2.21 apresenta o nivel de bolha (com curvatura exagerada) com a bolha na posição central. $O$ raio $R$ deve ser constante para que haja correspondência entre o valor indicado L e o ângulo de inclinação $\theta$. A relação é simples:

$$
L=R \times \theta
$$

A resolução do nível é definida como o ângulo de inclinação que causa o movimento da bolha em uma divisão.

Como é dificil equipar o nível de bolha com transdutores elétricos sua conexão com um microcomputador não pode ser feita facilmente. Esta desvantagem é superada com o nível eletrônico (Thomas, 1974).

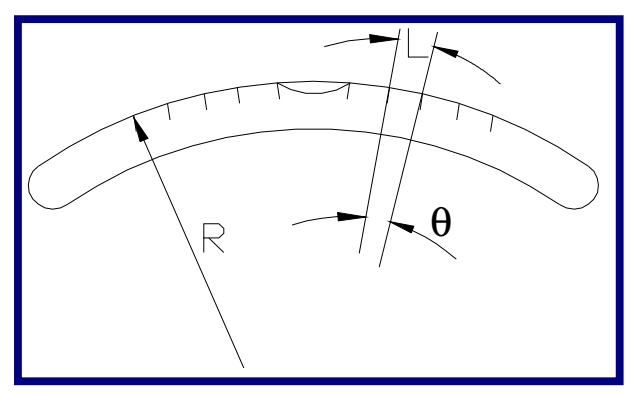

Figura 2.21: Nivel de Bolha

- NÍVEL ELETRÔNICO:

O nivel eletrônico é composto basicamente por um pêndulo e um sistema elétrico que detecta o movimento desse. O sinal elétrico é amplificado e usado para operar um display LCD. O instrumento pode ser utilizado para fazer medidas absolutas ou pode funcionar como um comparador. Possui duas unidades: base do nivel e unidade de medida.

A base do nivel deve ser colocada na superficie a ser verificada. Contém um pêndulo e um transdutor elétrico sensivel à posição do pêndulo. $\mathrm{O}$ circuito elétrico é essencialmente uma ponte elétrica balanceada quando o pêndulo se encontra eqüidistante das duas bobinas, isto é, quando possui inclinação nula. Quando a base do nivel está inclinada, a ponte é desbalanceada e a tensão induzida no 
transdutor é proporcional ao ângulo de inclinação da base do instrumento.

As vantagens do nivel eletrônico são:

- Acuracidade de 0,2" $\pm 3 \%$ da leitura indicada;

- Estabilidade: a variação das leituras devido à variação de temperatura é menor que $\pm 1 \%$ para uma faixa de temperatura de $5^{\circ} \mathrm{C}$ até $+40^{\circ} \mathrm{C}$ e

- Tempo de resposta de 2 segundos.

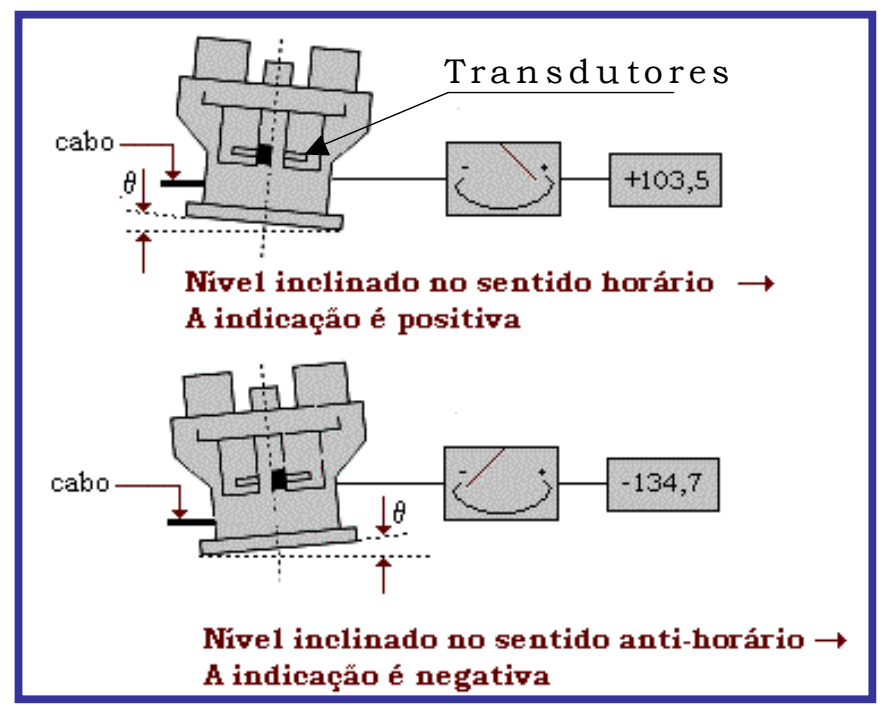

Figura 2.22: Nivel Eletrônico

\subsection{EVOLUÇÃo dOS ALGORITMOS PARA O CÁlCULO DO DESVIO DE PLANICIDADE}

A produção em série depende da qualidade e da intercambiabilidade entre as peças. Para garantir a equivalência funcional entre peças, pequenas variações dimensionais são permitidas nos processos de fabricação (Carr e Ferreira, 1995). As variações na dimensão ou na forma de peças resultam de erros sistemáticos e aleatórios inerentes ao processo de fabricação. Para estabelecer limites 
para essas variações, tolerâncias são especificadas no desenho da peça. As peças são inspecionadas de acordo com os valores de tolerância especificados pelo projetista. Tradicionalmente, essas inspeções são feitas com o auxílio de blocos padrões e comparadores.

A partir dos anos 80, depois de grande avanço nas áreas de metrologia e de computação, passou-se a utilizar sistemas metrológicos auxiliados por computadores. Nesses sistemas vários pontos são coletados por sensores de medição e depois usados no cálculo do desvio do mensurado. Para esse fim, muitos algoritmos foram desenvolvidos para avaliar os desvios de forma.

O método dos Mínimos Quadrados (MMQ) é amplamente empregado em equipamentos como as MM3C devido a sua facilidade de implementação. No MMQ a soma dos quadrados dos resíduos é minimizada e por isso o resultado do desvio é freqüentemente superestimado. E, portanto, não obedece às condições de mínimos desvios estabelecidas pela norma ISO/R1101. Uma variedade de técnicas foram desenvolvidas para obter resultados melhores, muitas delas resultando no desvio exato (Weber et al,2002).

Em 1989 Traband et al discutiram um método alternativo para encontrar o desvio mínimo de planicidade. O método usa a concepção de casco convexo (convex hull) que é definido como o menor conjunto convexo que contem todos os pontos medidos. O método procura iterativamente pares de planos paralelos que contenham todos os pontos medidos e que satisfaçam a condição de mínimos desvios, como descrito por Chetwynd. O valor mínimo das distâncias entre esses planos paralelos é o valor do desvio de planicidade da superfície.

Huang, Fan e Wu (1993) desenvolveram o método CPRS (control plane rotate scheme) para encontrar os dois planos paralelos que satisfaçam as condições de mínimos desvios. O método usa o MMQ para encontrar o plano médio. Dois planos paralelos ao plano médio e que passam pelos dois pontos ortogonalmente mais distantes ao plano médio são traçados e rotacionados iterativamente até encontrar o plano de mínimo desvio. 
Em 1995, Carr e Ferreira apresentaram o modelo Min $\left\{\operatorname{Max}\left|e_{i}\right|\right\}$. O modelo procura o plano de referência de forma que a distância máxima de cada ponto a esse plano seja mínima. A formulação matemática do problema é não linear e, portanto, de dificil implementação. Por isso, Carr e Ferreira usaram outro modelo, equivalente ao MinMax, mas que ao invés de procurar um plano de referência busca por dois planos paralelos que contenham todos os pontos medidos com a menor distância possivel. A formulação matemática continua sendo não linear, no entanto, a função objetivo e as restrições são lineares.

O cálculo do desvio de planicidade foi formulado como um problema não linear por Cheraghi et al (1996). Os autores assumiram que um dos planos paralelos coincide com o plano x-y e que o outro fica à distância $t_{f}$, equivalente ao erro de planicidade da superficie. $O$ problema solucionado foi: dados dois planos paralelos distantes de $t_{f}$, minimizar $t_{f}$, de forma que entre esses planos estejam todos os pontos medidos, depois de rotacionados e transladados. Os resultados foram comparados aos métodos de MMQ e de 'casco convexo' e os resultados foram iguais ou melhores.

Weber et al, em 2002, aplicou expansão de Taylor para linearizar as equações obtidas por Cheraghi (1996). Os resultados obtidos foram em torno de $5 \%$ maiores que os obtidos com a solução do problema de otimização e $14 \%$ menores que os valores obtidos com o MMQ. 


\section{CAPÍTULO 3}

\section{FerRamentas MATEMÁticas PARA O ESTUdO E ANÁlISE dO DESVIO DE PLANICIDADE E CÁLCULO DA INCERTEZA DE MEDIÇÃO}

Máquinas ferramentas capazes de usinar com acuracidade de micrometros já são realidade no contexto industrial. Essas máquinas, além de precisas, têm alta produtividade. Os processos de medição, no entanto, representam o gargalo dos processos de manufatura.

A qualidade de um processo de medição está intimamente relacionada com os equipamentos utilizados e com os procedimentos de coleta e de avaliação dos dados (Cheraghi et al, 1996). Mesmo equipamentos como as MM3C estão sujeitas a erros. Os erros que mais afetam o resultado das medições são os erros geométricos, decorrentes dos processos de fabricação e de montagem das diversas partes das 
máquinas de medição. Para eliminar esses erros, inerentes aos equipamentos de medição, podem-se utilizar técnicas de separação de erros. Eliminados os erros gerados pelo equipamento de medição utilizado, pode-se considerar o processo de medição acurado quanto ao equipamento.

Outra preocupação necessária é quanto à ordem de coleta de dados que é normalmente simples, mas se não forem tomados os devidos cuidados pode por a perder a medição. Obtidos os pontos de medição deve-se determinar o valor do desvio. Para facilitar esse processo, algoritmos foram desenvolvidos por muitos autores. Alguns algoritmos são de fácil implementação, no entanto, superestimam o valor do erro, fazendo com que peças boas sejam rejeitadas. Outros algoritmos são de difícil implementação, mas satisfazem o critério de mínimos desvios.

Neste capítulo são apresentados os fundamentos teóricos relativos às técnicas de separação de erros do instrumento de medição e dos erros do mensurando. Descreve também, ferramentas matemáticas para determinar o desvio de planicidade e, em seguida são apresentados os conceitos básicos referentes à incerteza de medição.

\subsection{TÉCNICAS HISTÓRICAS DE SEPARAÇÃO DE ERROS}

As medições estão sujeitas a erros e quanto mais desfavorável o ambiente de medição, maiores são os erros. Os erros de medição podem ser divididos em aleatórios e sistemáticos. Os erros aleatórios resultam

de influência externas e internas, não controladas, que provocam o aparecimento de erros não repetitivos. Os erros sistemáticos são aqueles que se repetem quando as condições de ensaios são mantidas constantes (ASME, 1997). A maneira de lidar com os erros depende de sua origem. Os erros sistemáticos podem ser pré-determinados e compensados dos dados de medição. As técnicas de reversão são formas simples de determinar esses erros. Já os erros aleatórios não podem ser 
eliminados através de métodos de compensação. Eles podem apenas ser avaliados durante a medição. A seguir são apresentados alguns métodos de separação de erros do instrumento de medição e de erros do mensurando.

\subsubsection{TESTE DOS TRÊS PLANOS}

Como já mencionado neste trabalho, o interferômetro de Fizeau usa um plano óptico como referência para as medições. Nessas condições, a figura interferométrica mostra as variações no caminho da luz entre o plano óptico e o mensurando, e isto é diretamente o resultado da soma algébrica dos erros das duas superficies. Torna-se necessário então, separar os desvios de planicidade da superfície de referência e o da peça medida (Dew, 1966).

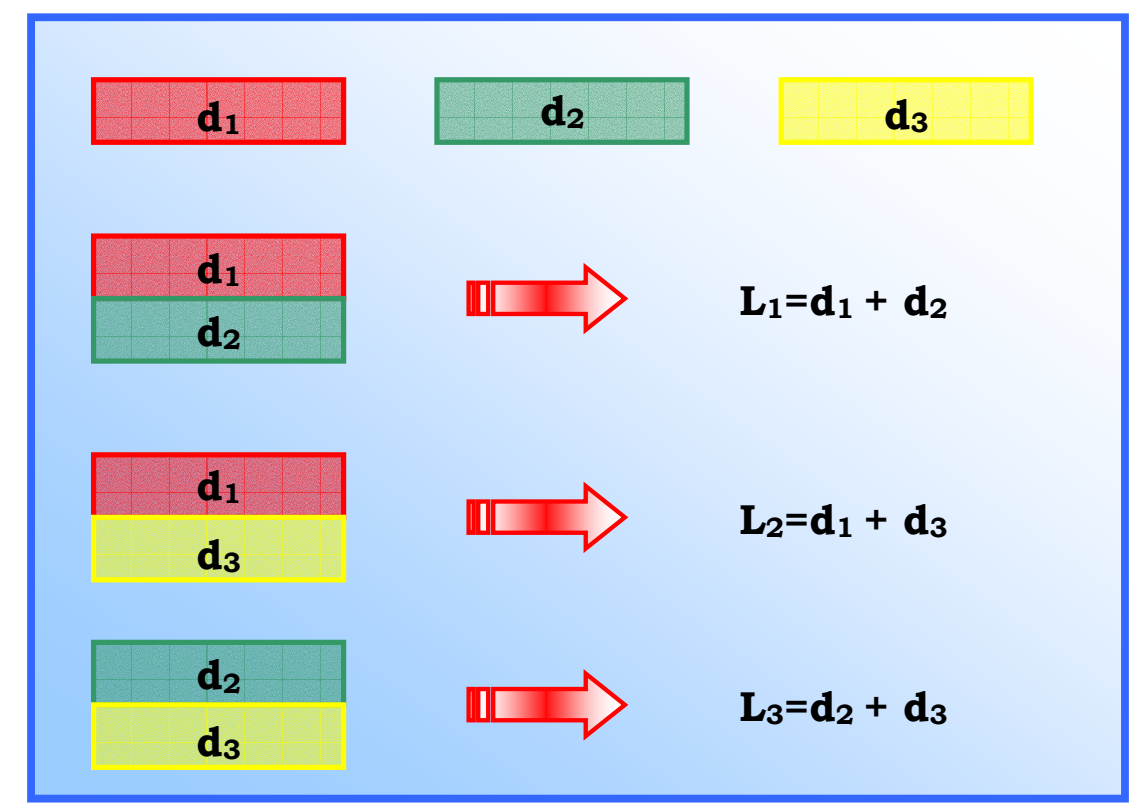

Figura 3.1: Teste de três planos

Considere três planos ópticos iguais, exceto quanto à forma da superficie. Comparações interferométricas das superficies podem ser feitas, combinado-as duas a duas. Na Figura 3.1, $\mathrm{d}_{1}, \mathrm{~d}_{2}$ e $\mathrm{d}_{3}$ representam o desvio de planicidade de cada uma das superficies e $L_{1}$, $\mathrm{L}_{2}$ e $\mathrm{L}_{3}$ as leituras dos desvios com cada uma das combinações. Assim, 
com três equações e três incógnitas, os desvios individuais dos planos podem ser determinados.

\subsubsection{REVERSÃO DO NÍVEL}

A inversão do nível é a técnica de separação de erro mais simples. Assumindo que a superfície está inclinada com ângulo $\varnothing_{2}$ e o sensor do instrumento está inclinado de $\varnothing_{1}$, com relação à superficie de referência do instrumento, as leituras do nivel serão dadas pelas equações (3.1) e (3.2), como mostra a Figura 3.2 (Evans, Hocken e Estler, 1996). Utilizando essas duas equações, a inclinação verdadeira da superficie, $\varnothing_{2}$, pode ser determinada.

$$
\begin{aligned}
& L_{1}=\phi_{1}+\phi_{2} \\
& L_{2}=\phi_{1}-\phi_{2}
\end{aligned}
$$

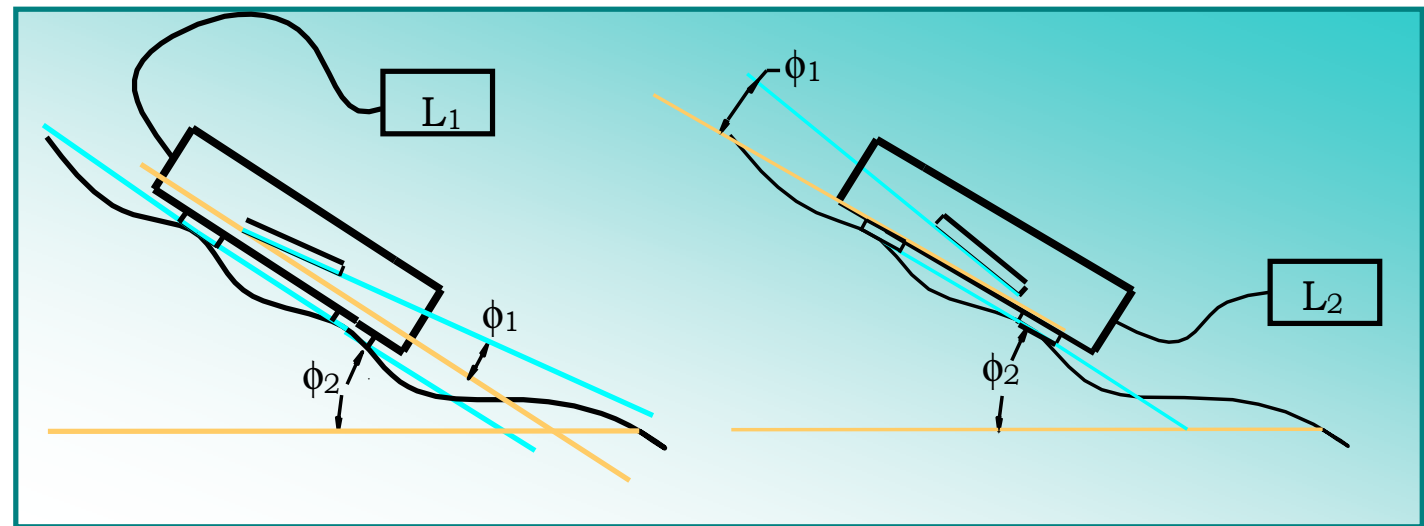

Figura 3.2: Esquema para inversão do nivel (Evans, Hocken e Estler, 1996) 


\subsection{TÉCNICAS ATUAIS DE SEPARAÇÃO DE ERROS}

Uma superficie plana é composta por infinitas linhas. Para a superficie estar realmente plana, todas as linhas devem ser retas e pertencerem ao mesmo plano (Galyer e Shotbolt, 1981). É notável que a primeira condição é mais fácil de se realizar, afinal todas as linhas podem ser retas, mas a superficie pode não ser plana.

Muitas vezes, a medição de erro de planicidade se faz pela medição do erro de retilineidade de várias linhas dentro da superficie de controle. A união das linhas medidas formará a figura tridimensional da superfície. Assim, técnicas de separação de erros, aplicadas na medição de erro de retilineidade, podem ser estendidas para a medição de desvio de planicidade. Algumas dessas técnicas são descritas a seguir.

\subsubsection{REVERSÃo DA RÉGUA PADRÃo}

Réguas padrões são usadas como referência para medição de reteilineidade. No entanto, mesmo uma régua padrão não tem a face de medição perfeitamente retilínea. Então os seus erros de forma se misturam com os erros da máquina dificultando a medição. Este problema pode ser resolvido por uma técnica conhecida como técnica da reversão da régua (Campbell, 1995).

A Figura 3.3a mostra uma montagem típica para a medição de retilineidade de uma guia utilizando uma régua padrão. Pode-se observar a régua e um transdutor de deslocamento que mostra a leitura $\mathrm{I}_{1}$. Na Figura $3.3 \mathrm{~b}$ tem-se a régua padrão girada em $180^{\circ}$ e o transdutor posicionado de forma a manter sua direção de sensibilidade com relação à régua. No transdutor de deslocamento tem-se a leitura $\mathrm{I}_{2}$ (Di Giacomo, Magalhães e Paziani, 2003). Assumindo-se que o erro de retilineidade da guia da máquina é dado por $\mathrm{G}(\mathrm{x})$ e que o desvio da régua padrão é dado por $\mathrm{R}(\mathrm{x})$, o indicador de saída $\mathrm{I}_{\mathrm{n}}(\mathrm{x})$ para as duas posições é dado pelas expressões (3.3) e (3.4): 
$\mathrm{I}_{1}(\mathrm{x})=\mathrm{G}(\mathrm{x})+\mathrm{R}(\mathrm{x})$

$\mathrm{I}_{2}(\mathrm{x})=-\mathrm{G}(\mathrm{x})+\mathrm{R}(\mathrm{x})$

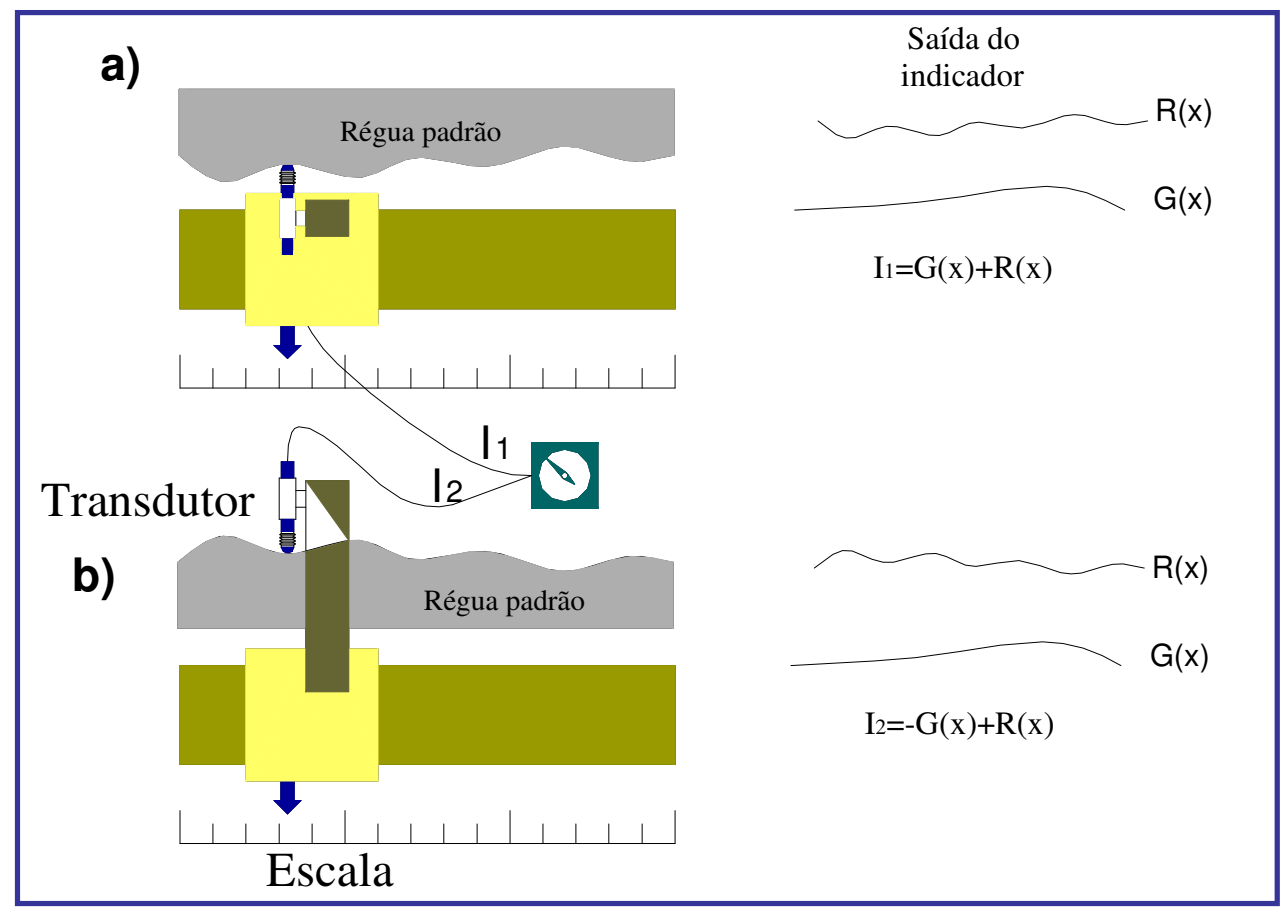

Figura 3.3: Esquema de montagem para medição de erro de retilineidade

Deste modo, os erros de retilineidade da guia e o da régua podem ser calculados respectivamente por (Evans, Hocken e Estler, 1996):

$$
\begin{aligned}
& G(x)=\frac{I_{1}(x)-I_{2}(x)}{2} \\
& R(x)=\frac{I_{1}(x)+I_{2}(x)}{2}
\end{aligned}
$$

\subsubsection{MÉTOdo “SEQUENTIAL-TWO-POINTS” (TSP)}

O método Sequential-Two-Points (TSP) foi idealizado de modo a realizar medidas de retilineidade tomadas com redundância, Figura 3.4. 
Dois transdutores são empregados em cada medida. Após a primeira medida, o dispositivo que contém os transdutores sofre uma translação sobre a estrutura de teste. Esta translação corresponde à distância entre os transdutores, e assim, sempre haverá uma medida redundante.

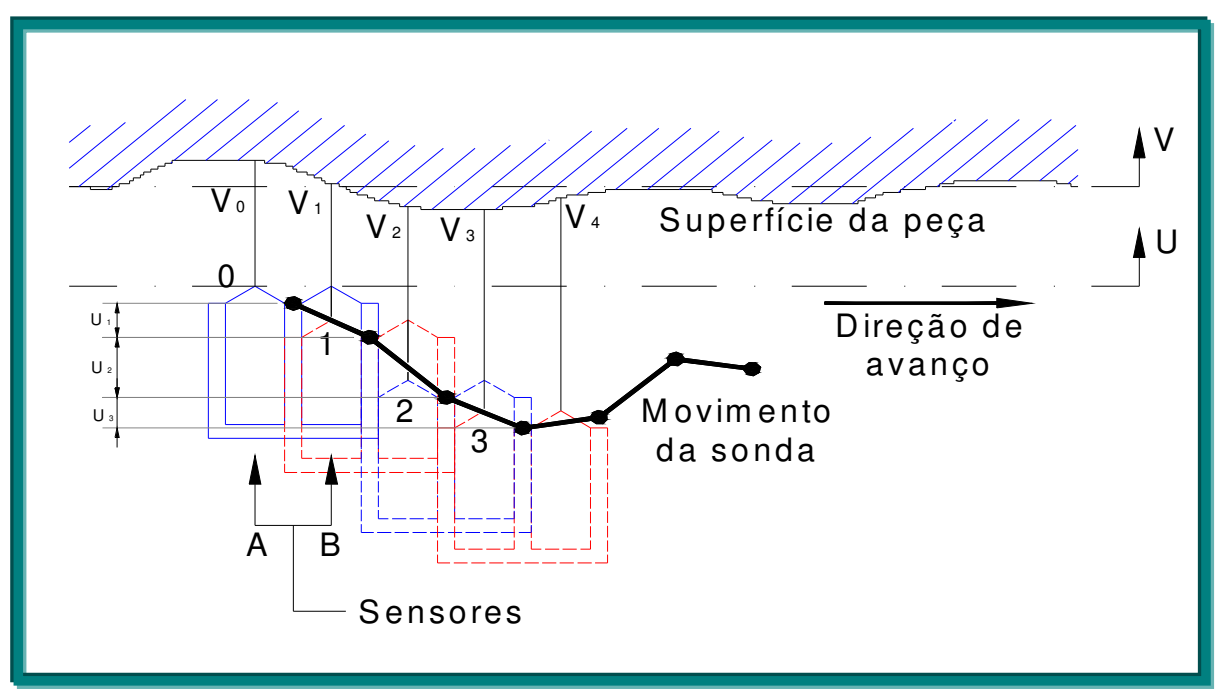

Figura 3.4- Princípio do método STP (Tozawa et al, 1982).

Como evidenciado na Figura 3.4, a retilineidade do movimento da sonda contendo os transdutores é designada por $\mathrm{U}_{1}, \mathrm{U}_{2}, \mathrm{U}_{3}, \ldots$ e a retilineidade da superficie sob análise por $\mathrm{V}_{1}, \mathrm{~V}_{2}, \mathrm{~V}_{3}, \ldots \mathrm{O}$ deslocamento relativo entre a sonda e a peça é medido pelos sensores A e B (Tozawa et al, 1982). Como a sonda é sempre avançada com a distância entre os sensores, um conjunto de deslocamentos relativos entre dois pontos pode ser obtido:

$$
\begin{aligned}
& D_{0, B}-D_{0, A}=V_{1} \\
& D_{1, A}-D_{0, A}=V_{1}-U_{1} \\
& D_{1, B}-D_{0, B}=\left(V_{2}-V_{1}\right)-U_{1} \\
& D_{2, A}-D_{0, A}=V_{2}-U_{2} \\
& D_{2, B}-D_{0, B}=\left(V_{3}-V_{1}\right)-U_{2}
\end{aligned}
$$


A generalização destas equações pode ser escrita como:

$$
\begin{aligned}
& D_{(i-1), B}-D_{0, B}=\left(V_{i}-V_{1}\right)-U_{i-1} \\
& D_{i, A}-D_{0, A}=V_{i}-U_{i}
\end{aligned}
$$

Desta forma, a retilineidade $U_{i}$ na i-ésima posição da sonda devido ao deslocamento relativo medido é dado:

$$
\begin{aligned}
& U_{i}=U_{i-1}+D_{(i-1), B}-D_{(i, A)} \\
& V_{i}=U_{i}+D_{i, A}-D_{0, A}
\end{aligned}
$$

Assumindo que $\mathrm{U}_{0}=\mathrm{V}_{0}=$ constante, séries de $\mathrm{U}_{\mathrm{i}} \quad$ e $\quad \mathrm{V}_{\mathrm{i}}$ são determinados.

O desalinhamento na direção axial dos sensores é uma fonte de erro, como pode ser verificado na Figura 3.5. Os sensores podem ser usados se antes do início da medição forem ajustados de forma a eliminar o desvio $\triangle$. No entanto, pequenas diferenças são deixadas.

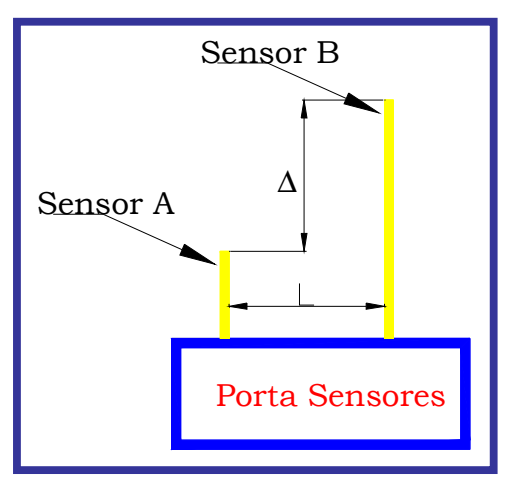

Figura 3.5- Desalinhamento entre os sensores (Tanaka e Sato, 1986).

Análises feitas por Tanaka apontaram que essas diferenças geram incremento linear na medição. Por isso, Tanaka e Sato (1986) propuseram um novo equacionamento incluindo o desalinhamento $\triangle$. A Equação 3.14 foi escrita como:

$$
U_{i}^{T}=U^{T}{ }_{i-1}+D_{(i-1), B}-D_{(i, A)}-\Delta
$$


O valor de $\triangle$ não é facilmente determinado e $U_{i}^{T}$ não pode ser determinado diretamente da equação (3.16). Então, $U_{i}^{C}$ é introduzida.

$$
U_{i}^{C}=U^{C}{ }_{i-1}+D_{(i-1), B}-D_{(i, A)}
$$

Considerando que para o intervalo inicial de medição os valores do desvio de retilineidade da guia e da peça são nulos, ou seja, $U_{0}^{T}=U_{0}^{C}=V_{0}=0$, tem-se a equação (3.18).

$$
U_{i}^{T}=U_{i}^{C}-i \times \Delta, \quad \mathrm{i}=0 \ldots \mathrm{N}
$$

A equação (3.18) pode ser resolvida se os desvios de retilineidade obtidos pelas equações (3.14) e (3.15) possuírem incremento linear, causado pelo termo $i \times \Delta$ na Eq. (3.18). Esse termo pode ser compensado passando uma reta pelos pontos $U_{0}^{C}$ e $U_{N}^{C}$. O que faz $U_{N}^{T}=0$ e conseqüentemente:

$$
\Delta=\frac{U_{N}^{C}}{N}
$$

$V_{i}$ pode ser calculado normalmente pela equação (3.15) já que $U_{i}^{T}$ foi compensado.

\subsubsection{MÉTODO “SEQUENTIAL-THREE-POINTS” (STRP)}

O método Sequential-Three-Points (STRP) distingue não apenas os erros de retilineidade, mas também o erro angular do carro de movimentação dos sensores. A Figura 3.6 ilustra o princípio do método STRP e as equações (3.20), (3.21), (3.22), e (3.23) podem ser escritas (Tanaka e Sato, 1986). 


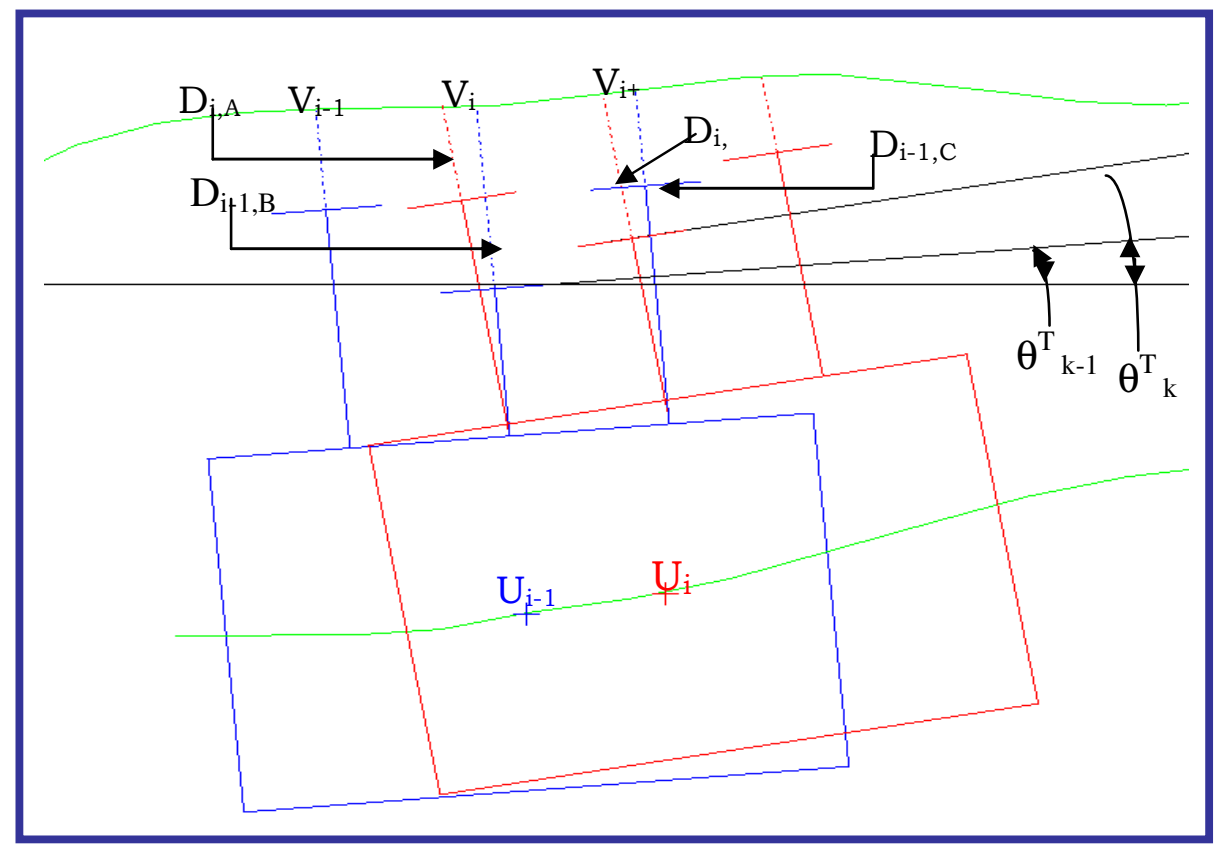

Figura 3.6- Princípio do método STRP (Tanaka e Sato, 1986)

$$
\begin{aligned}
& U_{i}^{T}=U_{i-1}^{T}+D_{i-1, B}-D_{i, A}+L \times \theta_{i}^{T}-\delta_{1} \\
& U_{i}^{T}=U_{i-1}^{T}+D_{i-1 C}-D_{i, B}+L \times \theta_{i-1}^{T}+\delta_{2} \\
& U_{i}^{C}=U_{i-1}^{C}+D_{i-1, B}-D_{i, A}+L \times \theta_{i}^{C} \\
& U_{i}^{C}=U_{i-1}^{C}+D_{i-1, C}-D_{i, B}+L \times \theta_{i-1}^{C}
\end{aligned}
$$

Eliminando $U_{i}^{C}, U_{i-1}^{C}, U_{i}^{T}$ e $U_{i-1}^{T}$ das equações (3.20) e (3.23) tem-se $\theta_{i}^{T}$ e $\theta_{i}^{C}$

$$
\begin{aligned}
& \theta_{i}^{T}=\theta_{i-1}^{T}+\frac{D_{i, A}-D_{i-1, B}-D_{i, B}+D_{i-1, C}+\delta_{1}+\delta_{2}}{L} \\
& \theta_{i}^{C}=\theta_{i-1}^{C}+\frac{D_{i, A}-D_{i-1, B}-D_{i,, B}+D_{i-1, C}}{L}
\end{aligned}
$$

Substituindo (3.25) em (3.24) e eliminando os termos D,

$$
\theta_{i}^{T}=\theta_{i}^{C}+\theta_{0}^{T}-\theta_{0}^{C}+\frac{k\left(\delta_{1}+\delta_{2}\right)}{L}
$$


Eliminando os termos D das equações (3.20) e (3.22) e fazendo $U_{0}^{T}=U_{0}^{C}=U_{N}^{T}=0$ e $\theta_{0}^{C}=\theta_{0}^{T}=0$, a equação para $U_{i}^{T}$ pode ser escrita como na expressão (3.27).

$$
U_{i}^{T}=U_{i}^{C}+i \times(i-1) \times \frac{\delta_{1}}{2}+i \times(i+1) \times \frac{\delta_{2}}{2}
$$

Como não é prático medir $\delta_{1}$ e $\delta_{2}$ diretamente, os três sensores devem ser colocados sobre uma régua padrão e deve-se calcular $\delta$ através da relação geométrica, equação (3.28).

$$
\delta=2 D_{B}-D_{A}-D_{C}
$$

Por outro lado, sabemos que

$$
\delta=\delta_{1}+\delta_{2}
$$

Expressando (3.29) como uma equação similar à (3.27) para i=N:

$$
\delta_{1}=\frac{\left(U_{N}^{C}+N \times(N-1) \times \frac{\delta}{2}\right.}{N}
$$

Inserindo (3.28) em (3.30), $\delta_{1}$ pode ser calculado e conseqüentemente $\delta_{2}$.

\subsubsection{MÉTOdo COMBINADo (KIYONO E GaO, 1994)}

Esse método foi desenvolvido para medir perfis que incluam componentes de alta freqüência, isto é, comprimentos de onda espaciais mais curtos que a distância entre as sondas. O método combina os métodos de dois pontos com o da inclinação.

A Figura 3.7 mostra esquematicamente o princípio do método de dois pontos. Como os dois sensores estão submetidas a erros na mesma direção, o erro do movimento do porta sensores, $e_{z}\left(x_{n}\right)$, pode ser cancelado pela diferença entre suas leituras $m_{A}\left(x_{n}\right)$ e $m_{B}\left(x_{n}\right)$.

$$
\begin{aligned}
& m_{A}\left(x_{n}\right)=f\left(x_{n}\right)-e_{z}\left(x_{n}\right) \\
& m_{B}\left(x_{n}\right)=f\left(x_{n}-L\right)-e_{z}\left(x_{n}\right)
\end{aligned}
$$


$\Delta m\left(x_{n}\right)=m_{A}\left(x_{n}\right)-m_{B}\left(x_{n}\right)=f\left(x_{n}\right)-f\left(x_{n}-L\right)$

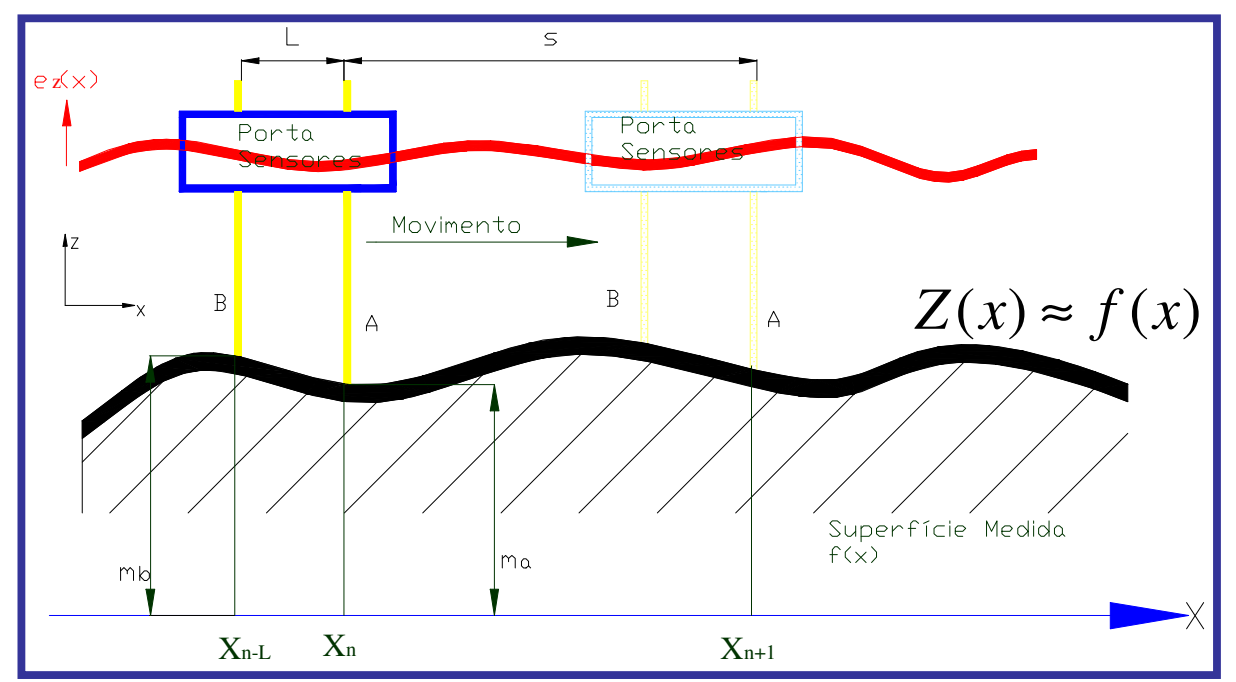

Figura 3.7- Princípio do Método Combinado (Kiyono e Gao,1994).

A derivada aproximada de $f\left(x_{n}\right)$ pode ser definida pela equação (3.34).

$$
m^{\prime}\left(x_{n}\right)=\frac{\Delta m\left(x_{n}\right)}{L}=\frac{f\left(x_{n}\right)-f\left(x_{n}-L\right)}{L}
$$

E a integração da equação (3.34) representa o perfil aproximado, $Z\left(x_{n}\right)$, da superficie medida.

$$
Z\left(x_{n}\right)=\sum_{i=1}^{n} m^{\prime}\left(x_{i}\right) \times s=Z\left(x_{n-1}\right)+m^{\prime}\left(x_{i}\right) \times s
$$

Quando o intervalo para coletas de dados, s, é igual à distância entre os transdutores, L, o método é chamado de método da inclinação e a equação (3.36) pode ser escrita da seguinte forma:

$$
Z\left(x_{n}\right)=Z\left(x_{n-1}\right)+\left(m_{A}\left(x_{n}\right)-m_{B}\left(x_{n}\right)\right)
$$

O método da inclinação permite medição de alturas do perfil em pontos discretos. No entanto, o número de dados é muito pequeno para expressar corretamente o perfil. Para aumentar o número de pontos no método da inclinação, são feitas várias medidas do perfil. O ponto inicial de medição de cada uma dessas medições é transladado de s, ou 
seja, do intervalo de coleta de dados. O número de medições, M, a serem feitas é dado por L/s. Sendo, s menor que a distância entre as sondas (Kiyono e Gao, 1994).

\subsubsection{MÉTODO COM TRÊS APALPADORES (GAO ET AL,2002)}

O esquema do método pode ser visto na Figura 3.8. Nesse método uma integração dupla da diferença das saídas dos sensores é usada para avaliar o perfil da superfície.

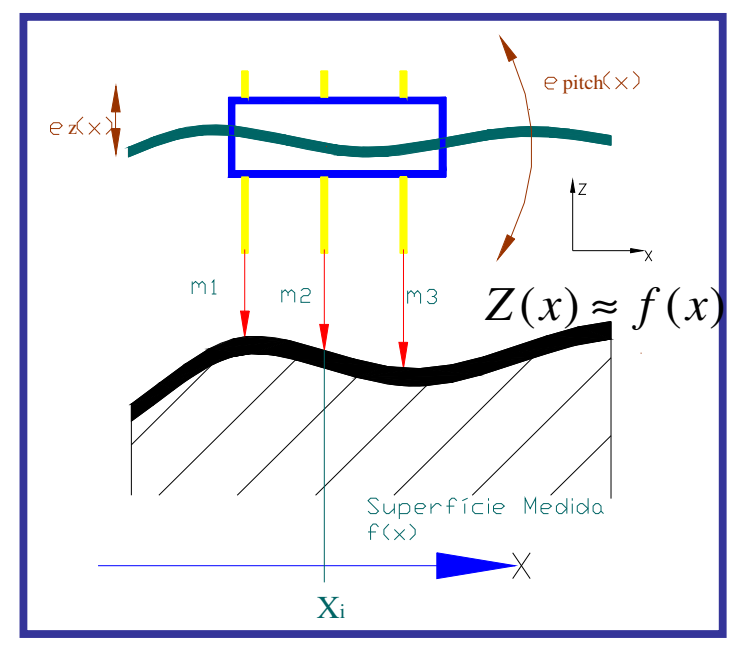

Figura 3.8- Método com três apalpadores (Gao et al,2002).

A leitura, $\mathrm{m}_{\mathrm{i}}$, em cada um dos sensores será:

$m_{1}\left(x_{i}\right)=f\left(x_{i}-L\right)+e_{Z}\left(x_{i}\right)-L \times e_{p i t c h}$

(3.37)

$$
\begin{aligned}
& m_{2}\left(x_{i}\right)=f\left(x_{i}\right)+e_{Z}\left(x_{i}\right) \\
& m_{3}\left(x_{i}\right)=f\left(x_{i}+L\right)+e_{Z}\left(x_{i}\right)+L \times e_{p i t c h}
\end{aligned}
$$

A diferença $m_{S}\left(x_{n}\right)$ é calculada para eliminar o erro de translação, $e_{z}\left(x_{n}\right)$, e o erro angular, $e_{p i t c h}$.

$$
\begin{aligned}
& m_{S}\left(x_{i}\right)=m_{3}\left(x_{i}\right)-2 \times m_{2}\left(x_{i}\right)+m_{3}\left(x_{i}\right) \\
& m_{S}\left(x_{i}\right)=f\left(x_{i}+L\right)-f\left(x_{i}\right)-f\left(x_{i}\right)-f\left(x_{i}-L\right)
\end{aligned}
$$

A derivada segunda de $m_{S}\left(x_{i}\right)$ será 


$$
m^{\prime \prime}\left(x_{n}\right)=\frac{f\left(x_{i}+L\right)-f\left(x_{i}\right)-f\left(x_{i}\right)-f\left(x_{i}-L\right)}{L^{2}}
$$

A integração dupla da equação (3.42) representa o perfil aproximado, $Z\left(x_{i}\right)$, da superficie medida.

$$
Z\left(x_{i}\right)=\iint m^{\prime \prime}\left(x_{j}\right) d s=\sum_{k=1}^{i} \sum_{j=1}^{k}\left(\left(m^{\prime \prime}\left(x_{j}\right) \times s\right) \times s\right)
$$

Onde $Z\left(x_{0}\right)=0$ e $\mathrm{i}=1 . . \mathrm{N}$.

Os valores de zero dos sensores não são ajustados ou medidos precisamente, como já mencionado. A diferença entre os valores de zero introduzirá erro na medição e a integração dupla desse erro fará com que o erro tenha perfil parabólico no resultado do perfil. A equação (3.44) considera o erro de desalinhamento entre os sensores.

$$
Z_{1}\left(x_{i}\right)=\sum_{k=1}^{i} \sum_{j=1}^{k}\left(\left(m^{\prime \prime}\left(x_{j}\right) \times s\right) \times s\right)+\frac{\alpha \times x_{i}^{2}}{2 L^{2}}=Z\left(x_{i}\right)+\frac{\alpha \times x_{i}^{2}}{2 L^{2}}
$$

Sendo $\alpha=\left(e_{m 3}-e_{m 2}\right)+\left(e_{m 1}-e_{m 2}\right)=e_{m 3}-2 \times e_{m 2}+e_{m 1}$ e $e_{m i}$ determinados como indica a Figura 3.9.

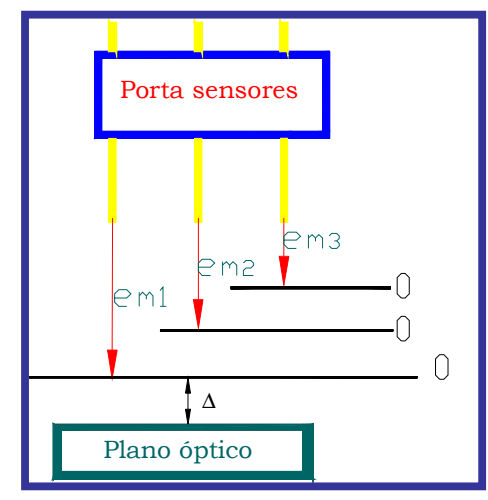

Figura 3.9- Desalinhamento entre os sensores (GAO et al,2002). 


\subsection{MÉtodos MATEMÁticos PARA DETERMinAÇÃo DO DESVIO DE PLANICIDADE}

$\mathrm{Na}$ medição de erro de planicidade as leituras obtidas devem ser cuidadosamente analisadas.

Para determinar o erro de planicidade de uma superfície é necessário gerar um plano de referência. O que pode ser feito utilizando três parafusos de regulagem vinculados a um desempeno ou através de diferentes algoritmos matemáticos. A seguir são apresentados alguns desses métodos.

A apresentação deste item foi subdividida em três partes. A primeira apresenta uma breve descrição sobre o Método dos Mínimos Quadrados (MMQ) para ajuste de uma reta a um dado conjunto de pontos. A descrição pode ser facilmente estendida para ajuste de um plano. Os dois sub-itens restantes apresentam métodos para determinar o desvio de planicidade de acordo com o critério de mínimos desvios.

\subsubsection{MÉtodo dos Mínimos QUADRAdOS}

Nas investigações cientificas freqüentemente deseja-se ajustar uma curva a um dado conjunto de pontos como um plano, uma reta, etc. Em geral tem-se um grande número de pontos, obtidos a partir de ensaios experimentais que podem ser indicados por: $\left\{x_{1}, y_{1}\right\}, \ldots,\left\{x_{i}, y_{i}\right\}, \ldots,\left\{x_{n}, y_{n}\right\}$.Para ajustar uma função $\mathrm{f}(\mathrm{x})$ a este conjunto de pontos utilizando o método dos mínimos quadrados a melhor função $\mathrm{f}(\mathrm{x})$ deve ser determinada a partir de uma função geral, $\mathrm{f}\left(\mathrm{x}, \mathrm{a}_{1}, \mathrm{a}_{2}, \ldots, \mathrm{a}_{\mathrm{p}}\right)$ previamente escolhida. Isto é, a função $\mathrm{f}(\mathrm{x})$ tem forma e número de parâmetros predeterminados. 
Esta segunda condição significa que a melhor função $f(x)$ é $f(x)=\mathrm{f}\left(\mathrm{x}, \mathrm{a}_{1}, \mathrm{a}_{2}, \ldots, \mathrm{a}_{\mathrm{p}}\right)$, onde os valores particulares de $\mathrm{a}_{1}, \mathrm{a}_{2}, \ldots, \mathrm{a}_{\mathrm{p}}$ devem ser determinados conforme o método dos minimos quadrados.

De acordo com o método dos mínimos quadrados a melhor aproximação da função a ser ajustada, $\mathrm{f}(\mathrm{x})$, ocorre quando os parâmetros $a_{1}, a_{2}, \ldots, a_{p}$ minimizam a soma dos quadrados dos resíduos, dada pela expressão (3.47):

$$
S=\sum_{i=1}^{N}\left|y_{i}-f\left(x_{i} ; a_{1}, a_{2}, \ldots, a_{p}\right)\right|^{2}
$$

Para a determinação dos erros de retilineidade deve-se ajustar uma reta ao conjunto de pontos medidos. O modelo linear a ser ajustado é dado pela eq. (3.48), onde $\varepsilon_{i}$ é o resíduo (diferença entre o valor calculado pelo modelo,f( $\left.\mathrm{x}_{\mathrm{i}}\right)$, e o valor real, $\left.y_{i}\right)$ e $\mathrm{a}_{1}$, a são os parâmetros a serem determinados.

$$
f\left(x_{i}\right)=a_{1}+a_{2} \cdot x_{i}+\varepsilon_{i}, \mathrm{i}=1, \ldots, \mathrm{N}(\mathrm{N} \geq 2)
$$

Os resíduos $\varepsilon_{i}$ são considerados variáveis aleatórias, independentes e identicamente distribuídas, isto é, com distribuição normal de média zero e variância constante.

Como mencionado anteriormente, o método dos mínimos quadrados minimiza a soma dos quadrados dos resíduos e para o ajuste de uma reta a equação a ser minimizada é dada por:

$$
S=\sum_{i=1}^{N}\left(y_{i}-\left(\hat{\beta}_{0}+\hat{\beta}_{1} \cdot x_{i}\right)\right)^{2}
$$

Os estimadores $\hat{\beta}_{0}$ e $\hat{\beta}_{1}$ que minimizam a expressão (3.49) são denominados estimadores de mínimos quadrados a serem calculados.

Para encontrar o mínimo de (3.49) deve-se fazer com que as derivadas parciais de $\mathrm{S}$ com relação a $\hat{\beta}_{0}$ e $\hat{\beta}_{1}$ sejam nulas. Desta forma, obtém-se o conjunto de equações (3.50), chamadas de equações normais. 


$$
\left\{\begin{array}{l}
\sum_{i=1}^{N} y_{i}=\hat{\beta}_{0} \cdot N+\hat{\beta}_{1} \cdot \sum_{i=1}^{N} x_{i} \\
\sum_{i=1}^{N} x_{i} \cdot y_{i}=\hat{\beta}_{0} \cdot \sum_{i=1}^{N} x_{i}+\hat{\beta}_{1} \cdot \sum_{i=1}^{N} x_{i}^{2}
\end{array}\right.
$$

Resolvendo o sistema de equações (3.50), os estimadores de minimos quadrados resultam nas expressões dada em (3.51), onde $\bar{x}$ e $\bar{y}$ são respectivamente as médias aritméticas dos valores $\mathrm{x}_{\mathrm{i}}$ e $\mathrm{y}_{\mathrm{i}}$.

$$
\begin{aligned}
& \hat{\beta}_{1}=\frac{\sum_{i=1}^{N} y_{i} \cdot\left(x_{i}-\bar{x}\right)}{\sum_{i=1}^{N}\left(x_{i}-\bar{x}\right)^{2}} \\
& \hat{\beta}_{0}=\bar{y}-\hat{\beta}_{1} \cdot \bar{x}
\end{aligned}
$$

As equações descritas em (3.51) são sempre soluções viáveis e únicas de (3.49) se nem todos os $\mathrm{x}_{\mathrm{i}}$ forem iguais.

No MMQ os resíduos maiores têm maior influência no resultado. Isto ocorre pois há uma ponderação indireta pelo uso de quadrado. Assim, o MMQ oferece apenas uma aproximação para o desvio e, normalmente, é superestimada. Na Figura 3.10 pode-se visualizar a diferença entre os resultados obtidos com o MMQ e com o método de mínimos desvios.

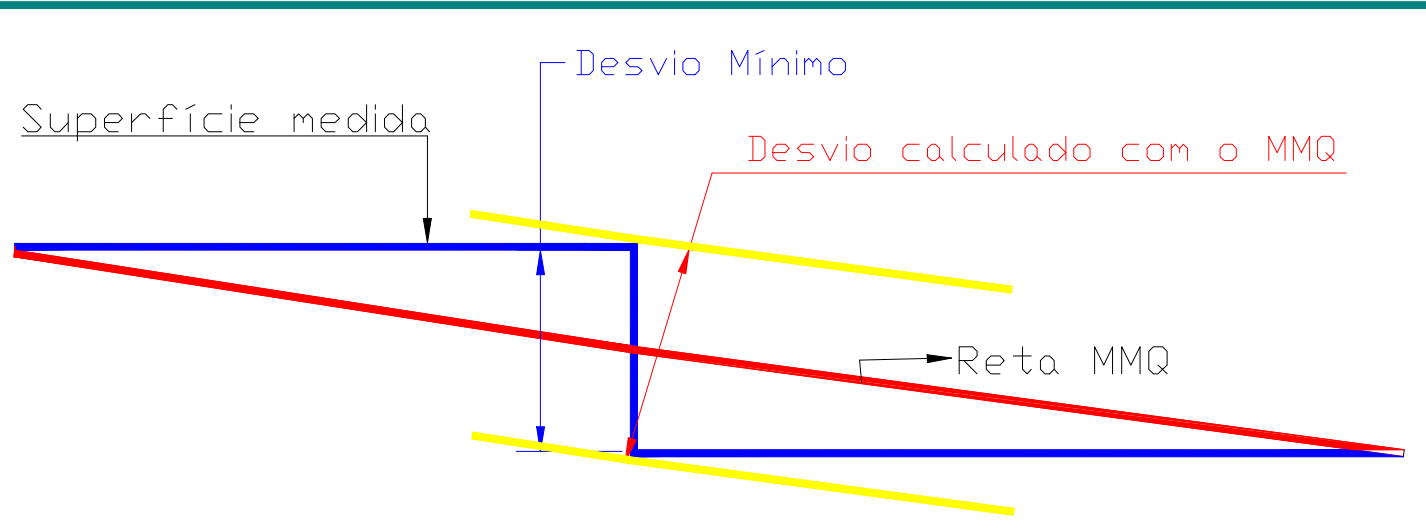

Figura 3.10- Compararação entre MMQ e Mínimo Desvio 
A seguir a descrição dos métodos propostos por Huang et al (1993) e por Weber (2002) que tentam encontrar o desvio mínimo de planicidade.

\subsubsection{MÉtodo de Mínimos desvios PROPOSTO POR HUANG et aL (1993)}

Para um método garantir o critério de mínima zona para o cálculo do erro de planicidade as seguintes condições devem ser verificadas no último estágio de cálculo:

Pelo menos quatro pontos devem estar em contato com os dois planos paralelos que contêm todos os pontos medidos. Esses quatro pontos devem ter uma das duas configurações abaixo:

- 3 pontos em contato com o plano de cima e 1 ponto em contato com o plano de baixo ou vice-versa, formando o modelo 3-1;

- 2 pontos em contado com o plano de cima e 2 pontos em contado com o plano de baixo, formando o modelo 2-2.

- Para o caso do modelo 3-1: a projeção do ponto 'sozinho' no plano que contem os outros três pontos deve pertencer ao triângulo formado por esses três pontos.

- Para o caso do modelo 2-2: a projeção da reta que une dois pontos de um mesmo plano deve interceptar a reta que une os outros dois pontos.

O verdadeiro erro de planicidade é a distância entre os dois planos paralelos que satisfazem a essas condições. Os seguintes modelos devem ser construídos para encontrar os dois planos: Modelo 1-1:

Como primeira aproximação para o plano que melhor se ajusta aos pontos medidos adota-se o plano determinado pelo método dos mínimos quadrados (MMQ).

O ponto mais alto com relação ao plano MMQ é definido como ponto de controle alto e o mais baixo definido como ponto de controle baixo. O modelo 1-1 é estabelecido de tal forma que os planos de controle alto baixo são gerados respectivamente pelo ponto de controle 
alto e pelo ponto de controle baixo, com os dois planos paralelos ao plano MMQ.

A Figura 3.11 mostra a configuração do modelo 1-1.

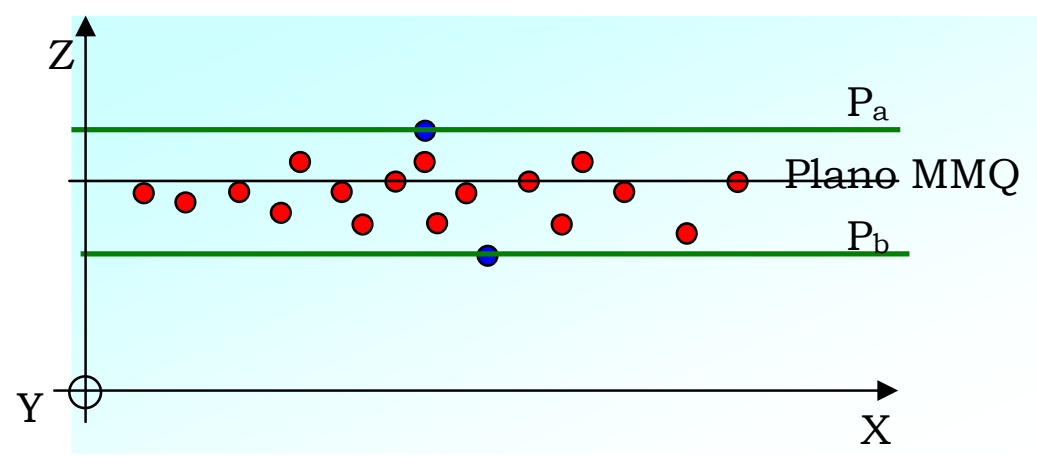

Figura 3.11: Determinação do modelo 1-1

Modelo 2-2:

Para encontrar o terceiro ponto de controle deve-se rotacionar os planos determinados no modelo 1-1. Considere uma vista lateral dos dados em relação ao plano MMQ. Cada plano de controle será rotacionado em uma direção para encontrar o terceiro ponto de contato, que será aquele com menor ângulo com relação ao plano de controle, como pode ser visto a Figura 3.12.

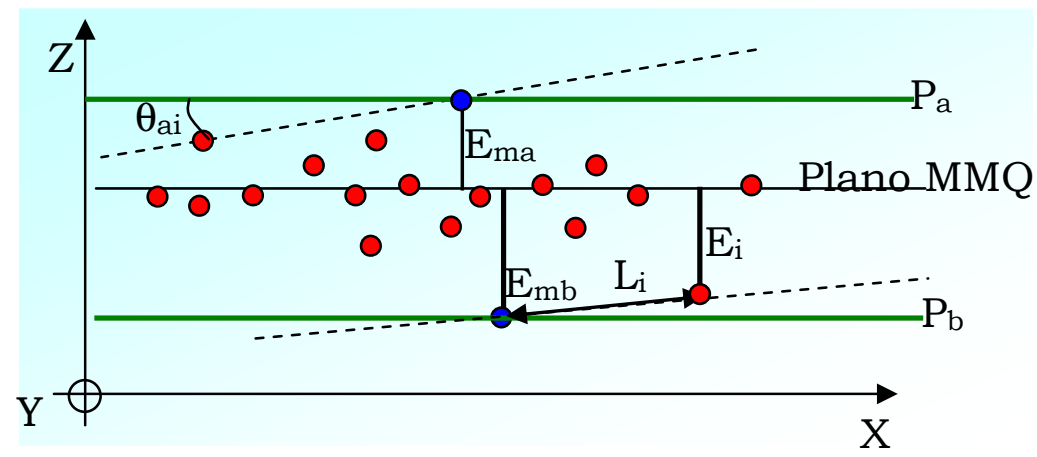

Figura 3.12: Rotação dos planos de controle para formar modelo 2-1 
O ângulo de rotação do plano de controle alto em relação a sua posição inicial é dado pela equação (3.53):

$$
\theta_{a i}=\operatorname{sen}^{-1}\left(\frac{E_{m a}-E_{i}}{L_{i}}\right)
$$

Sendo:

- $\mathrm{L}_{\mathrm{i}}$ a distância do ponto alto de controle ao ponto $\mathrm{i}$;

- $\mathrm{E}_{\mathrm{ma}}$ a distância do ponto de controle alto ao plano MMQ e

- $\mathrm{E}_{\mathrm{i}}$ a distância do ponto i ao plano MMO.

O mesmo deve ser feito para o plano de controle baixo. O ângulo de rotação do plano de controle baixo em relação à sua posição inicial é:

$$
\theta_{b i}=\operatorname{sen}^{-1}\left(\frac{E_{m b}-E_{i}}{L_{i}}\right)
$$

Sendo $\mathrm{E}_{\mathrm{mb}}$ a distância do ponto de controle baixo ao plano MMQ. O terceiro ponto de controle será o menor entre todos $\theta_{\mathrm{a}}$ e $\theta_{\mathrm{b}}$, ou seja, $\theta_{3}=\min \left(\theta_{a}, \theta_{b}\right)$. Encontrado o terceiro ponto de controle deve-se determinar o quarto ponto de controle através do modelo 3-1_2-2.

Modelo 3-1_2-2:

Para encontrar o quarto ponto de controle, deve-se considerar a vista dos pontos medidos na direção que une os dois pontos de controle pertencentes ao mesmo plano de controle. O modelo 2-1 deve ser aplicado novamente, ou seja, os planos de controle devem ser rotacionados para encontrar o quarto ponto de controle.

No final desse estágio os quatro pontos de controle foram determinados. A equação do plano médio é dada pela equação (3.55).

$$
Z=a X+b Y+c
$$

Caso estes pontos tenham a configuração do modelo 3-1, os coeficientes a, b, c da equação do plano médio são calculados pelas seguintes equações.

$$
a=\frac{\left(z_{2}-z_{1}\right)\left(y_{3}-y_{4}\right)-\left(z_{3}-z_{4}\right)\left(y_{2}-y_{3}\right)}{D_{1}}
$$




$$
\begin{aligned}
& b=\frac{\left(x_{2}-x_{1}\right)\left(z_{3}-z_{4}\right)-\left(x_{3}-x_{4}\right)\left(z_{2}-z_{3}\right)}{D_{1}} \\
& c=\frac{\left(z_{2}+z_{1}\right)-a\left(x_{1}+x_{2}\right)-b\left(y_{1}+y_{2}\right)}{2}
\end{aligned}
$$

Onde,

$$
D_{1}=\left(x_{2}-x_{3}\right)\left(y_{3}-y_{4}\right)-\left(x_{3}-x_{4}\right)\left(y_{2}-y_{3}\right)
$$

Sendo $\mathrm{P}_{1}\left(\mathrm{x}_{1}, \mathrm{y}_{1}, \mathrm{z}_{1}\right), \mathrm{P}_{2}\left(\mathrm{x}_{2}, \mathrm{y}_{2}, \mathrm{z}_{2}\right)$ e $\mathrm{P}_{3}\left(\mathrm{x}_{3}, \mathrm{y}_{3}, \mathrm{z}_{3}\right)$ pontos pertencentes ao mesmo plano de controle e $\mathrm{P}_{4}\left(\mathrm{x}_{4}, \mathrm{y}_{4}, \mathrm{Z}_{4}\right)$ pertencente ao outro plano de controle.

Caso os quatro pontos de controle satisfaçam ao modelo 2-2 os coeficientes $\mathrm{a}, \mathrm{b}$ e c do plano médio são determinados por:

$$
\begin{aligned}
& a=\frac{\left(y_{1}-y_{2}\right)\left(z_{3}-z_{4}\right)-\left(z_{1}-z_{2}\right)\left(y_{3}-y_{4}\right)}{D_{2}} \\
& b=\frac{\left(x_{3}-x_{4}\right)\left(z_{1}-z_{2}\right)-\left(x_{1}-x_{2}\right)\left(z_{3}-z_{4}\right)}{D_{2}} \\
& c=\frac{\left(z_{2}+z_{3}\right)-a\left(x_{2}+x_{3}\right)-b\left(y_{2}+y_{3}\right)}{2}
\end{aligned}
$$

Onde,

$$
D_{2}=\left(x_{3}-x_{4}\right)\left(y_{1}-y_{2}\right)-\left(x_{1}-x_{2}\right)\left(y_{3}-y_{4}\right)
$$

Sendo $\mathrm{P}_{1}\left(\mathrm{x}_{1}, \mathrm{y}_{1}, \mathrm{z}_{1}\right)$ e $\mathrm{P}_{2}\left(\mathrm{x}_{2}, \mathrm{y}_{2}, \mathrm{z}_{2}\right)$ os pontos de controle pertencentes ao plano alto e $\mathrm{P}_{3}\left(\mathrm{x}_{3}, \mathrm{y}_{3}, \mathrm{z}_{3}\right)$ e $\mathrm{P}_{4}\left(\mathrm{x}_{4}, \mathrm{y}_{4}, \mathrm{z}_{4}\right)$ pontos pertencentes ao plano baixo.

As equações dos dois planos de controle são obtidas pela equação (3.55). O coeficiente 'c' da equação (3.55) será dado por:

$$
\begin{aligned}
& c_{a}=z_{1}-a x_{1}-b y_{1} \\
& c_{b}=z_{3}-a x_{3}-b y_{3}
\end{aligned}
$$

O erro de planicidade é dado pela distância entre os dois planos de controle.

No entanto, se os quatro pontos de controle não satisfizerem a condição 2 ou a 3 do método dos mínimos desvios, deve-se reformular o modelo 3-1_2-2, descartando o ponto que não obedecer à condição 2 ou 3. 


\subsubsection{MÉTOdo DE OTIMIZAÇÃo PARA DETERMINAÇÃo DO DESVIO DE PLANicidade PROPOSTO POR WeBER ET AL, 2002}

Como já definido no Capítulo 2, o desvio de planicidade exato de um superfície é a menor distâmcia entre dois planos paralelos que contêm todos os pontos medidos. Assim, o o problema matemático para determinar o desvio de planicidade exato pode ser escrito como: dado o conjunto $\mathrm{S}$ de $\mathrm{n}$ pontos medidos $\mathrm{P}_{\mathrm{i}}, \mathrm{i}=1 \ldots \mathrm{n}$, encontrar os dois planos paralelos com a menor distância entre eles e que contenham o conjunto de pontos $\mathrm{S}$.

Se o conjunto de pontos no espaço, S, é transladado ao longo de um eixo arbitrário ou rotacionado em torno de um eixo, a posição relativa entre os pontos será a mesma. Cheraghi et al (1996) buscaram os dois planos paralelos de mínimos desvios depois que os pontos fossem transladados ou rotacionados. Como os planos poderiam estar em qualquer lugar do espaço, os autores assumiram que um dos planos coincide com o plano $\mathrm{x} y, z=0$, e que o outro fica à distancia $t_{\mathrm{s}}$ do primeiro.

Rotacionando os dados com os ângulos $\theta$ e $\gamma$ em torno dos eixos $\mathrm{x}$ e y, respectivamente e transladando-os de $\left(X_{0}, Y_{0}, Z_{0}\right)$, a nova posição do conjunto de pontos $\left(x_{i}, y_{i}, z_{i}\right)$ é representada por $\left(\bar{x}_{i}, \bar{y}_{i}, \bar{z}_{i}\right)$, equação (3.66).

$\left|\begin{array}{c}\overline{x_{i}} \\ \overline{y_{i}} \\ \overline{z_{i}}\end{array}\right|=\left|\begin{array}{ccc}\cos \gamma & 0 & \operatorname{sen} \gamma \\ \operatorname{sen} \theta \times \operatorname{sen} \gamma & \cos \theta & -\operatorname{sen} \theta \times \cos \gamma \\ -\cos \theta \times \operatorname{sen} \gamma & \operatorname{sen} \theta & \cos \theta \times \cos \gamma\end{array}\right| \times\left|\begin{array}{c}x_{i} \\ y_{i} \\ z_{i}\end{array}\right|+\left|\begin{array}{c}X_{0} \\ Y_{0} \\ Z_{0}\end{array}\right|$

Resolvendo o sistema de equações (3.66) tem-se:

$\overline{z_{i}}=-x_{i} \times \cos \theta \times \operatorname{sen} \gamma+y_{i} \times \operatorname{sen} \theta+z_{i} \times \cos \theta \times \cos \gamma+Z_{0}$

O valor mínimo de erro de planicidade é a solução do seguinte problema de otimização. Minimizar $t_{f}$, tal que:

$$
\left\{\begin{array}{l}
\overline{z_{i}} \leq t_{f} \\
\overline{z_{i}} \geq 0 \\
i=1, \ldots, n
\end{array}\right.
$$


Para diminuir a complexidade matemática do método descrito acima, Weber et al (2002) utilizaram expansão de Taylor para linearizar a equação (3.67). O desvio de planicidade mínimo pode ser determinado pela solução do problema linear da expressão (3.69).

MinimizarT $_{f}$, obedecendo:

$$
\begin{aligned}
& \left(-x_{i} \cos \theta_{0} \sin \gamma_{0}+y_{i} \operatorname{sen} \theta_{0}+\cos \theta_{0} \cos \gamma_{0}+Z_{0}\right) \\
& +\left(x_{i} \operatorname{sen} \theta_{0} \operatorname{sen} \gamma_{0}+y_{i} \cos \theta_{0}-\operatorname{sen} \theta_{0} \cos \gamma_{0}\right) d \theta \\
& +\left(x_{i} \cos \theta_{0} \cos \gamma_{0}-z_{i} \cos \theta_{0} \operatorname{sen} \gamma_{0}\right) d \gamma+Z_{0}=T_{f} \\
& \left(-x_{i} \cos \theta_{0} \sin \gamma_{0}+y_{i} \operatorname{sen} \theta_{0}+z_{i} \cos \theta_{0} \cos \gamma_{0}+Z_{0}\right) \\
& +\left(x_{i} \operatorname{sen} \theta_{0} \operatorname{sen} \gamma_{0}+y_{i} \cos \theta_{0}-z_{i} \operatorname{sen} \theta_{0} \cos \gamma_{0}\right) d \theta \\
& +\left(x_{i} \cos \theta_{0} \cos \gamma_{0}-z_{i} \cos \theta_{0} \operatorname{sen} \gamma_{0}\right) d \gamma+d Z_{0} \geq T_{f}
\end{aligned}
$$

As variáveis do problema linear são $d \theta, d \gamma$ e $d Z_{0}$. Os valores de $\theta_{0}, \gamma_{0}$ e $Z_{0}$ são relacionados aos parâmetros $a, b$ e c determinados através do MMQ, como indicam as equações (3.70), (3.71) e (3.72).

$$
\begin{aligned}
& \theta_{0}=\operatorname{sen}^{-1}(b) \\
& \gamma_{0}=\operatorname{sen}^{-1}\left[\frac{a}{\cos \left(\theta_{0}\right)}\right] \\
& Z_{0}=-c \times \cos \left(\theta_{0}\right) \times \cos \left(\gamma_{0}\right)
\end{aligned}
$$

A Tabela 3.1 apresenta os resultados do desvio de planicidade obtidos com o método dos mínimos quadrados, com o método de otimização de Cheraghi et al e com o método de aproximação linear de Weber et al.

Tabela 3.1: Comparação entre os métodos (Weber et al, 2002)

\begin{tabular}{|c|c|c|c|}
\hline Exemplo & MMQ & Cheraghi et al & Weber et al \\
\hline 1 & 2,3664 & 1,9612 & 2,0715 \\
2 & 9,1797 & 4,8573 & 4,8626 \\
3 & 0,1856 & 0,1465 & 0,1561 \\
4 & 0,0044 & 0,0042 & 0,0042 \\
5 & 0,0030 & 0,0026 & 0,0026 \\
\hline
\end{tabular}




\subsection{Conceitos ESTAtísticos BÁsicos PARA TRATAMENTO DE DADOS EXPERIMENTAIS}

Todo resultado de medição é apenas uma estimativa do valor verdadeiro. Isto devido a influência de vários fatores que interferem no processo de medição, tais como: variações associadas ao instrumento de medição, ao operador, às condições ambientes, à temperatura e outros.

Com a evolução da tecnologia, Institutos de Normalização Industrial de vários países sentiram a necessidade de indicar quantitativamente a qualidade do resultado de uma medição, ou seja, acrescentar ao resultado da medição uma declaração sobre a confiança associada a ele. Isto requer estabelecimento de critérios para a determinação do valor que representa a incerteza de medição. Esse valor pode ser considerado como um indicador do desempenho do sistema de medição (PHILLIPS, 1995).

A diferença entre o valor "verdadeiro" e o valor encontrado em uma medição é denominado erro de medição. Como em muitos processos de medição o valor verdadeiro é desconhecido, o erro de medição é dado pela diferença entre o resultado da medição e o valor calibrado.

De acordo com seu comportamento os erros de medição podem ser classificados em erros sistemáticos e aleatórios. Erros sistemáticos são aqueles que permanecem constantes em grandeza e sinal ou variam, de acordo com uma lei definida, quando um número considerável de medições de um mesmo mensurando são efetuadas sob as mesmas condições. Estes erros podem ser reduzidos através de correções nos resultados finais da medição. Quanto menor for o erro sistemático, maior será a acuracidade do instrumento.

Os erros aleatórios são resultados de influências externas e internas, não controladas, que provocam o surgimento de erros não repetitivos. Em geral, estes erros diferem a cada leitura, podendo-se apenas ter noção dos seus limites. Tais erros estarão sempre presentes 
provocando variações nas medições sucessivas e somente podem ser avaliados estatisticamente (Slocum, 1992). Quanto menor for o erro aleatório, maior será a repetibilidade do instrumento. Quando nenhuma das causas que provocam os erros aleatórios é predominante, pode-se dizer que sua ocorrência e comportamento coincidem com a curva de probabilidade normal ou curva de distribuição de Gauss. Portanto, pode-se assumir que erros aleatórios seguem a lei de distribuição normal.

Porém, nem todas as fontes de erros num processo de medição apresentam distribuições normais de probabilidade. São freqüentes, por exemplo, distribuições quadradas,trapezoidais e triangulares.

Após avaliar todos os componentes de erros conhecidos e efetuar as correções dos efeitos sistemáticos no resultado de uma medição, ainda permanece uma dúvida sobre o quanto correto é o valor obtido. Essa dúvida, proveniente dos efeitos aleatórios e da correção imperfeita do resultado, no que diz respeito aos efeitos sistemáticos, é denominada incerteza de medição (ISO, 1993).

Segundo o documento ISO (GUM), a incerteza de medição pode ser definida como sendo o parâmetro, associado ao resultado de uma medição, que caracteriza a dispersão dos valores que poderiam ser atribuídos ao mensurando. Tal parâmetro pode ser, por exemplo, um desvio padrão (ou múltiplo dele) ou a metade de um intervalo correspondente a um dado nivel de confiança.

A incerteza de medição é expressa, geralmente, como uma faixa de valores distribuídos simetricamente em torno do valor obtido como resultado de uma medição (PHILLIPS, 1995). Na incerteza de medição estão contidos os efeitos de todos os fatores que influenciam o resultado da medição. A incerteza associada a um resultado pode ser especificada de diferentes formas: incerteza padrão, incerteza padrão combinada, incerteza expandida. 


\subsubsection{InCERTEZa PadRÃo}

Toda medição é um conjunto de operações que têm por objetivo determinar o valor de uma grandeza. O mensurando, geralmente, não é medido diretamente e sim determinado a partir de $\mathrm{N}$ outras grandezas $\mathrm{X}_{1}, \mathrm{X}_{2}, \ldots, \mathrm{X}_{\mathrm{N}}$, denominadas grandezas de entrada, através de uma relação funcional $\mathrm{f}$, como mostra a equação (3.73).

$$
Y=f\left(X_{1}, X_{2}, \cdots X_{N}\right)
$$

As grandezas de entrada, por sua vez, podem também ser consideradas mensurandos que dependem de outras grandezas. Seus valores e respectivas incertezas podem ser obtidos a partir de uma única observação ou de repetidas observações, de dados fornecidos pelos fabricantes dos instrumentos, da experiência do observador, da literatura, de medições realizadas anteriormente, de padrões de calibração, de materiais de referência ou de certificados de calibração, etc.

Assim sendo, a incerteza associada ao resultado da medição deve levar em consideração as incertezas individuais das variáveis que afetam o processo de medição.

De acordo com o método usado para determinar o valor numérico das incertezas, estas podem ser classificadas em incertezas do Tipo A e incertezas do Tipo B.

A incerteza do Tipo A é aquela obtida estatisticamente à partir de medições ou observações repetidas de uma dada grandeza, assumindo uma distribuição normal ou outra qualquer. A incerteza do Tipo B, por sua vez, não é estimada através de análise estatística de séries de observações e, sim, através de considerações de efeitos físicos que afetam os resultados (Piratelli, 1997; Decker e Pekelsky, 1999).

No caso de incerteza do tipo A, a média dos valores obtidos em um dado experimento é a estimativa do mensurando e a raiz quadrada da variância é a incerteza padrão associada ao estimador. A incerteza padrão considera as flutuações aleatórias dos resultados do 
experimento e outras influências que são consideradas constantes para este experimento (BS 6808: Code of Practice, 1989). A representação das componentes de incertezas é feita pela estimativa de um desvio padrão, denotada por $\mathrm{u}$, chamada incerteza padrão. No caso de incerteza Tipo A, quando o componente de $\mathrm{n}$ medições representam uma amostra, a incerteza padrão é determinada pela equação (3.74), onde a estimativa do mensurando é $\bar{x}$.

$$
\bar{x}=\frac{x_{1}+x_{2}+\cdots x_{n}}{n} \text { e } u=\sqrt{s^{2}}=\sqrt{\frac{\sum_{i=1}^{n}\left(x_{i}-\bar{x}\right)^{2}}{n-1}}
$$

A incerteza do tipo B é estimada a partir de um julgamento científico baseado em todas as informações relevantes disponíveis sobre o instrumento e o processo de medição. (ISO GUM, 1993; Decker e Pekelsky, 1999).

Quando a estimativa do mensurando for obtida de uma especificação do fabricante, certificado de calibração, manual técnico ou de outra fonte e sua incerteza dada como um múltiplo do desvio padrão, a incerteza padrão é a incerteza citada dividida pelo multiplicador (ISO GUM, 1993). Por outro lado, se a incerteza declarada é um parâmetro ao qual está associado um dado nível de confiança, o cálculo da incerteza padrão só será efetuado se a distribuição de probabilidade caracterizada pela estimativa do mensurando e sua incerteza for conhecida. Neste caso, a incerteza padrão é a incerteza citada dividida pelo fator de abrangência apropriado para a distribuição adotada. Tal fator é encontrado nas tabelas de distribuições de probabilidades.

A distribuição mais usada para calcular a incerteza padrão é a normal, pois é geralmente utilizada para descrever erros experimentais. A tabela 3.2 apresenta alguns fatores de abrangência para essa distribuição de probabilidade. 


\begin{tabular}{|l|c|}
\hline Nivel de Confiança (\%) & Fator de Abrangência (k) \\
\hline 68.27 & 1 \\
90 & 1.645 \\
95 & 1.960 \\
95.45 & 2 \\
99 & 2.576 \\
99.73 & 3 \\
\hline
\end{tabular}

Tabela 3.2: Fator de abrangência e seu respectivo nível de confiança assumindo uma distribuição normal (gaussiana)

Em geral, de posse de todas as informações disponíveis sobre o instrumento e a medição, é possível determinar o intervalo que contém o valor "verdadeiro" da grandeza analisada e fazer alguma hipótese sobre a distribuição de erros. Quando, porém, o intervalo é bem definido, mas a distribuição de erros não é bem conhecida, deve-se admitir uma distribuição mais simples que a normal, tal como uma distribuição retangular, uma distribuição trapezoidal ou uma distribuição triangular (ISO GUM, 1993).

A distribuição trapezoidal é utilizada quando a probabilidade do valor do mensurando estar no intervalo $\left(a_{-}, a^{+}\right)$é igual a 1 e a probabilidade de estar fora é praticamente zero. Além disso, é provável que ele esteja mais próximo do ponto médio do que dos limites do intervalo. A melhor estimativa para o mensurando é $\left(a_{+}+a_{-}\right) / 2$ e a incerteza é $u=a \sqrt{\frac{1+\beta^{2}}{6}}$, onde $0 \leq \beta \leq 1$ e $a=\left(a_{+}+a_{-}\right) / 2$. Quando $\beta \rightarrow 1$, a distribuição trapezoidal se aproxima da distribuição retangular, enquanto com $\beta=0$ tem-se a distribuição triangular.

\subsubsection{INCERTEZA PADRÃo COMBINAdA}


A incerteza padronizada pode ser calculada a partir das incertezas padrões individuais das variáveis que interferem no processo de medição, através de uma lei conhecida como "lei de propagação de incertezas". A incerteza assim determinada é definida pelo Comitê Internacional de Pesos e Medidas (CIPM) como incerteza padronizada combinada e é designada por $u_{c}$. A lei de propagação de incertezas, porém, somente pode ser aplicada quando o modelo matemático que relaciona a variável resposta da medição com as variáveis que afetam o seu comportamento for conhecido. Isto é, quando a função $f$ é conhecida. Nesse caso, a incerteza padronizada combinada, $\mathrm{u}_{\mathrm{c}}(\mathrm{y})$, é dada pela raiz quadrada positiva da variância, equação (3.75).

$$
u_{c}^{2}(y)=\sum_{i=1}^{N}\left(\frac{\partial f}{\partial x_{i}}\right)^{2} u^{2}\left(x_{i}\right)+2 \sum_{i=1}^{N-1} \sum_{j=i+1}^{N} \frac{\partial f}{\partial x_{i}} \frac{\partial f}{\partial x_{j}} \mathrm{u}\left(\mathrm{x}_{\mathrm{i}}\right) \cdot u\left(x_{j}\right) \cdot r\left(x_{i}, x_{j}\right)
$$

Onde, y é a estimativa da grandeza $\mathrm{Y}, \mathrm{x}_{\mathrm{i}}$ é a estimativa da variável $\mathrm{X}_{\mathrm{i}}$ e $u^{2}\left(x_{i}\right)$ é a variância associada a $\mathrm{X}_{\mathrm{i}}$, para todo i variando de 1 até $\mathrm{N}$, onde $\mathrm{N}$ é o número de variáveis que afetam a variável resposta $\mathrm{Y}$. $\mathrm{E}$ $u\left(x_{i}\right)$ é a incerteza associada à fonte de erro representada pela estimativa $\mathrm{x}_{\mathrm{i}}$ e $r\left(x_{i}, x_{j}\right)$ é o coeficiente de correlação entre as estimativas $x_{i}$ e $x_{j}$

A equação (3.75), referenciada como a lei de propagação de incerteza, é baseada numa aproximação da série de Taylor de primeira ordem de $Y=f\left(X_{1}, X_{2}, \cdots X_{N}\right)$.

As derivadas parciais em função de cada variável $x_{i}(i=1, \ldots, n)$ que aparecem na expressão (3.75) são denominadas coeficientes de sensibilidade. A grandeza desses coeficientes descreve a contribuição de cada fonte de incerteza no valor final da incerteza de medição.

O segundo termo da equação (3.75) expressa a correlação existente entre duas fontes de incertezas $x_{i}$ e $x_{j}(i \neq j)$. O coeficiente $r$ fornece uma medida do grau de correlação entre as variáveis. A expressão (3.76) apresenta o coeficiente de correlação entre duas variáveis $\mathrm{x}_{\mathrm{i}}, \mathrm{x}_{\mathrm{j}}$. 


$$
r\left(x_{i}, x_{j}\right)=\frac{\sum_{k=1}^{M}\left(x_{i k}-\bar{x}_{i}\right) \cdot\left(x_{j k}-\bar{x}_{j}\right)}{\sqrt{\sum_{k=1}^{M}\left(x_{i k}-\bar{x}_{i}\right)^{2} \cdot \sum_{k=1}^{M}\left(x_{j k}-\bar{x}_{j}\right)^{2}}}
$$

Onde, $\mathrm{M}$ é o número de valores atribuídos às variáveis $\mathrm{x}_{\mathrm{i}}$ e $\mathrm{x}_{\mathrm{j}} \mathrm{e} \bar{x}_{i} \mathrm{e}$ $\bar{x}_{j}$ são respectivamente as médias aritméticas dos $\mathrm{M}$ valores atribuídos a $\mathrm{x}_{\mathrm{i}} \mathrm{e} \mathrm{x}_{\mathrm{j}}$.

O coeficiente de correlação varia de -1 a 1 . Quando esse valor se aproxima dos extremos significa que as variáveis $\mathrm{x}_{\mathrm{i}}$ e $\mathrm{x}_{\mathrm{j}}$ têm um alto grau de correlação. Por outro lado, se o coeficiente de correlação é zero significa que não há correlação entre as variáveis. Portanto, se as estimativas $\mathrm{x}_{\mathrm{i}}, \mathrm{x}_{\mathrm{j}}$ são independentes entre si, o coeficiente de correlação é igual a zero e o segundo termo da equação (3.75) desaparece, diminuindo, assim, o número de cálculos necessários para determinação da incerteza padrão combinada.

\subsubsection{INCERTEZA EXPANDIDA}

Além da incerteza padronizada combinada, o Comitê Internacional de Pesos e Medidas (CIPM) propõe descrever a incerteza de medição através de intervalos que representam os valores esperados para os erros de medição, com uma probabilidade conhecida. O CIPM usa o termo incerteza expandida $\left(U_{p}\right)$ para descrever tal intervalo. Seu valor é obtido pela expressão (3.77), onde $u_{c}$ é a incerteza padrão combinada e $\mathrm{k}>0$ é o fator de abrangência.

$$
\mathrm{U}_{\mathrm{p}}=\mathrm{k} \cdot \mathrm{u}_{\mathrm{c}}
$$

$\mathrm{O}$ fator $\mathrm{k}$ está associado à distribuição de probabilidades dos valores obtidos na medição, que geralmente apresentam uma distribuição Normal. Para esta distribuição, assume-se k igual a 2 para um intervalo de confiança de $95,5 \%$ ( ou aproximadamente $95 \%$ ) e 3 para um intervalo com $99.7 \%$ de probabilidade, conforme mostrado na tabela 1. 
A incerteza expandida é uma maneira de apresentar a informação para satisfazer requisitos de algumas aplicações comerciais e industriais, que necessitam de um intervalo de valores em torno do resultado de medição (ISO GUM, 1993). Ela deve ser apresentada junto do valor médio, $\bar{y}$, conforme a expressão (3.78)

$$
\bar{y} \pm U_{p}
$$




\section{CAPÍTULO 4}

\section{Sistema Para Medição de ErRo de Planicidade}

A acuracidade dos processos de medição e de montagem que utilizam os desempenos como referência depende principalmente da planicidade dessas superficies. Se a referência está fora das especificações é inútil utilizar instrumentos sofisticados e de alta acuracidade.

Neste trabalho é apresentado um sistema para medição de desvios de planicidade de desempenos. O sistema é constituído por três transdutores de deslocamento do tipo LVDT fixados no eixo $z$ de uma Máquina de Medir a Três Coordenadas (MM3C). Para executar as medições o eixo $z$ foi travado enquanto os eixos $\mathrm{x}$ e y foram usados para deslocar os transdutores. 
Durante a medição a intenção é avaliar apenas os desvios da superficie, no entanto, os mancais das MM3C não se deslocam perfeitamente e as leituras obtidas são as componentes dos desvios da superficie e dos erros de movimentação dos mancais. Uma estratégia que pode ser utilizada para a separação desses erros é a tomada de dados com redundância. Nesse tipo de medição, o mesmo ponto é verificado mais de uma vez. Para eliminar as componentes de erros da máquina dos dados medidos, pode-se usar as técnicas de separação de erros, e então, o desvio da superficie pode ser determinado.

O sistema desenvolvido foi utilizado para medir o desvio de planicidade de um desempeno. Para verificar a eficiência do mesmo foi realizada uma comparação entre os valores de erro de planicidade obtidos através de medição com o sistema proposto e aqueles obtidos com interferômetro a laser, nivel eletrônico e MM3C.

Para melhor entendimento do sistema de medição a apresentação do trabalho foi dividida em 5 itens. O primeiro item descreve a interface entre MM3C, transdutores e operador. O segundo item descreve o método de coleta de dados e os demais itens apresentam: método matemático, técnica de separação de erros, método para avaliação do sistema de múltiplas sondas e cálculo de incerteza de medição.

\subsection{DESENVOLVIMENTO DAS INTERFACES ENTRE MÁQUINA, COMPUTADOR E OPERADOR}

Para medir o desvio de planicidade o mensurando foi colocado sobre três parafusos de regulagem no desempeno da máquina de medir e alinhado com o plano formado pelas guias $x$ e y da máquina. Para medir as variações de altura na superficie foi fixado no eixo $z$ da máquina um dispositivo contendo três transdutores. Esse conjunto foi denominado garra.

As medições foram feitas "on-the fly", ou seja, pelo método de medição em que a máquina não pára e as leituras dos transdutores são 
executadas quando as posições programadas são atingidas. Para tanto, os sinais das escalas da máquina e dos transdutores foram enviados para um microcomputador.

Os sinais dos "encoders" das escalas da máquina foram capturados através do sistema implementado por Marques (2003). Tal sistema tem como função capturar e enviar esses sinais para o microcomputador, que recebe o sinal através de uma placa de aquisição confeccionada exclusivamente para esse fim.

Os transdutores foram conectados a uma coluna de medição para processamento dos sinais e esses foram enviados para o microcomputador através de uma placa de aquisição de dados.

Com os sinais das escalas $\mathrm{x}$ e y e dos transdutores disponiveis no microcomputador foi possivel elaborar um programa computacional para ler as escalas x e y da máquina de medir e os deslocamentos dos transdutores. Quando o carro da máquina passa pelas posições estabelecidas pelo usuário, o programa armazena os dados dos transdutores. Além disso, o programa faz o gerenciamento do processo de coleta de dados, a manipulação dos dados e apresenta o resultado da medição.

\subsection{MÉTODO DE TOMADA DE DADOS}

Em qualquer processo de medição deve-se escolher a estratégia a ser adotada para a tomada de leituras. Existem diferentes tipos de estratégias para medição de desvio de planicidade e as mais comuns são os métodos "union Jack" e grades retangulares. No método "union Jack" a divisão da superfície é feita imitando a bandeira do Reino Unido e no método de grades retangulares são traçadas linhas paralelas e perpendiculares. Em ambos os casos são medidos os desvios de retilineidade de cada linha e esses desvios são usados para formar a superficie tridimensional. O método aplicado neste trabalho foi o de células retangulares, pois com ele, maior número de pontos são 
verificados e, portanto, consegue-se uma melhor representação da superficie.

Foi medida uma superficie de granito de dimensões 500 x 300mm. Foram traçadas linhas paralelas e uma linha perpendicular a essas, que foi utilizada para vincular as linhas paralelas. A distância entre as linhas foi de $18 \mathrm{~mm}$ e equivale à distância entre os transdutores. $\mathrm{O}$ desvio de retilineidade de cada linha foi medido e cada ponto foi apalpado pelos três sensores. Como mencionado, esses dados são, na verdade, uma mistura de erros da máquina e da peça e por isso, foram aplicadas as técnicas de separação de erros. Muitos autores têm estudado e sugerido técnicas de separação de erros, mas nenhum estudo foi encontrado contendo a comparação entre essas técnicas. Por isso, decidiu-se aplicar quatro técnicas de separação de erros. Duas propostas por Tanaka (1986) e duas propostas por Gao (2002).

Aplicadas as técnicas de separação de erros o desvio da peça pode ser calculado. Até então, os dados representam apenas o desvio de retilineidade de cada linha. Para formar a superficie tridimensional, a linha perpendicular é usada para vincular as paralelas e fazer com que as alturas de todos os pontos sejam relativas a um mesmo referencial.

\subsection{MÉTOdo MAtemÁtico}

Para o cálculo do desvio de planicidade, primeiramente, foi determinado o plano que melhor representa os pontos medidos através do método dos mínimos quadrados. Em seguida, foi calculada a distância de cada ponto medido até esse plano. A distância entre os dois pontos de lados opostos e mais distantes do plano de MMQ é o desvio de planicidade da superficie. 


\subsection{Avaliação do Sistema Múltiplas Sondas}

Para verificar a eficiência do sistema de múltiplas sondas foi feita a medição do desvio de planicidade de uma superficie de granito utilizando o sistema de múltiplas sondas, MM3C, nível eletrônico e interferômetro a laser. Os aspectos considerados para comparação foram: custo de cada equipamento, tempo de medição e valor do desvio de planicidade fornecido por cada equipamento. Como o interferômetro a laser é considerado o instrumento padrão na área de metrologia dimensional mecânica, o erro de planicidade medido com esse instrumento foi considerado o verdadeiro desvio de planicidade da superficie.

\subsection{CÁlCUlo dA INCERTEZA DE MEDIÇÃo}

Após a validação do modelo proposto, procedeu-se finalmente, à determinação das incertezas associadas ao processo de medição. Para tanto, utilizou-se o procedimento proposto pelo Guia para Expressão das Incertezas de Medição (1999), que recomenda a aplicação da lei de propagação das incertezas.

Tal procedimento exigiu a identificação e a observação de todas as grandezas que interferiram nos resultados obtidos, como resolução dos transdutores e variação da temperatura ambiente. A seguir procede-se à determinação da incerteza padrão de todas as grandezas e a avaliação segundo seus tipos A ou B. Por fim, aplicação da lei de propagação de incertezas para calcular a incerteza associada ao desvio de cada ponto medido. 


\section{CAPÍTULO 5}

\section{DESENVOLVIMENTO DO SISTEMA PARA MEDIÇÃo DE ERRO DE PLANICIDADE}

Conhecidos os diversos métodos de medição, separação de erros e cálculo de desvio de planicidade, segue-se a proposta de um sistema que concilie os três assuntos estudados. Tal sistema deve possibilitar a separação dos erros relativos aos mensurandos e os relativos ao sistema de medição. Para isso, o sistema proposto foi idealizado de forma a medir desvio de retilineidade de diversas linhas e em seguida utilizar um programa computacional para separar os erros em cada uma das linhas medidas. O algoritmo deve também organizar os dados de forma que cada ponto medido seja referenciado a um único sistema de 
coordenadas. Esse procedimento é adotado para cálculo do plano que melhor representa os pontos medidos através do MMQ.

Organizados os dados e calculado o plano de MMQ, o programa computacional deve calcular o desvio de planicidade.

Este capítulo descreve os detalhes relativos ao sistema de medição proposto. Apresenta, também, as equações para cálculo da incerteza de medição utilizando tal sistema.

\subsection{DESENVOLVIMENTO DA INTERFACE ENTRE MÁQUINA E COMPUTADOR}

Os experimentos para levantamento do erro de planicidade da superficie foram feitos em uma Máquina de Medir a Três Coordenadas (MM3C) do tipo Ponte Móvel, fabricada pela Brown \& Sharpe Mfg. Co. modelo Micro Validator.

As MM3C, com estrutura Ponte Móvel, têm como características principais um desempeno de granito fixo para suporte do mensurando e uma ponte que se movimenta para posicionar o apalpador de medição sobre a peça. Três conjuntos de mancais aerostáticos permitem o movimento dos eixos $\mathrm{X}, \mathrm{Y}, \mathrm{e} Z$ sobre as guias. Esses mancais necessitam de ar comprimido, seco e limpo para a formação de um colchão de ar que sustenta a parte móvel da estrutura.

O sistema de medição da máquina de medir consiste de escalas ópticas de vidro fixadas nas guias. O gatilhamento do sinal para a aquisição de pontos sobre a superficie do mensurando é feito por um apalpador de medição, que emite um sinal elétrico toda vez que é encostado na peça. Nesse instante, as posições nos eixos X, Y e Z são armazenadas no microcomputador dedicado à MM3C. 
A Figura 5.1 apresenta um esquema da MM3C e alguns de seus componentes.

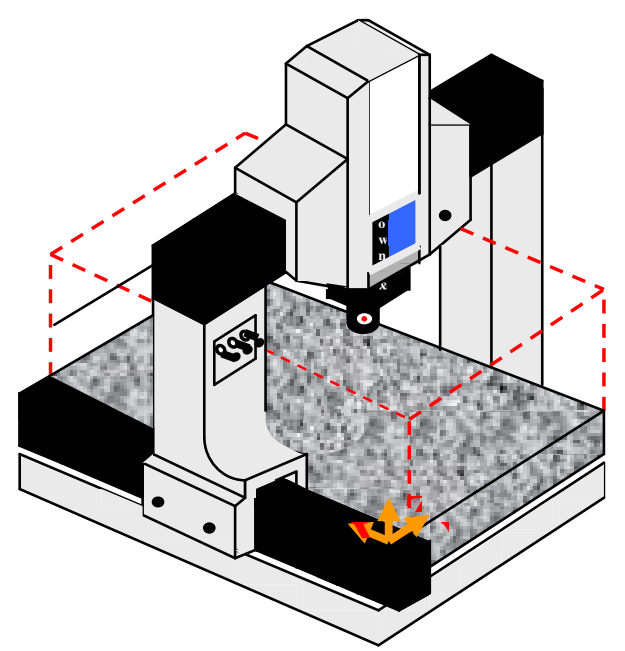

Figura 5.1: Representação da máquina de medir a três coordenadas do tipo ponte móvel

MARQUES, A. (2003) desenvolveu uma interface para obter os sinais das escalas ópticas e do apalpador de medição. O sistema captura os sinais das três escalas ópticas antes que sofram qualquer tipo de manipulação numérica. Esses sinais são enviados para um microcomputador equipado com uma placa de aquisição confeccionada exclusivamente para esse fim.

Neste trabalho, o apalpador de medição foi substituído por dois ou três transdutores do tipo LVDT. Uma peça, com três furos passantes e igualmente espaçados, foi fabricada para alojar os transdutores. Esse conjunto foi chamado de garra de medição e sua foto pode ser vista na Figura 5.2.

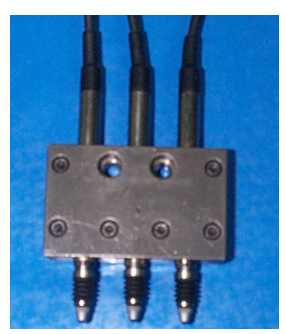

Figura 5.2: Garra de medição 
Os sinais dos três transdutores foram enviados para uma placa de aquisição de sinais instalada no mesmo microcomputador que possui a placa de aquisição de sinais das escalas ópticas. A Figura 5.3 apresenta o esquema do sistema de medição.

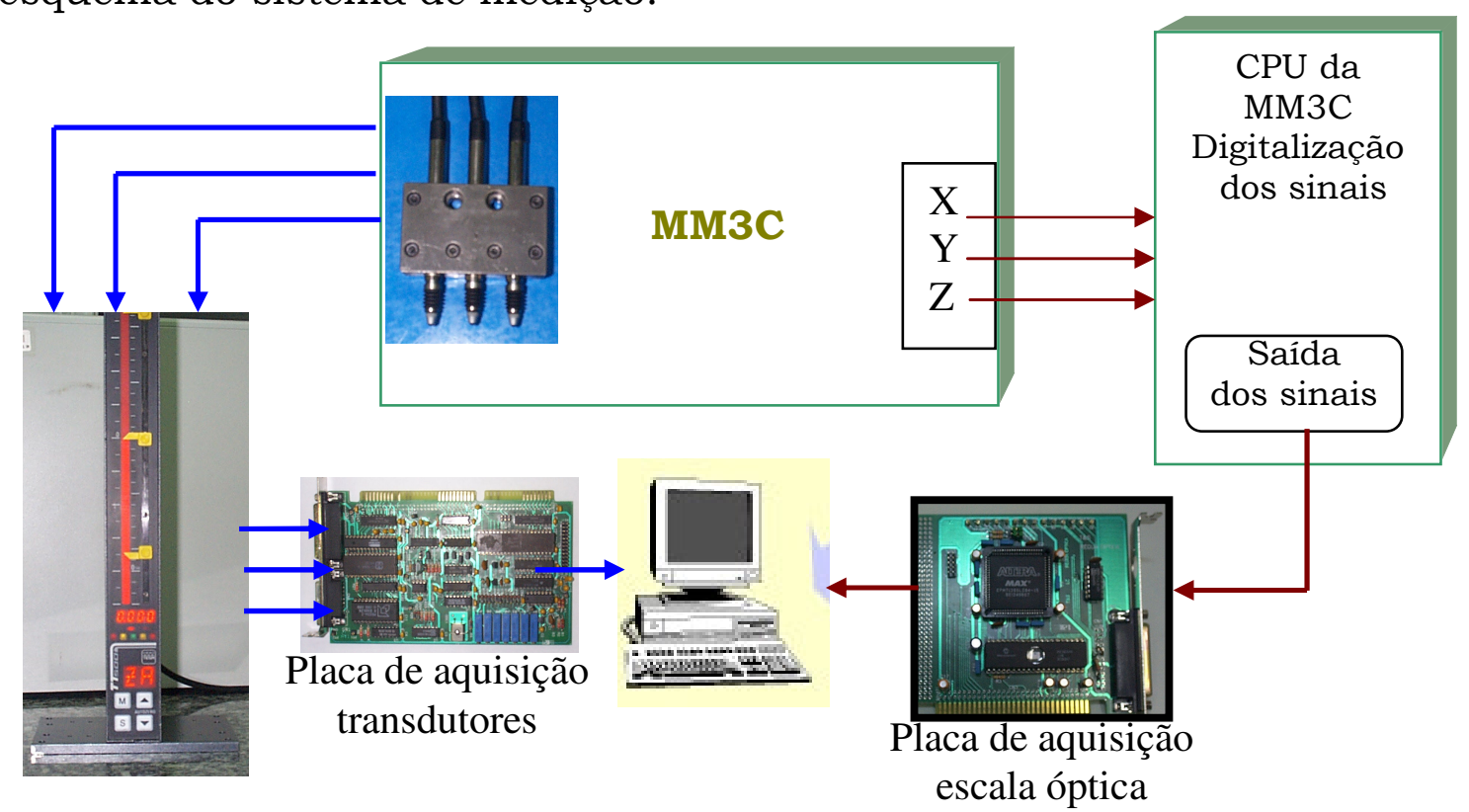

Figura 5.3: Esquema do sistema de medição

\subsection{MÉTODO DE TOMADA DE DADOS}

Em qualquer processo de medição, deve-se estabelecer uma seqüência de tomada de dados. Existem alguns métodos, estabelecidos pelas normas técnicas, para divisão da superfície e para coleta de pontos nas medições de planicidade. Cabe citar, entre estes, o método das linhas diagonais, o método de grades retangulares e o método Union Jack.

O primeiro divide a superficie como na Figura 5.4. As linhas são traçadas dentro de uma área interna à superficie e as diagonais são medidas (JIS B 7513).

No segundo método mostrado na Figura 5.5 todas as linhas são medidas. O método 'Union Jack' é freqüentemente criticado pela baixa cobertura da área de medição. No entanto, os erros máximos 
geralmente estão nos cantos dos desempenos e como este método cobre os cantos não há problemas na sua utilização (WHITEHOUSE, 1976).

O método das linhas cruzadas utiliza um sistema de coordenadas 'XYZ' fixo e as medidas são relativas a ele (MILLER, 1962). As linhas para medição são traçadas como mostra a Figura 5.6. Quando se utiliza nível eletrônico ou nível de bolha para medição a distância entre as linhas deve ser igual ao comprimento da base do instrumento.

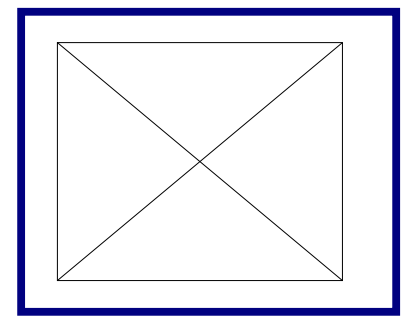

Figura 5.4 - Método das linhas diagonais

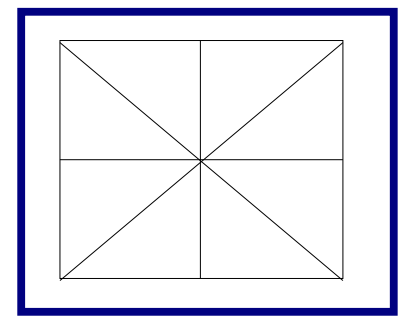

Figura 5.5 - Union Jack

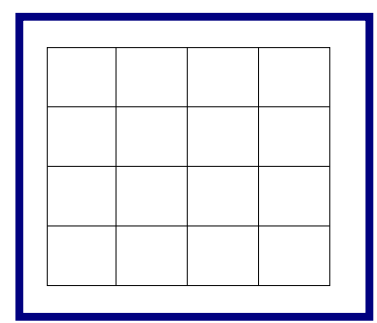

Figura 5.6 - Método de grades retangulares

Os métodos citados consistem em medir o erro de retilineidade de cada linha. A união das linhas medidas formará a figura tridimensional da superficie. A ordem de coleta dos dados deve ser especificada para reduzir erros de cálculo e para a construção de um mapa com a distribuição dos erros, assim pode-se ter idéia da parte da superfície que se apresenta mais plana.

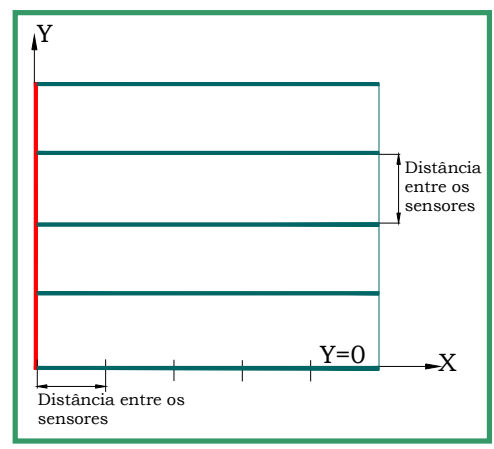

Figura 5.7: Linhas para coleta de dados

O método escolhido para tomada de leituras foi o de grades retangulares, pois com ele, maior número de pontos é verificado e, portanto, a superfície é melhor representada. Nesse método, todas as linhas horizontais e uma linha vertical, indicada em vermelho na Figura 
5.7, são medidas. A linha vertical é usasa para unir as linhas horizontais e formar a figura tridimensional da superficie medida.

Foi definida uma ordem de entrada de dados no programa computacional desenvolvido. A primeira linha a ser medida é a vertical, desenhada em vermelho na Figura 5.7. Em seguida, as linhas horizontais são medidas partindo da posição $\mathrm{y}=0$, como indicado na Figura 5.7. O passo de medição é a distância entre os sensores, ou seja, $18 \mathrm{~mm}$.

\subsection{Algoritmo para Cálculo do Desvio de Planicidade}

Com os sinais das escalas ópticas e dos transdutores disponíveis no microcomputador e com o método de tomada de dados definido, passou-se à fase de desenvolvimento de um programa computacional para manipulação dos dados medidos.

$\mathrm{Na}$ primeira tela do programa computacional o operador deve informar as dimensões da superficie a ser medida, o passo de medição e a distância entre os sensores. A segunda tela pode ser visualizada na Figura 5.8. Nela visualiza-se um mapa de medição que indica ao operador a posição em que a garra deve ser colocada sobre a peça. $O$ programa lê constantemente as leituras das réguas ópticas para verificar se a garra está na posição de armazenar as leituras dos transdutores. Quando a garra de medição passa por essa posição as leituras são armazenadas e a próxima posição em que a garra deve ser colocada é indicada ao usuário. Para fazer a indicação, a linha que representa a posição no mapa de medição fica piscando. Enquanto a posição indicada no mapa não for medida, o programa não armazena outros dados.

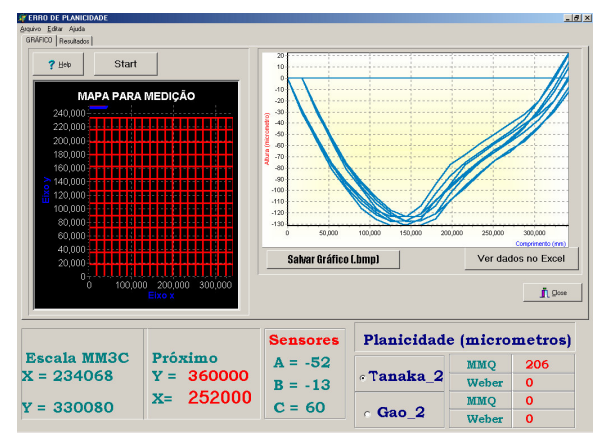

Figura 5.8: Tela do programa computacional 
O fluxograma do programa computacinal pode ser visualizado na Figura 5.9.

Dados de entrada do programa: comprimento e largura da peça, passo de medição e distância entre os sensores.

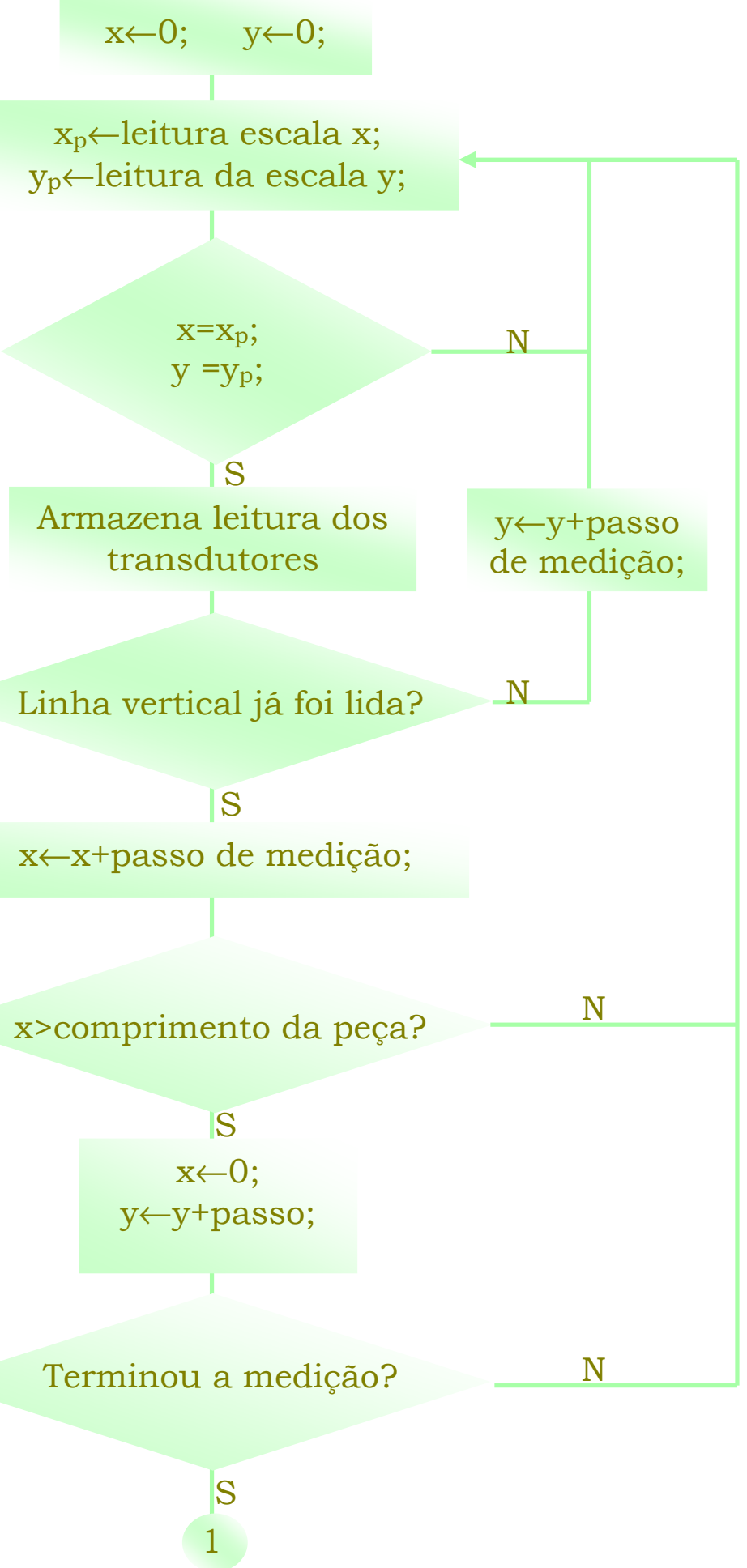

Figura 5.9: Fluxograma para coleta de dados 
Terminada a medição, os erros de movimentação são eliminados de cada uma das linhas medidas através da técnica de separação de erros propostas por Tanaka \& Sato (1986) e Gao et al (2002). Para verificar a adequabilidade dessas técnicas testes preliminares foram feitos. Nesses testes foram medidos os erros de retilineidade de uma régua com desvios de retilineidade conhecidos. A Figura 5.10 mostra a seqüência de operações realizadas para separar os erros da peça dos erros do sistema de medição.
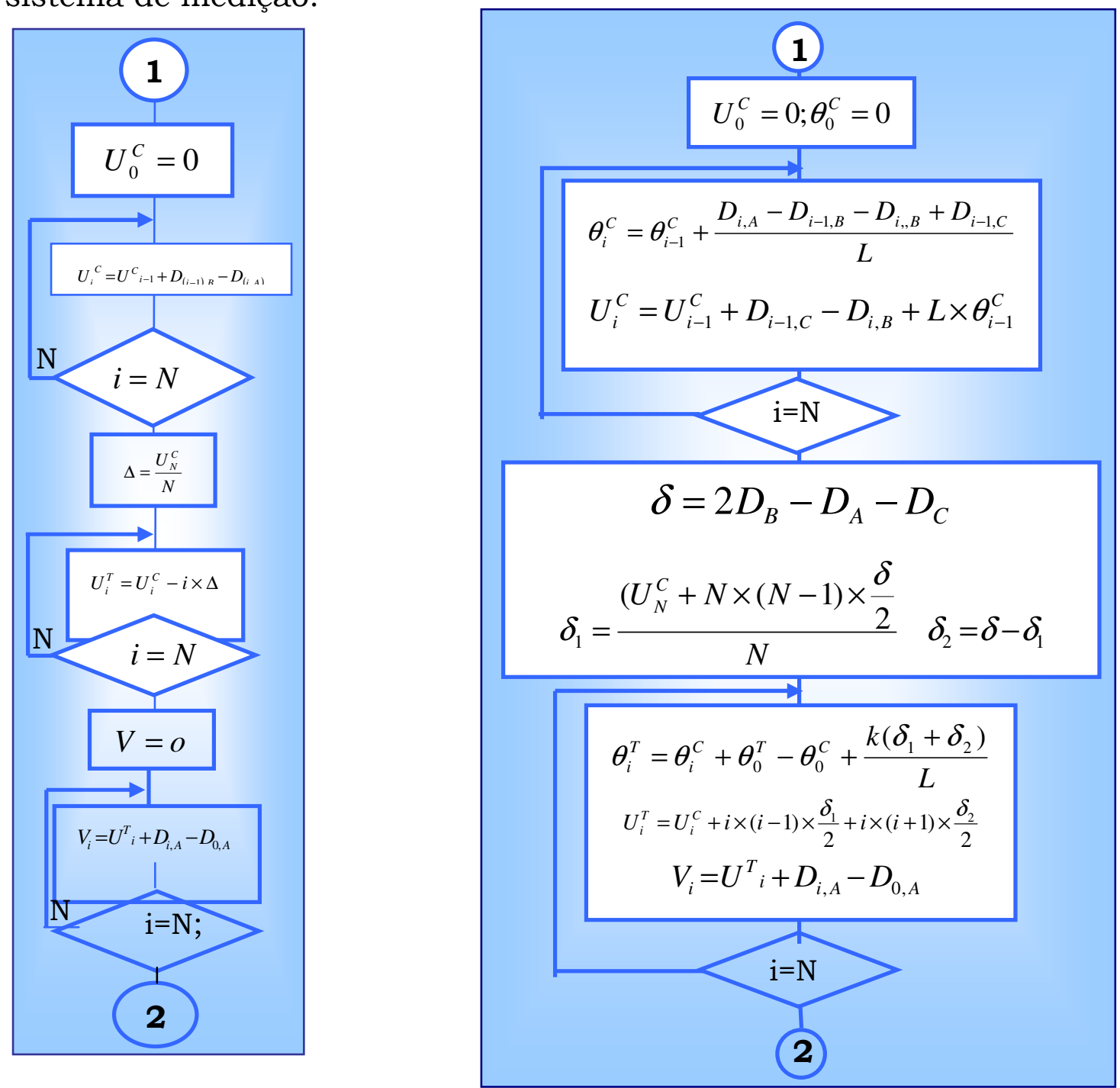

Figura 5.10: Fluxograma dos métodos de separação de erros com 2 e 3 sensores propostos por Tanaka \& Sato (1986)

Sendo, $U_{i}$ o desvio de retilineidade do sistema de medição, $V_{i}$ o desvio de retilineidade do mensurando, $\theta_{i}$ o desvio angular da garra de medição e $\delta$ o desalinhamento entre os sensores de medição. 
Como já descrito, os métodos que usam dois sensores permitem eliminar o erro de retilineidade da referência, enquanto os métodos que utilizam três sensores permitem eliminar os erros de retilineidade e angular da referência adotada. Observou-se, no entanto, que os métodos propostos por Tanaka \& Sato (1986) e GAO et al (2002) utilizando três sensores não apresentaram repetibilidade. Os resultados obtidos quando foram empregados apenas dois sensores representaram corretamente o desvio de retilineidade da régua. Esses resultados serão apresentados e discutidos no Capítulo 6.

Como a referência adotada para a medição foram as guias de uma MM3C, com pequeno desvio angular, decidiu-se aplicar os métodos de Tanaka e Sato (1986) e Gao et al (2002) com dois sensores para separar os erros da peça e os erros da máquina de medir.

Eliminados os desvios de retilineidade da guia da MM3C, cabe agora calcular o desvio de planicidade.

Para determinar o erro de planicidade de uma superficie é necessário gerar um plano de referência. Assim, pode-se determinar quanto fora deste plano estão os picos e os vales da superficie. Para o desenvolvimento do presente projeto o plano de referência foi definido pelo melhor plano que representa os pontos medidos e foi utilizado o Método dos Mínimos Quadrados (MMQ) para sua determinação. A seguir será apresentada uma breve discussão sobre o MMQ para o ajuste de um plano.

Considere $\mathrm{N}$ pontos espaciais não colineares, $\mathrm{N} \geq 3$, medidos sobre uma superficie teoricamente plana e a função matemática que descreve a relação entre as variáveis :

$$
z=\beta_{0}+\beta_{1} \cdot x+\beta_{2} \cdot y
$$

onde $Z$ é a variável medida.

Para determinar os estimadores de mínimos quadrados basta escolhe-los de maneira que a equação (5.2) seja mínima. Isto é, fazer com que as derivadas parciais da função dada em (5.2) com relação aos coeficientes $\beta_{\mathrm{i}}(\mathrm{i}=0, \ldots, 2)$ sejam nulas, (5.3)-(5.5). 


$$
\begin{aligned}
& M Q=\sum_{i=1}^{N}\left[z_{i}-\left(\beta_{0}+\beta_{1} \cdot x_{i}+\beta_{2} \cdot y_{i}\right)\right]^{2} \\
& \frac{\partial M Q}{\partial \beta_{0}}=2 \cdot\left[\beta_{0} \cdot N+\beta_{1} \cdot \sum_{i=1}^{N} x_{i}+\beta_{2} \cdot \sum_{i=1}^{N} y_{i}-\sum_{i=1}^{N} z_{i}\right]=0 \\
& \frac{\partial M Q}{\partial \beta_{1}}=2 \cdot\left[\beta_{0} \cdot \sum_{i=1}^{N} x_{i}+\beta_{1} \cdot \sum_{i=1}^{N} x_{i}^{2}+\beta_{2} \cdot \sum_{i=1}^{N} x_{i} \cdot y_{i}-\sum_{i=1}^{N} x_{i} \cdot z_{i}\right]=0 \\
& \frac{\partial M Q}{\partial \beta_{2}}=2 \cdot\left[\beta_{0} \cdot \sum_{i=1}^{N} y_{i}+\beta_{1} \cdot \sum_{i=1}^{N} x_{i} \cdot y_{i}+\beta_{2} \cdot \sum_{i=1}^{N} y_{i}^{2}-\sum_{i=1}^{N} y_{i} \cdot z_{i}\right]=0
\end{aligned}
$$

Os coeficientes do plano que melhor ajusta os $\mathrm{N}$ pontos são, então, a solução do sistema de equações normais, escrito na forma matricial em (5.6). Utilizou-se aqui o símbolo $\sum$ para representar o somatório para i variando de 1 até $\mathrm{N}$.

$$
\left[\begin{array}{ccc}
\mathrm{N} & \sum \mathrm{x}_{\mathrm{i}} & \sum \mathrm{y}_{\mathrm{i}} \\
\sum \mathrm{x}_{\mathrm{i}} & \sum \mathrm{x}_{\mathrm{i}}^{2} & \sum \mathrm{x}_{\mathrm{i}} \cdot \mathrm{y}_{\mathrm{i}} \\
\sum \mathrm{y}_{\mathrm{i}} & \sum \mathrm{x}_{\mathrm{i}} \cdot \mathrm{y}_{\mathrm{i}} & \sum \mathrm{y}_{\mathrm{i}}^{2}
\end{array}\right] \cdot\left[\begin{array}{c}
\beta_{0} \\
\beta_{1} \\
\beta_{2}
\end{array}\right]=\left[\begin{array}{c}
\sum \mathrm{z}_{\mathrm{i}} \\
\sum \mathrm{x}_{\mathrm{i}} \cdot \mathrm{z}_{\mathrm{i}} \\
\sum \mathrm{y}_{\mathrm{i}} \cdot \mathrm{z}_{\mathrm{i}}
\end{array}\right]
$$

As expressões dos coeficientes de mínimos quadrados estão em (5.7)-(5.8) e (5.9).

$$
\begin{aligned}
& \beta_{2}=\frac{\left.\left(\left(\sum x_{i}\right) \sum y_{i}-N \sum x_{i} y_{i}\right)\left(N \sum x_{i} z_{i}-\left(\sum x_{i}\right) \sum z_{i}\right)+\left(N \sum x_{i}^{2}-\left(\sum x_{i}\right)^{2}\right)\left(N \sum y_{i} z_{i}-\left(\sum y_{i}\right) \sum z_{i}\right)\right)}{\left(\left(N \sum x_{i}^{2}-\left(\sum x_{i}\right)^{2}\right)\left(N \sum y_{i}^{2}-\left(\sum y_{i}\right)^{2}\right)-\left(N \sum x_{i} y_{i}-\left(\sum x_{i}\right) \sum y_{i}\right)^{2}\right)} \\
& \beta_{1}=\frac{\left(\left(\sum x_{i} z_{i}\right)\left(\sum y_{i}\right)^{2}-\left(\sum y_{i} z_{i}\right)\left(\sum x_{i}\right) \sum y_{i}-N\left(\sum x_{i} z_{i}\right) \sum y_{i}^{2}+\left(\sum x_{i}\right)\left(\sum y_{i}^{2}\right) \sum z_{i}+\left(\sum x y\right)\left(N \sum y_{i} z_{i}-\left(\sum y_{i}\right) \sum z_{i}\right)\right)}{\left.\left(N\left(\sum x_{i} y_{i}\right)^{2}-2\left(\sum x_{i}\right)\left(\sum y_{i}\right) \sum x_{i} y_{i}+\left(\sum x_{i}\right)^{2} \sum y_{i}^{2}+\left(\sum x_{i}^{2}\right)\left(\sum y_{i}\right)^{2}-N \sum y_{i}^{2}\right)\right)} \\
& \beta_{0}=\frac{\left.\left(\left(\sum z_{i}\right)\left(\sum x_{i} y_{i}\right)^{2}-\left(\left(\sum y_{i} z_{i}\right) \sum x_{i}+\left(\sum x_{i} z_{i}\right) \sum y_{i}\right) \sum x_{i} y_{i}+\left(\sum y_{i} z_{i}\right)\left(\sum x^{2}\right) \sum y_{i}+\left(\sum y_{i}^{2}\right)\left(\sum x_{i} z_{i}\right) \sum x_{i}-\left(\sum x_{i}^{2}\right) \sum z_{i}\right)\right)}{\left.\left(N\left(\sum x_{i} y_{i}\right)^{2}-2\left(\sum x_{i}\right)\left(\sum y_{i}\right) \sum x_{i} y_{i}+\left(\sum x_{i}\right)^{2} \sum y_{i}^{2}+\left(\sum x_{i}^{2}\right)\left(\sum y_{i}\right)^{2}-N \sum y_{i}^{2}\right)\right)}
\end{aligned}
$$


Calculado o melhor plano que representa os pontos medidos devese determinar a distância de cada ponto até este plano. A equação para o cálculo da distância entre ponto e plano é dada por (5.10):

$$
\operatorname{dist}=\frac{z_{i}-\left(\beta_{0}+\beta_{1} \times X_{i}+\beta_{2} \times y_{i}\right)}{\sqrt{\beta_{2}^{2}+\beta_{1}^{2}+1}}
$$

O erro de planicidade será a distância entre os dois planos paralelos que contêm todos os pontos medidos. Sendo que um dos planos passa pelo ponto mais acima do plano de MMQ e o outro plano passa pelo ponto mais abaixo do plano de MMQ.

Erro $=\operatorname{Máx}($ dist $)-\operatorname{Mín}($ dist $)$

A Figura 5.11 apresenta o fluxograma para o cálculo do desvio de planicidade usando o MMQ.

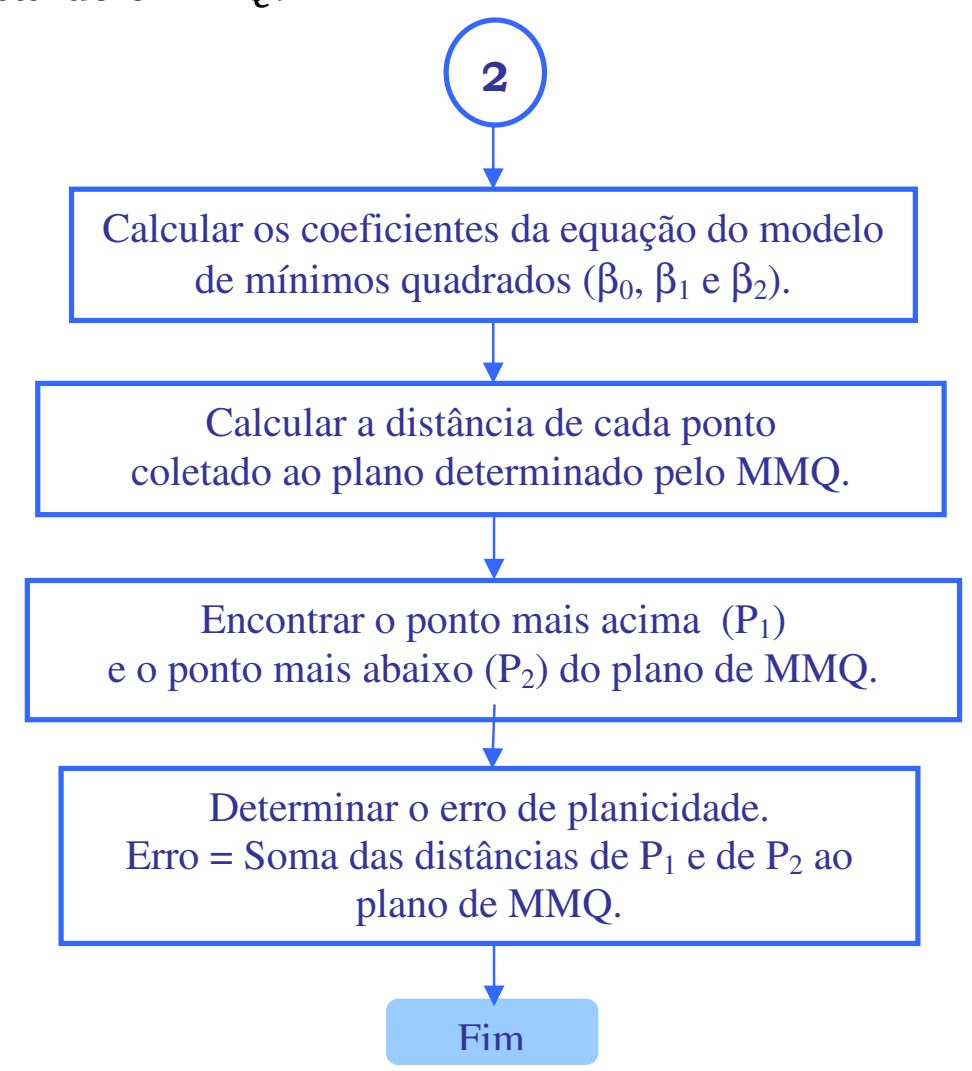

Figura 5.11: Cálculo do desvio de planicidade 


\subsection{Avaliação do Sistema De Múltiplas Sondas}

Para verificar a eficiência de um sistema de medição, é recomendado que o instrumento adotado como referência possua resolução 10 vezes menor que o analisado, ou pelo menos acuracidade e repetibilidade iguais ou melhores que o sistema a ser verificado. Como os transdutores utilizados possuem resolução de $0,10 \mu \mathrm{m}$, um instrumento com resolução de ordem 10 vezes menor é necessário. O interferômetro a laser foi adotado como padrão por possuir resolução de 0,03 $\mu \mathrm{m}$ (HEWLETT-PACKARD, 1988).

Um instrumento de medição é considerado competitivo se além de medições acuradas, garantir medições rápidas e de baixo custo. O custo de um sistema de medição está associado principalmente ao custo de compra do instrumento e ao tempo gasto para realizar cada medição. Decidiu-se também utilizar o nível eletrônico para medir o desvio de planicidade da superficie, e assim, comparar o custo inicial desses instrumentos, o tempo para realizar a medição e o resultado do desvio de planicidade.

Uma peça teste foi medida com os três sistemas de medição - nivel eletrônico, interferômetro a laser e sistema múltiplas sondas. Todas as medições foram realizadas com a mesma configuração de apoio da peça sobre o desempeno da máquina de medir. Tal procedimento foi adotado para evitar influências dos efeitos gravitacionais, que podem modificar a distribuição de erros na superficie medida. Os procedimentos para coleta de dados e para cálculo do desvio de planicidade também foram os mesmos: método de grades retangulares e Método dos Mínimos Quadrados.

O nível eletrônico foi conectado a um microcomputador através de um sistema de aquisição de dados. Este converte os sinais do instrumento em sinais digitais, enviando-os ao microcomputador. Algumas características da placa de aquisição de dados como resolução e faixa de operação são importantes para total aproveitamento do 
sistema. A resolução de uma placa de aquisição de dados depende do número de bits que o conversor analógico-digital usa para representar o valor do sinal. Quanto menor for a resolução, maior será a quantidade de divisões que terá a escala da grandeza que está sendo medida e, portanto, menor será a variação dessa grandeza que o sistema poderá detectar.

A placa de aquisição de dados, utilizada na medição com o nível eletrônico, possui resolução de 12 bits e faixa de operação de $-5 \mathrm{~V}$ a $+5 \mathrm{~V}$. Os sinais elétricos do nível, que são da ordem de $-50 \mathrm{mV}$ a $+50 \mathrm{mV}$, foram amplificados em 100 vezes e enviados para a placa A/D especificada anteriormente. Desta forma os sinais de entrada estão na faixa de operação da placa de aquisição. Foi determinada a curva de calibração das leituras do nível eletrônico e dos números digitais da placa A/D. Um programa computacional foi desenvolvido em Borland Delphi para ler os números digitais da placa de aquisição, convertê-los em deslocamentos e calcular o desvio de planicidade da superficie. A Figura 5.12 mostra o esquema do sistema montado.

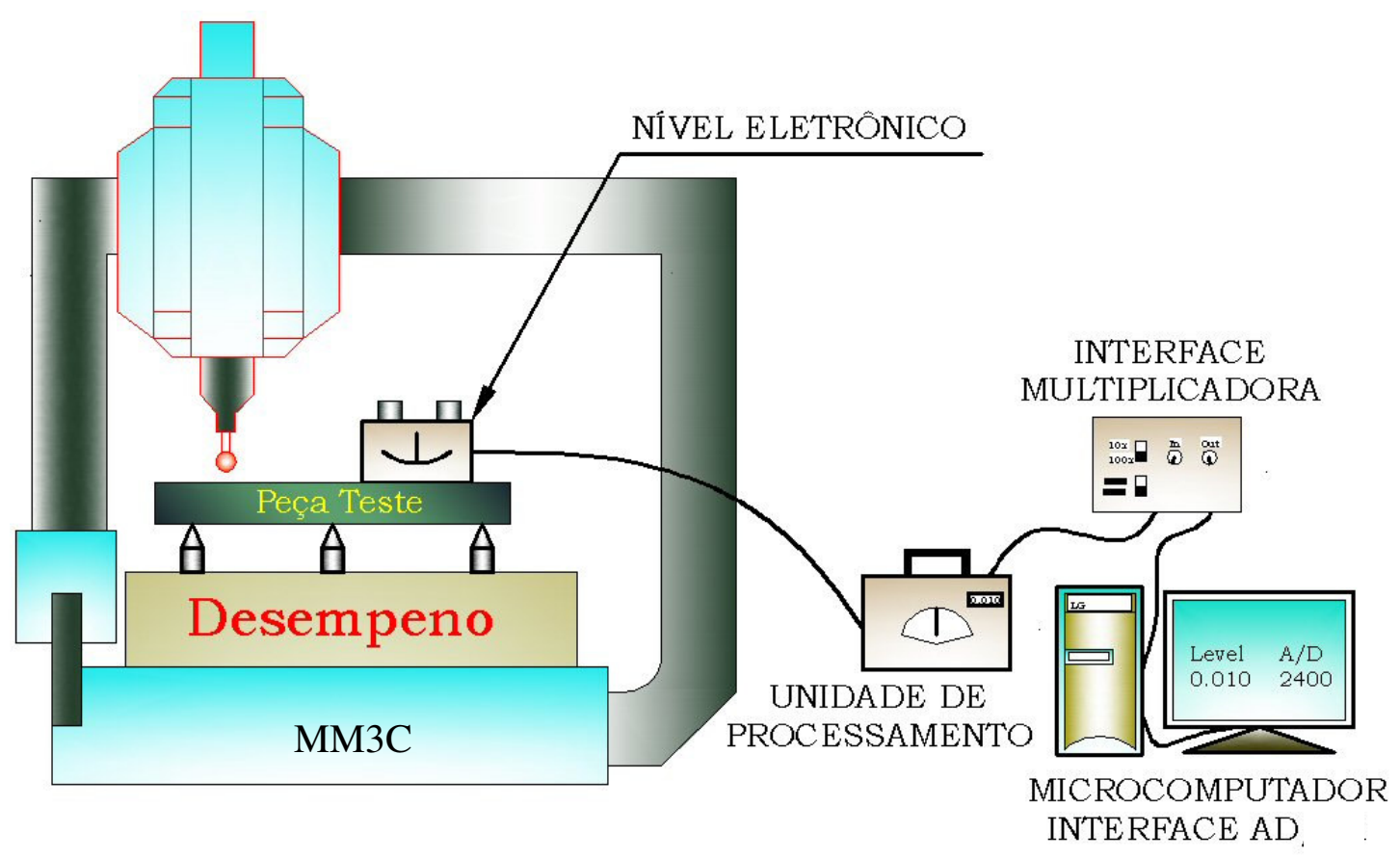

Figura 5.12: Medição da peça teste com nível eletrônico 
$\mathrm{Na}$ medição com o interferômetro a laser, um conjunto de ópticas para medição de deslocamento angular foi utilizado. Na Figura 5.13 pode-se visualizar a foto da montagem.

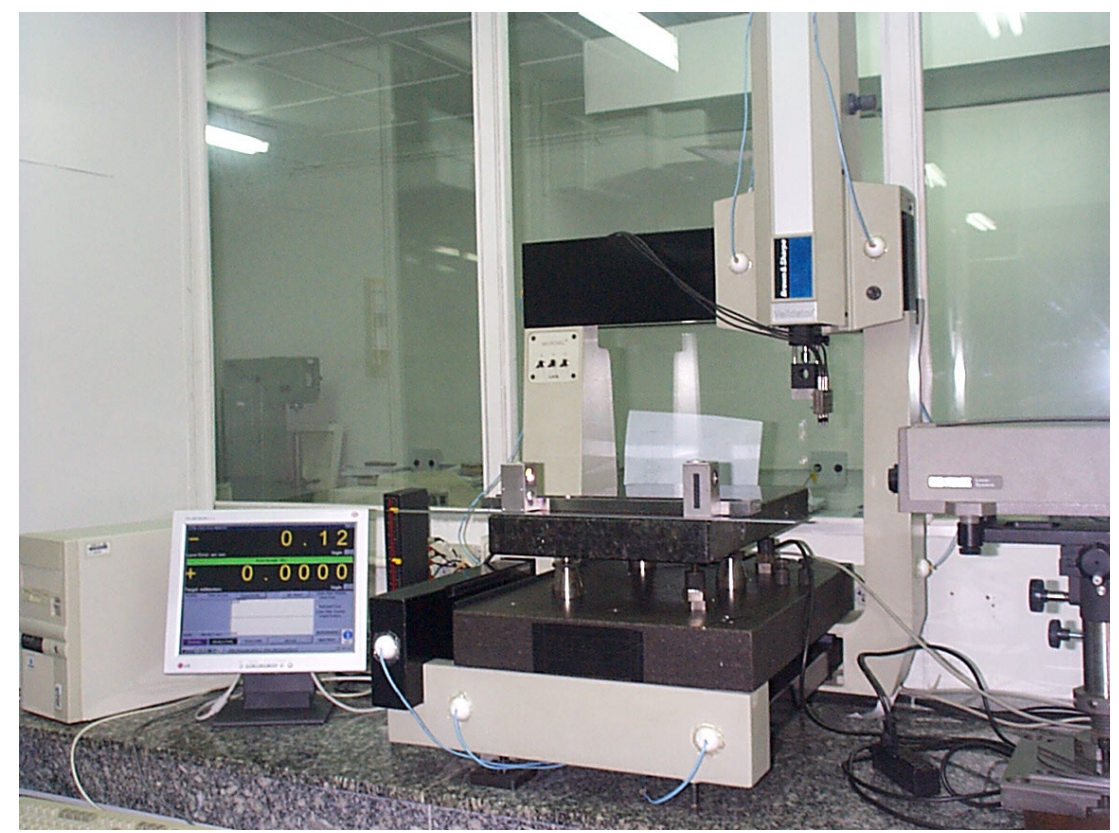

Figura 5.13 : Foto da medição da peça teste com interferômetro a laser

\subsection{CálCulo da incerteza de medição}

Para calcular a incerteza de medição é necessário definir as variáveis que influenciam o resultado da medição. As principais variáveis que influenciam no processo de medição de planicidade utlizando o sistema proposto são a resolução das escalas ópticas da MM3C, a resolução dos transdutores e as incertezas associadas ao cálculo dos coeficiêntes de mínimos quadrados e as associadas às equações de separação de erros.

Para cálculo da incerteza de medição do desvio de planicidade, primeiramente foi calculada a incerteza quanto ao cálculo do desvio de retilineidade utilizando as equações de separação de erros propostas por Tanaka e Sato (1986). Em seguida, foram calculadas as incertezas 
relacionadas ao cálculo dos coeficientes de MMQ e finalmente a incerteza relativa ao erro de planicidade foi determinada.

As equações para cálculo da incerteza de medição foram determinadas seguindo as recomendações do documento ISO GUM e são descritas a seguir.

Sabemos que o erro de planicidade é calculado por:

$$
\text { Erro }=\operatorname{Máx}(\text { dist })-\operatorname{Mín}(\text { dist }) \text {; }
$$

Sendo,

$$
\text { dist }=\frac{z_{i}-\left(\beta_{0}+\beta_{1} \times X_{i}+\beta_{2} \times y_{i}\right)}{\sqrt{\beta_{2}^{2}+\beta_{1}^{2}+1}}
$$

Aplicando a lei de propagação de incertezas, descrita no Capítulo 3, na equação 5.12 tem-se a equação 5.13 que é a expressão utilizada para estimativa da incerteza do valor de 'dist'. Os termos de segunda ordem, que aparecem na equação 3.75, foram desprezados por representarem parcelas muito pequenas da incerteza e para facilitar os cálculos.

$$
\begin{aligned}
& u^{2}(\text { dist })=\left(\frac{\partial d i s t}{\partial z}\right)^{2} * u^{2}(z)+\left(\frac{\partial d i s t}{\partial \beta_{0}}\right)^{2} * u^{2}\left(\beta_{0}\right)+\left(\frac{\partial d i s t}{\partial \beta_{1}}\right)^{2} * u^{2}\left(\beta_{1}\right)+\left(\frac{\partial d i s t}{\partial x}\right)^{2} * u^{2}(x)+ \\
& +\left(\frac{\partial d i s t}{\partial \beta_{2}}\right)^{2} * u^{2}\left(\beta_{2}\right)++\left(\frac{\partial d i s t}{\partial y}\right)^{2} * u^{2}(y)
\end{aligned}
$$

\subsubsection{INCERTEZA NO CÁLCULO DAS ALTURAS U²( $(z)$}

A variável $\mathrm{z}$ representa a altura de cada ponto com relação ao sistema de referência adotado, como já foi descrito. Adotaremos a variável $\mathrm{V}$ para representar o desvio de retilineidade de cada ponto com relação ao primeiro ponto da linha medida.

Como já mencionado, as equações para cálculo do desvio de retilineidade proposta por Tanaka e Sato (1986) são:

$$
V_{i}=U^{T}{ }_{i}+D_{i, A}-D_{0, A}
$$




$$
\begin{aligned}
& U_{i}^{C}=U^{C}{ }_{i-1}+D_{(i-1), B}-D_{(i, A)} \\
& U_{i}^{T}=U_{i}^{C}-i \times \Delta \\
& \Delta=\frac{U_{N}^{C}}{N} \\
& U_{0}^{C}=0
\end{aligned}
$$

A incerteza padrão combinada $u_{c}^{2}\left(V_{i}\right)$, como o próprio nome sugere, é a soma da incerteza de cada uma das variáveis que influenciam ou modificam o valor de $\mathrm{V}_{\mathrm{i}}$. Aplicando a lei de propagação das incertezas de medição na equação 5.14 tem-se a equação 5.19 que é a expressão utilizada para estimativa da incerteza do valor de $V_{\mathrm{i}}$.

$$
u_{c}\left(V_{i}\right)=\sqrt{\left(\frac{\partial V_{i}}{\partial U^{T}{ }_{i}}\right)^{2} * u^{2}\left(U^{T}{ }_{i}\right)+\left(\frac{\partial V_{i}}{\partial D_{i, A}}\right)^{2} * u^{2}\left(D_{i, A}\right)+\left(\frac{\partial V_{i}}{\partial D_{0, A}}\right)^{2} * u^{2}\left(D_{0, A}\right)}
$$

Utilizando a equação 5.15 determina-se $u\left(U^{T}{ }_{i}\right)$ :

$$
u_{c}\left(U^{T}{ }_{i}\right)=\sqrt{\left(\frac{\partial U^{T}{ }_{i}}{\partial U_{i}^{c}}\right)^{2} * u^{2}\left(U_{i}^{c}\right)+\left(\frac{\partial U^{T}{ }_{i}}{\partial(\Delta)}\right)^{2} * u^{2}(\Delta)}
$$

Da mesma forma, a incerteza de, $u\left(\begin{array}{l}U_{i}^{c} \\ )\end{array}\right)$, é dada por:

$$
u_{c}\left(U_{i}^{c}\right)=\sqrt{\left(\frac{\partial U^{c} i}{\partial U_{i-1}^{c}}\right)^{2} * u^{2}\left(U_{i-1}^{c}\right)+\left(\frac{\partial U^{c}{ }_{i}}{\partial\left(D_{i-1, B}\right)}\right)^{2} * u^{2}\left(D_{i-1, B}\right)+\left(\frac{\partial U^{c} i}{\partial\left(D_{i, A}\right)}\right)^{2} * u^{2}\left(D_{i, A}\right)}
$$

As incertezas relativas às leituras dos transdutores serão relacionadas à resolução dos apalpadores utilizados. Como os apalpadores utilizados possuem mesma resolução, seus valores de incerteza serão iguais.

$$
u\left(D_{i-1, B}\right)=u\left(D_{i, A}\right)=\frac{u\left(\operatorname{Re} s_{L V D T}\right)}{\sqrt{6}}
$$

Dessa forma, a equação para cálculo de $u_{c}^{2}\left(U_{i}^{c}\right)$ pode ser escrita como indica a expressão (5.23).

$$
u_{c}^{2}\left(U_{i}^{c}\right)=2 * i * \frac{u^{2}\left(\operatorname{Re} s_{L V D T}\right)}{6}
$$


E a incerteza, $u(\Delta)$, é dada por:

$$
u(\Delta)=\sqrt{\left(\frac{\partial(\Delta)}{\partial\left(U_{N}^{C}\right)}\right)^{2} * u^{2}\left(U_{N}^{C}\right)=\left(\frac{1}{N}\right)^{2} *\left(2 * N * \frac{u^{2}\left(\operatorname{Re} s_{L V D T}\right)}{6}\right)}
$$

As derivada parciais que aparecem nas equações (5.19)-(5.22) e (5.24) são apresentadas a seguir.

$$
\begin{array}{lllll}
\frac{\partial V_{i}}{\partial U_{i}{ }^{T}}=1 & \frac{\partial V_{i}}{\partial D_{0, A}}=1 & \frac{\partial U^{T}{ }_{i}}{\partial \Delta}=i & \frac{\partial U^{C}{ }_{i}}{\partial D_{i-1, B}}=1 & \frac{\partial \Delta}{\partial U_{N}^{C}}=\frac{1}{N} \\
\frac{\partial V_{i}}{\partial D_{i, A}}=1 & \frac{\partial U^{T}{ }_{i}}{\partial U^{C_{i}}}=1 & \frac{\partial U^{C_{i}}}{\partial U^{C_{i-1}}}=1 & \frac{\partial U^{C_{i}}}{\partial D_{i, A}}=-1 &
\end{array}
$$

Assim, a equação 5.33 pode ser utilizada para determinar a incerteza relativa ao cálculo de $u_{c}\left(V_{i}\right)=u_{c}\left(Z_{i}\right)$.

$$
u_{c}\left(Z_{i}\right)=u_{c}\left(V_{i}\right)=\sqrt{2 * i * \frac{u^{2}\left(\operatorname{Re} s_{L V D T}\right)}{6}+(i)^{2} *\left(\left(\frac{1}{N}\right)^{2} *\left(2 * N * \frac{u^{2}\left(\operatorname{Re} s_{L V D T}\right)}{6}\right)\right)+}+
$$

\subsubsection{CÁlCUlo DE U $\mathrm{U}^{2}\left(\beta_{0}\right), \mathrm{U}^{2}\left(\beta_{1}\right)$ E U $\mathrm{U}^{2}\left(\beta_{2}\right)$}

Os coeficientes da equação do plano, determinados através do Método dos Mínimos Quadrados, dependem dos valores $\left(x_{i}, y_{i}, z_{i}\right)$ dos pontos medidos e são determinados através das equações (5.7), (5.8) e (5.9). As expressões (5.34), (5.35) e (5.36) podem ser utilizadas para cálculo da incerteza relativa aos valores de $\beta_{0}, \beta_{1}$ e $\beta_{2}$.

$$
u\left(\beta_{0}\right)=\sqrt{\left(\frac{\partial \beta_{0}}{\partial y}\right)^{2} * u^{2}(y)+\left(\frac{\partial \beta_{0}}{\partial x}\right)^{2} * u^{2}(x)+\left(\frac{\partial \beta_{0}}{\partial z}\right)^{2} * u^{2}(z)}
$$




$$
\begin{aligned}
& u\left(\beta_{1}\right)=\sqrt{\left(\frac{\partial \beta_{1}}{\partial y}\right)^{2} * u^{2}(y)+\left(\frac{\partial \beta_{1}}{\partial x}\right)^{2} * u^{2}(x)+\left(\frac{\partial \beta_{1}}{\partial z}\right)^{2} * u^{2}(z)} \\
& u\left(\beta_{2}\right)=\sqrt{\left(\frac{\partial \beta_{2}}{\partial y}\right)^{2} * u^{2}(y)+\left(\frac{\partial \beta_{2}}{\partial x}\right)^{2} * u^{2}(x)+\left(\frac{\partial \beta_{2}}{\partial z}\right)^{2} * u^{2}(z)}
\end{aligned}
$$

As derivadas parciais que aparecem nas equações (5.34), (5.35) e (5.36) são apresentadas podem ser determinadas através das equações (5.37)-(5.45).

$$
\begin{aligned}
& \frac{\partial \beta_{0}}{\partial X}=\left(( \sum Y _ { i } Z _ { i } ) \left(\sum \frac{\partial X_{i}^{2}}{\partial X} \sum Y_{i}-\left(\sum \frac{\partial\left(X_{i} Y_{i}\right)}{\partial X}\right)\left(\left(\sum Y_{i} Z_{i}\right) \sum X_{i}+\left(\sum X_{i} Z_{i}\right) \sum Y_{i}\right)-\left(\sum Y_{i} X_{i}\right)\right.\right. \\
& \left.\left(\left(\sum Y_{i} Z_{i}\right) \sum \frac{\partial X_{i}}{\partial X}\right)+\left(\sum \frac{\partial\left(X_{i} Z_{i}\right)}{\partial X}\right) \sum Y_{i}\right)+2\left(\sum X_{i} Y_{i}\right)\left(\sum \frac{\partial\left(X_{i} Y_{i}\right)}{\partial X} \sum Z_{i}+\left(\sum Y_{i}^{2}\right)\left(\left(\sum X_{i} Z_{i}\right)\right.\right. \\
& \left.\left.+\left(\sum \frac{\partial\left(X_{i} Z_{i}\right)}{\partial X}\right) \sum X_{i}-\left(\sum \frac{\partial X_{i}^{2}}{\partial X}\right) \sum Z_{i}\right)\right) /\left(N\left(\sum X_{i} Y_{i}\right)^{2}-2\left(\sum X_{i}\right)\left(\sum Y_{i}\right) \sum X_{i} Y_{i}+\left(\sum X_{i}\right)^{2}\right. \\
& \left.\sum y_{i}+\left(\sum X_{i}^{2}\right)\left(\left(\sum Y_{i}\right)^{2}-N \sum Y_{i}^{2}\right)\right)-\left(\left(2 N\left(\sum X_{i} Y_{i}\right) \sum \frac{\partial\left(X_{i} Y_{i}\right)}{\partial X}--2\left(\sum X_{i}\right)\left(\sum Y_{i}\right) \sum \frac{\partial\left(X_{i} Y_{i}\right)}{\partial X_{i}}-\right.\right. \\
& \left.2\left(\sum Y_{i} X_{i}\right) \sum Y_{i}+2\left(\sum X_{i}\right) \sum Y_{i}^{2}+\left(\sum \frac{\partial X_{i}^{2}}{\partial X}\right)\left(\left(\sum Y_{i}\right)^{2}-N \sum Y_{i}^{2}\right)\right)\left(\left(\sum Z_{i}\right)\left(\sum Y_{i} X_{i}\right)^{2}-\right. \\
& \left(\left(\sum Y_{i} Z_{i}\right) \sum X_{i}+\left(\sum X_{i} Z_{i}\right) \sum Y_{i}\right) \sum X_{i} Y_{i}+\left(\sum Z_{i} Y_{i}\right)\left(\sum X_{i}^{2}\right) \sum Y_{i}+\left(\sum Y_{i}^{2}\right)\left(\left(\sum X_{i} Z_{i}\right)\right. \\
& \left.\left.\left.\sum X_{i}-\left(\sum X_{i}^{2}\right) \sum Z_{i}\right)\right)\right) /\left(N\left(\sum X_{i} Y_{i}\right)^{2}-2\left(\sum X_{i}\right)\left(\sum Y_{i}\right) \sum Y_{i} X_{i}+\left(\sum X_{i}\right)^{2} \sum Y_{i}^{2}+\right. \\
& \left.\left(\sum X_{i}^{2}\right)\left(\left(\sum Y_{i}\right)^{2}-N \sum Y_{i}^{2}\right)\right)^{2}
\end{aligned}
$$

$\left.\frac{\partial \beta_{0}}{\partial Y}=\left(-\sum X_{i} Y_{i}\left(\sum X_{i} Z_{i}\right)+\left(\sum Z_{i}\right) \sum X_{i}\right)+\left(\sum Z_{i} Y_{i}\right) \sum X_{i}^{2}+\left(\sum Z_{i}\right)\left(\sum X_{i}^{2}\right) \sum Y_{i}-\left(\sum X_{i}\right)\left(\sum Z_{i} Y_{i}\right) \sum X_{i}+\left(\sum X_{i} Z_{i}\right) \sum Y_{i}\right)$ $\left.\left.+2\left(\sum X_{i} Y_{i}\right)\left(\sum X_{i}\right)+\sum Z_{i}+\left(\sum 2 Y_{i}\right)\left(\sum Z_{i} X_{i}\right) \sum X_{i}-\left(\sum X_{i}^{2}\right) \sum Z_{i}\right)\right) /\left(N\left(\sum X_{i} Y_{i}\right)^{2}-2\left(\sum X_{i}\right)\left(\sum Y_{i}\right) \sum X_{i} Y_{i}+\left(\sum X_{i}\right)^{2} \sum Y_{i}^{2}\right.$ $\left.\left.+\left(\sum X_{i}^{2}\right)\left(\sum Y_{i}\right)^{2}-N \sum Y_{i}^{2}\right)\right)-\left(\left(\sum 2 Y_{i}\right)\left(\sum X_{i}\right)^{2}-2\left(\sum X_{i} Y_{i}\right) \sum X_{i}-2\left(\sum X_{i}\right)\left(\sum Y_{i}\right) \sum X_{i}+2 N\left(\sum X_{i} Y_{i}\right) \sum X_{i}+\left(\sum X_{i}^{2}\right)\right.$ $\left(2\left(\sum Y_{i}-N \sum 2 Y_{i}\right)\right)\left(\sum Z_{i}\right)\left(\sum X_{i} Y_{i}\right)^{2}-\left(\left(\sum Z_{i} Y_{i}\right) \sum X_{i}+\left(\sum X_{i} Z_{i}\right) \sum Y_{i} \sum X_{i} Y_{i}+\left(\sum Z_{i} Y_{i}\right)\left(\sum X_{i}^{2}\right) \sum Y_{i}+\left(\sum Y_{i}^{2}\right)\left(\sum X_{i} Z_{i}\right)\right.$ $\left.\left.\left.\sum X_{i}-\left(\sum X_{i}^{2}\right) \sum Z_{i}\right)\right) y\left(N\left(\sum X_{i} Y_{i}\right)^{2}-2\left(\sum X_{i}\right)\left(\sum Y_{i}\right) \sum Y_{i} X_{i}+\left(\sum X_{i}\right)^{2} \sum Y_{i}^{2}+\left(\sum X_{i}^{2}\right)\left(\sum Y_{i}\right)^{2}-N \sum Y_{i}^{2}\right)\right)^{2}$

$$
\begin{aligned}
& \frac{\partial \beta_{0}}{\partial Z}=\left(\left(\sum X_{i} Y_{i}\right)^{2}-\left(\left(\sum Y_{i}\right) \sum X_{i}+\left(\sum X_{i}\right) \sum Y_{i}\right)\left(\sum X_{i} Y_{i}\right)+\left(\sum Y_{i}\right)\left(\sum X_{i}^{2}\right) \sum Y_{i}+\left(\left(\sum X_{i}\right) \sum X_{i}-\sum X_{i}^{2}\right) \sum Y_{i}^{2}\right) / \\
& \left(N\left(\sum X_{i} Y_{i}\right)^{2}-2\left(\sum X_{i}\right)\left(\sum Y_{i}\right) \sum X_{i} Y_{i}+\left(\sum X_{i}\right)^{2} \sum Y_{i}^{2}+\left(\sum X_{i}^{2}\right)\left(\sum Y_{i}\right)^{2}-N\left(\sum Y_{i}^{2}\right)\right)
\end{aligned}
$$


$\left.\left.\left.\left.\frac{\partial \beta_{1}}{\partial X}=\left(\sum Z_{i}\right) \sum Y_{i}\right)^{2}-\left(\sum Z_{i} Y_{i}\right) \sum Y_{i}\right)-N\left(\sum Z_{i}\right) \sum Y_{i}^{2}+\left(\sum Y_{i}^{2}\right) \sum Z_{i}\right)+\left(\sum Y_{i}\right)\left(N \sum Y_{i} Z_{i}-\left(\sum Y_{i}\right) \sum Z_{i}\right)\right) /$ $\left.\left.\left(N\left(\sum X_{i} Y_{i}\right)^{2}-2\left(\sum X_{i}\right) \sum Y_{i}\right) \sum X_{i} Y_{i}+\left(\sum X_{i}\right)^{2} \sum Y_{i}^{2}+\left(\sum X_{i}^{2}\right)\left(\sum Y_{i}\right)^{2}-N \sum Y_{i}^{2}\right)\right)-\left(\left(2 N\left(\sum X_{i} Y_{i}\right) \sum Y_{i}\right)-\right.$ $\left.\left.\left.\left.2\left(\sum X_{i}\right) \sum Y_{i}\right) \sum Y_{i}-2\left(\sum X_{i} Y_{i}\right) \sum Y_{i}+2\left(\sum X_{i}\right) \sum Y_{i}^{2}+\left(\sum 2 X_{i}\right)\left(\sum Y_{i}\right)^{2}-N \sum Y_{i}^{2}\right)\right)\left(\sum X_{i} Z_{i}\right) \sum Y_{i}\right)^{2}-$ $\left.\left.\left(\sum Y_{i} Z_{i}\right) \sum X_{i} \sum Y_{i}-N\left(\sum X_{i} Z_{i}\right) \sum Y_{i}^{2}+\left(\sum X_{i}\right) \sum Y_{i}^{2}\right) \sum Z_{i}+\left(\sum X_{i} Y_{i}\right)\left(N \sum Y_{i} Z_{i}-\left(\sum Y_{i}\right) \sum X_{i}\right)\right) y$ $\left.\left(N\left(\sum X_{i} Y_{i}\right)^{2}-2\left(\sum X_{i}\right)\left(\sum Y_{i}\right) \sum Y_{i} X_{i}+\left(\sum X_{i}\right)^{2} \sum Y_{i}^{2}+\left(\sum X_{i}^{2}\right)\left(\sum Y_{i}\right)^{2}-N \sum Y_{i}^{2}\right)\right)^{2}$

$\left.\frac{\partial \beta_{1}}{\partial Y}=\left(-N\left(\sum Z_{i} X_{i}\right) \sum 2 Y_{i}+\left(\sum X_{i}\right) \sum Z_{i}\right) \sum X_{i}-\left(\sum Z_{i} Y_{i}\right) \sum X_{i}+2\left(\sum Z_{i} X_{i}\right) \sum Y_{i}-\left(\sum Z_{i}\right) \sum X_{i}\right) \sum Y_{i}+$ $\left.\left(\sum X_{i} Y_{i}\right)\left(N \sum Z_{i}-\sum Z_{i}\right)+\left(\sum X_{i}\right)\left(N \sum Z_{i} Y_{i}-\left(\sum Y_{i}\right) \sum Z_{i}\right)\right)\left(\left(N\left(\sum X_{i} Y_{i}\right)^{2}-2 \sum \sum X_{i}\right) \sum Y_{i}\right) \sum X_{i} Y_{i}+\left(\sum X_{i}\right)^{2} \sum Y_{i}^{2}$ $\left.\left.\left.+\left(\sum X_{i}^{2}\right)\left(\sum Y_{i}\right)^{2}-N \sum Y_{i}^{2}\right)\right)-\left(\left(\sum 2 Y_{i}\right) \sum X_{i}\right)^{2}-2\left(\sum Y_{i} X_{i}\right) \sum X_{i}-2\left(\sum Y_{i}\right) \sum Y_{i}\right) \sum X_{i}+2 N\left(\sum X_{i} Y_{i}\right) \sum X_{i}+$ $\left.\left.\left.\left(\sum X_{i}^{2}\right)\left(\sum Y_{i}-N \sum 2 Y_{i}\right)\left(\sum X_{i} Z_{i}\right) \sum Y_{i}\right)^{2}-\left(\sum Z_{i} Y_{i}\right) \sum X_{i}\right) \sum Y_{i}-N\left(\sum X_{i} Z_{i}\right) \sum Y_{i}^{2}+\left(\sum X_{i}\right) \sum Y_{i}^{2}\right) \sum Z_{i}$ $+\left(\sum Y_{i} X_{i}\right)\left(N \sum Z_{i} Z_{i}-\left(\sum Y_{i} \sum Z_{i}\right)\right)\left(\left(N\left(\sum X_{i} Y_{i}\right)^{2}-2\left(\sum X_{i}\right) \sum Y_{i}\right) \sum Y_{i}+\left(\sum X_{i}\right)^{2} \sum Y_{i}^{2}+\left(\sum X_{i}^{2}\right)\left(\sum Y_{i}\right)^{2}-N \sum Y_{i}^{2}\right)^{2}$

$$
\begin{aligned}
& \left.\left.\frac{\partial \beta_{1}}{\partial Z}=\left(\sum X_{i}\right) \sum Y_{i}\right)^{2}-\left(\sum Y_{i}\right) \sum X_{i}\right) \sum Y_{i}+\left(\sum X_{i} Y_{i}\left(N \sum Y_{i}-\sum Y_{i}\right)-N\left(\sum X_{i}\right) \sum Y_{i}^{2}+\left(\sum X_{i}\right) \sum Y_{i}^{2}\right) / \\
& \left.\left.\left(N\left(\sum X_{i} Y_{i}\right)^{2}-2\left(\sum X_{i}\right) \sum Y_{i}\right) \sum Y_{i} X_{i}+\left(\sum X_{i}\right)^{2} \sum Y_{i}^{2}+\left(\sum X_{i}^{2}\right)\left(\sum Y_{i}\right)^{2}-N \sum Y_{i}^{2}\right)\right)
\end{aligned}
$$

$\frac{\partial \beta_{2}}{\partial X}=\left(\left(\sum X_{i}\right) \sum Y_{i}-N \sum X_{i} Y_{i}\right)\left(N \sum Z_{i}-\sum Z_{i}\right)+\left(\sum Y_{i}-N \sum Y_{i}\right)\left(N \sum X_{i} Z_{i}-\sum X_{i} \sum Z_{i}\right)+\left(N \sum 2 X_{i}-2 \sum X_{i}\right)$ $\left.\left(N \sum X_{i}-\left(\sum Y_{i}\right) \sum Z_{i}\right)\right)\left(\left(N \sum X_{i}^{2}-\left(\sum X_{i}\right)^{2}\right)\left(N \sum Y_{i}^{2}-\left(\sum Y_{i}\right)^{2}\right)-\left(N \sum Y_{i} X_{i}-\left(\sum X_{i}\right) \sum Y_{i}\right)^{2}\right)-\left(\left(N \sum 2 X_{i}-2 \sum X_{i}\right)\right.$ $\left.\left(N \sum Y_{i}^{2}-\left(\sum Y_{i}\right)^{2}\right)-2\left(N \sum Y_{i}-\sum Y_{i}\right)\left(N \sum Y_{i} X_{i}-\left(\sum X_{i}\right) \sum Y_{i}\right)\right)\left(\left(\sum X_{i}\right) \sum Y_{i}-N \sum Y_{i} X_{i}\right)\left(N \sum Z_{i} X_{i}-\left(\sum X_{i}\right) \sum Z_{i}\right)+$ $\left.\left(N \sum X_{i}^{2}-\left(\sum X_{i}\right)^{2}\right)\left(N \sum Z_{i} Z_{i}-\left(\sum Y_{i}\right) \sum Z_{i}\right)\right)\left(\left(N \sum X_{i}^{2}-\left(\sum X_{i}\right)^{2}\right)\left(N \sum Y_{i}^{2}-\left(\sum Y_{i}^{2}\right)^{2}\right)-\left(N \sum Y_{i} X_{i}-\left(\sum X_{i}\right) \sum Y_{i}\right)^{2}\right)^{2}$

$\left.\frac{\partial \beta_{2}}{\partial Y}=\left(\left(N \sum X_{i}^{2}\left(\sum X_{i}\right)^{2}\right)\left(N \sum Z_{i}-\sum Z_{i}\right)+\left(\sum X_{i}-N \sum X_{i}\right)\left(N \sum Z_{i} X_{i}\right)-\left(\sum X_{i}\right) \sum Z_{i}\right)\right)$

$\left(\left(N \sum X_{i}^{2}-\left(\sum X_{i}\right)^{2}\right)\left(N \sum Y_{i}^{2}-\left(\sum Y_{i}\right)^{2}\right)-\left(N \sum Y_{i} X_{i}-\left(\sum X_{i}\right) \sum Y_{i}\right)^{2}\right)-\left(\left(\left(N \sum X_{i}^{2}-\left(\sum X_{i}\right)^{2}\right)\left(N \sum 2 Y_{i}-2 \sum Y_{i}\right)\right.\right.$ $\left.\left.-2\left(N \sum X_{i}-\sum X_{i}\right)\left(N \sum Y_{i} X_{i}-\left(\sum X_{i}\right) \sum Y_{i}\right)\right)\left(\sum X_{i}\right) \sum Y_{i}-N \sum Y_{i} X_{i}\right)\left(N \sum Z_{i} X_{i}-\left(\sum X_{i}\right) \sum Z_{i}\right)+$ $\left.\left.\left(N \sum X_{i}^{2}-\left(\sum X_{i}\right)^{2}\right)\left(N \sum Y_{i} Z_{i}-\left(\sum Y_{i}\right) \sum Z_{i}\right)\right)\right)\left(\left(N \sum X_{i}^{2}-\left(\sum X_{i}\right)^{2}\right)\left(N \sum Y_{i}^{2}-\left(\sum Y_{i}\right)^{2}\right)-\left(N \sum Y_{i} X_{i}-\left(\sum X_{i}\right) \sum Y_{i}^{2}\right)^{2}\right.$ 


$$
\begin{aligned}
& \left.\left.\frac{\partial \beta_{2}}{\partial Z}=\left(\left(N \sum X_{i}-\sum X_{i}\right)\left(\sum X_{i}\right) \sum Y_{i}\right)-N \sum Y_{i} X_{i}\right)+\left(N \sum X_{i}^{2}-\left(\sum X_{i}\right)^{2}\right)\left(N \sum Y_{i}-\sum Y_{i}\right)\right) \\
& \left(\left(N \sum X_{i}^{2}-\left(\sum X_{i}\right)^{2}\right)\left(N \sum Y_{i}^{2}-\left(\sum Y_{i}\right)^{2}\right)-\left(N \sum Y_{i} X_{i}-\left(\sum X_{i}\right) \sum Y_{i}\right)^{2}\right)
\end{aligned}
$$

Os valores de $u(y)$ e $u(x)$ são relativos à incerteza das leituras da régua óptica da MM3C e podem ser determinados através da equação (5.46).

$$
u(y)=u(x)=\sqrt{\frac{u^{2}\left(\operatorname{Re} s_{M M 3 C}\right)}{3}}
$$

Na equação (5.46), $u\left(\operatorname{Re} s_{M M 3 C}\right)$ é a resolução da MM3C.

As derivadas parciais da equação (5.13) podem ser calculadas a partir das equações (5.47) - (5.52).

$$
\begin{aligned}
& \frac{\partial d i s t}{\partial z}=1 \\
& \frac{\partial d i s t}{\partial \beta_{1}}=-\frac{\beta_{1}\left(z-\beta_{0}-x \beta_{1}-y \beta_{2}\right)}{\left(1+\beta_{1}^{2}+\beta_{2}^{2}\right)^{3 / 2}}-\frac{x}{\sqrt{1+\beta_{1}^{2}+\beta_{2}^{2}}} \\
& \frac{\partial d i s t}{\partial x}=-\frac{\beta_{1}}{\sqrt{1+\beta_{1}^{2}+\beta_{2}^{2}}} \\
& \frac{\partial d i s t}{\partial \beta_{0}}=-\frac{1}{\sqrt{1+\beta_{1}^{2}+\beta_{2}^{2}}} \\
& \frac{\partial d i s t}{\partial \beta_{2}}=-\frac{\beta_{2}\left(z-\beta_{0}-x \beta_{1}-y \beta_{2}\right)}{\left(1+\beta_{1}^{2}+\beta_{2}^{2}\right)^{3 / 2}}-\frac{y}{\sqrt{1+\beta_{1}^{2}+\beta_{2}^{2}}} \\
& \frac{\partial d i s t}{\partial y}=-\frac{\beta_{2}}{\sqrt{1+\beta_{1}^{2}+\beta_{2}^{2}}}
\end{aligned}
$$

Através da equação (5.13) pode-se determinar a incerteza relativa ao cálculo das distâncias entre ponto e plano. A incerteza do cálculo do desvio de planicidade é determinada aplicando a lei de propagação de incertezas na equação (5.11). 


$$
u^{2}(\text { Erro })=\left(\frac{\partial(\text { Erro })}{\partial(\text { Máx }(\text { dist }))}\right)^{2} * u^{2}(\text { Máx }(\text { dist }))+\left(\frac{\partial(\text { Erro })}{\partial(\operatorname{Min}(\text { dist }))}\right)^{2} * u^{2}(\text { Mín }(\text { dist }))
$$

Ou seja,

$$
u^{2}(\operatorname{Erro})=u^{2}(\operatorname{Máx}(\text { dist }))+u^{2}(\operatorname{Mín}(\text { dist }))
$$




\section{CAPÍTULO 6}

\section{TESTES EXPERIMENTAIS, RESULTADOS E DISCUSSÕES}

Descrito o sistema de medição de desvio de planicidade, cabe agora apresentar os resultados obtidos com a sua aplicação. A primeira parte deste capítulo apresenta os resultados das medições de erro de retilineidade realizadas para validação das técnicas de separação de erros. A segunda apresenta os resultados das medições de erro de planicidade e comparação com sistemas convencionais de medição desse erro. Em seguida, são apresentados os cálculos de incerteza de medição. 


\subsection{MEDIÇÃO DO ERRO DE RETILINEIDADE}

Para verificar a aplicabilidade das técnicas de separação de erros descritas no Capítulo 5 foram realizadas medições de erro de retilineidade de duas superficies, uma fabricada em granito com erro de retilineidade muito pequeno e outra fabricada em aço e com erro de retilineidade da ordem de $40 \mu \mathrm{m}$. O valor verdadeiro dos desvio de retilineidade dessas duas superficies foi determinado através do método de reversão da régua, descrito no Capítulo 3. A seguir são apresentados os resultados e a análise dessas medições.

\subsubsection{Resultados OBTIDOS COM O MÉtodo COMBINADO PROPOSTO POR KIYONO \& GAO, 1994}

O método proposto por Kiyono e Gao exige o uso de apenas dois sensores para medição. Como a garra de medição construída suporta três sensores, decidiu-se combiná-los dois a dois e aplicar a equação proposta por Gao a cada uma das combinações. De acordo com Gao, quando a equação 6.1 é utilizada, os erros de retilineidade da superficie de referência, ou seja, do eixo y da MM3C, são eliminados.

$$
Z\left(x_{i}\right)=\sum_{i=1}^{n} m^{\prime}\left(x_{i}\right) \times s=Z\left(x_{i-1}\right)+\frac{\left(m_{B}\left(x_{i}\right)-m_{A}\left(x_{i}\right)\right)}{D} \times s
$$

$\mathrm{Na}$ equação 6.1, 's' é a distância entre os sensores $\mathrm{A}$ e B, 'D' é o intervalo de tomada de dados e $Z\left(\mathrm{x}_{\mathrm{i}}\right)$ corresponde ao desvio de retilineidade do mensurando no ponto i.

$\mathrm{Na}$ combinação entre os sensores $\mathrm{A}$ e $\mathrm{B}$, o intervalo de tomada de dados é igual à distância entre os sensores, $\mathrm{s}=\mathrm{D}=18 \mathrm{~mm}$. Portanto, a equação 6.2 pode ser utilizada.

$$
Z\left(x_{i}\right)=Z\left(x_{i-1}\right)+\left(m_{B}\left(x_{i}\right)-m_{A}\left(x_{i}\right)\right)
$$


Da mesma forma, quando a combinação dos sensores B e C é avaliada, o erro de retilineidade do mensurando é calculado pela equação 6.3.

$$
Z\left(x_{i}\right)=Z\left(x_{i-1}\right)+\left(m_{C}\left(x_{i}\right)-m_{B}\left(x_{i}\right)\right)
$$

$\mathrm{Na}$ combinação entre os sensores A e C, 's' $=18 \mathrm{~mm}$ e 'D' $=32 \mathrm{~mm}$, portanto, a equação 6.4 pode ser aplicada para a separação de erros.

$$
Z\left(x_{i}\right)=Z\left(x_{i-1}\right)+\frac{\left(m_{C}\left(x_{i}\right)-m_{A}\left(x_{i}\right)\right)}{32000} \times 18000
$$

Os resultados obtidos para a medição da régua de granito, com cada uma das combinações de sensores, podem ser vistos nos Gráfico 6.1 e 6.2. Onde também, podem ser visualizadas as leituras individuais dos sensores.

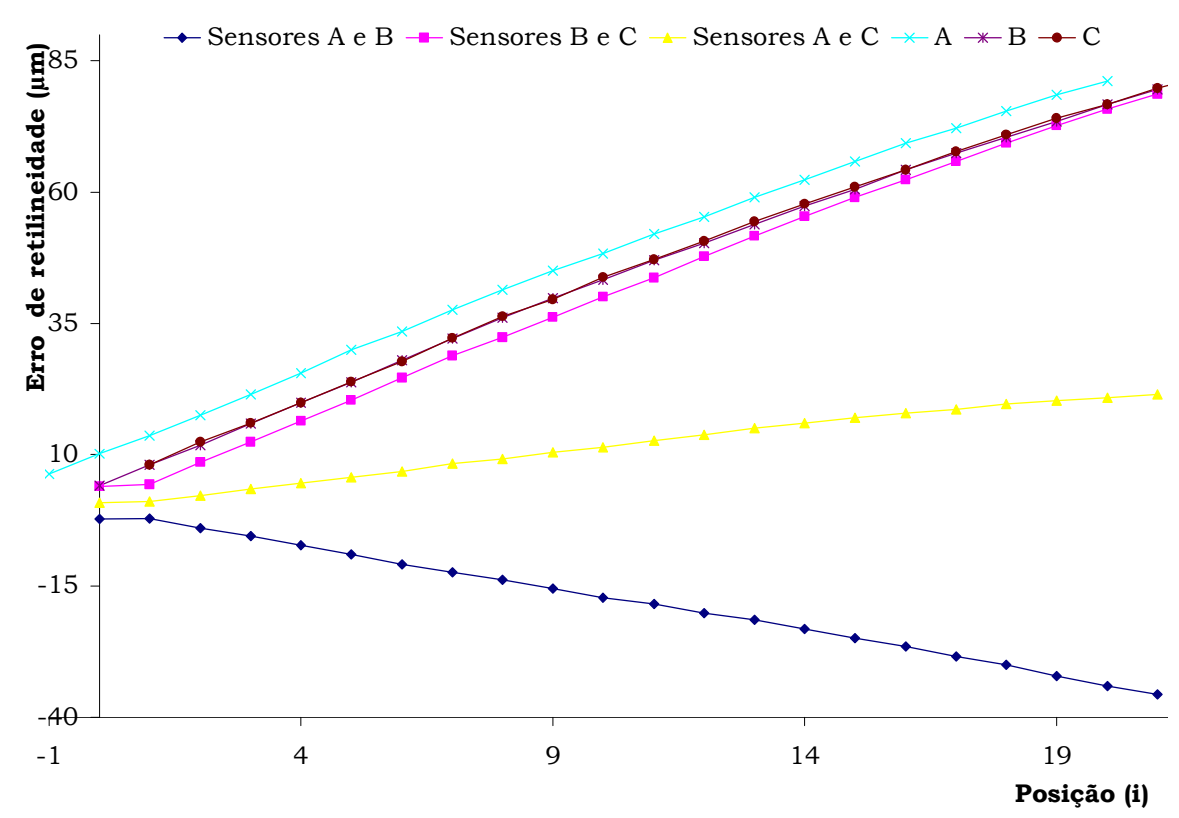

Gráfico 6.1: Comparação entre os resultados obtidos com cada uma das combinações de sensores na medição da régua de granito. 


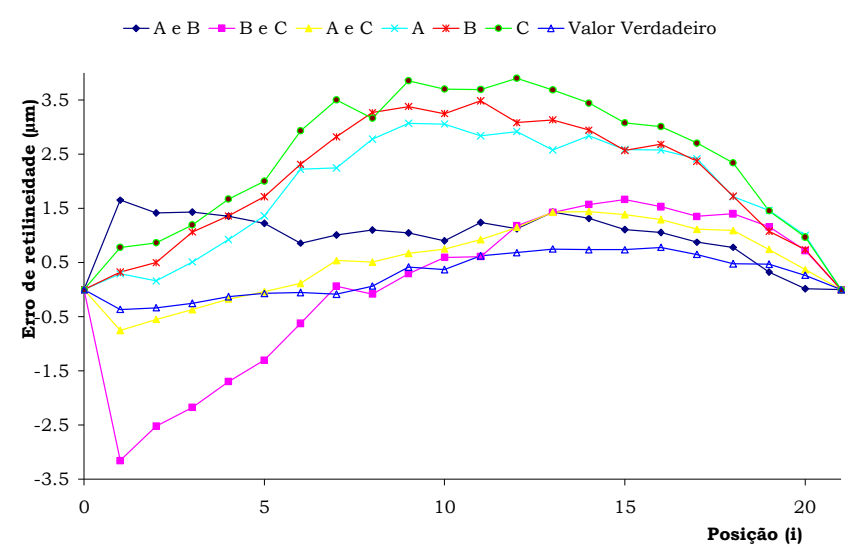

Gráfico 6.2: Comparação entre os resultados obtidos com cada uma das combinações de sensores na medição da régua de granito desalinhamento eliminado

Verifica-se através do Gráfico 6.2 que o melhor resultado obtido com o modelo proposto por Kiyono e Gao foi o da combinação dos sensores A e B e que esse resultado se aproxima em $69 \%$ do valor verdadeiro do desvio de retilineidade da régua de granito. Já o pior resultado foi quatro vezes maior que o valor verdadeiro.

Idealmente as três combinações de sensores deveriam dar o mesmo resultado, afinal foi utilizado o mesmo conjunto de dados e, portanto, trata-se do mesmo desalinhamento entre régua e guia. $\mathrm{O}$ desalinhamento entre régua e guia pode ser verificado quando observada as leituras individuais dos sensores A, B e C no Gráfico 6.1. Percebe-se, então, que além do desalinhamento entre régua e guia existem outros fatores que tornam os resultados de cada combinação diferentes. A diferença entre os resultados pode ser justificada pela presença de erros angulares no movimento do eixo y da MM3Cs que sendo da ordem dos erros do mensurando, interferem no resultado. Com isso, pode-se concluir que o modelo proposto por Kiyono e Gao em 1994 não deve ser utilizado quando os erros angulares da referência de medição são da mesma ordem que os erros do mensurando. 
O procedimento de análise dos resultados de medição da régua de aço fabricada com maior desvio foi o mesmo adotado para analisar os resultados da régua de granito. O resultado das três combinações de sensores pode ser visto no Gráfico 6.3.

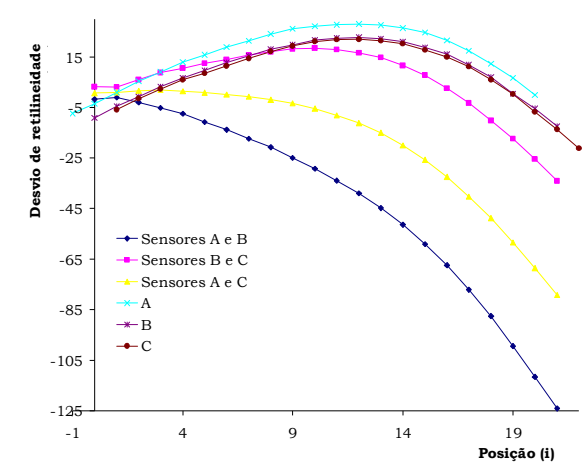

a- com desalinhamento

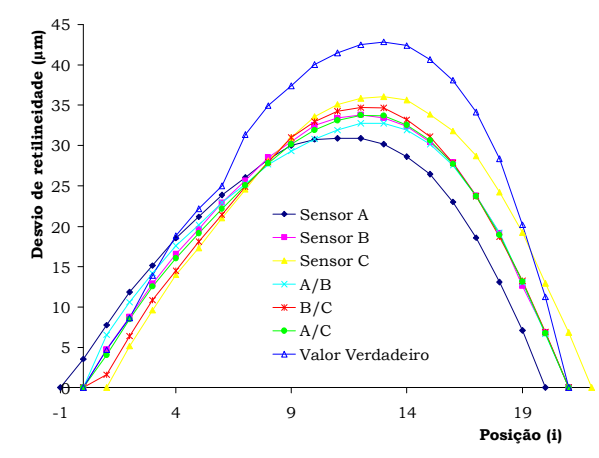

b- sem desalinhamento

Gráfico 6.3-Erro de retilineidade régua de aço

Como pode ser observado, a diferença entre os resultados não é tão discrepante como no caso da régua de granito. O melhor resultado, obtido com a combinação dos sensores B e C, aproximou-se em 83\% do valor verdadeiro. Como o erro de retilineidade da régua de aço é da ordem de 10 vezes o erro angular da MM3C, esses erros,os angulares, não influenciam tanto os resultados.

\subsubsection{RESUltados OBTIDOS COM O MÉTODO UTILIZANDO TRÊS APALPADORES ROPOSTO POR GAO ET AL,2002}

O mesmo conjunto de dados usado para avaliar o método anterior foi analisado. O modelo apresentado na equação 6.5 foi proposta por GAO et al,2002 para eliminar os erros de retilineidade e angular, inerentes ao sistema de medição.

$$
\begin{gathered}
Z\left(x_{i}\right)=\sum_{k=1}^{i} \sum_{j=1}^{k} \frac{A\left(x_{i}\right)-2 * B\left(x_{i}\right)+C\left(x_{i}\right)}{d^{2}} * s * s-\frac{\alpha}{2 * d^{2}} * x_{i}^{2} \\
Z\left(x_{1}\right)=0 ; i=2, \ldots, N ; s=d=18 m m \text { e } \alpha=A\left(x_{1}\right)-2 * B\left(x_{1}\right)+C\left(x_{1}\right)
\end{gathered}
$$


O resultado obtido para a régua de granito pode ser visto no Gráfico 6.4 .

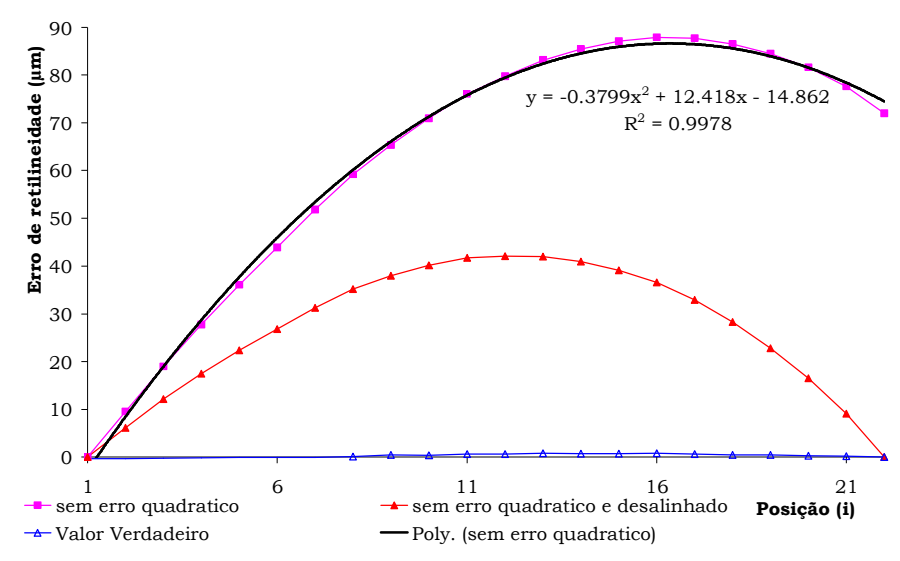

Gráfico 6.4: Erro de retilineidade régua de granito calculado com método proposto por GAO et al,2002.

De acordo com GAO et al, o segundo termo da equação 6.5 é utilizado para eliminar o erro causado pelo desalinhamento entre os sensores, que segundo o mesmo autor, causa um erro parabólico nos resultados da medição. Pode-se verificar nos resultados do Gráfico 6.4 que mesmo depois de eliminar o erro quadrático através da equação 6.5, a curva do erro de retilineidade da régua de granito ainda é parabólico, como pode ser observado através da curva de aproximação linear do Gráfico 6.4 .

Para entender melhor o método, a seguinte análise foi feita: suponha que seja medida uma superficie perfeitamente retilinea com um sistema de medição ideal, ou seja, um sistema de medição que não possui erros de movimentação. Portanto, nesse sistema ideal, a leitura de cada um dos sensores será constante. Suponha também que, seja possivel alinhar os sensores perfeitamente, de forma que durante todo o curso de medição as leituras dos três sensores sejam iguais.

Verifica-se na Tabela 6.2 que o resultado seria coerente, ou seja, o erro de retilineidade da superficie seria nulo. 
Tabela 6.1: Leitura dos sensores A, B e C em sistema idealizado

\begin{tabular}{|c|c|c|c|c|}
\hline $\mathrm{A}\left(\mathrm{x}_{\mathrm{i}}\right)$ & $\mathrm{B}\left(\mathrm{x}_{\mathrm{i}}\right)$ & $\mathrm{C}\left(\mathrm{x}_{\mathrm{i}}\right)$ & $\alpha=\mathrm{A}-2 \mathrm{~B}+\mathrm{C}$ & $\mathrm{Z}(\mathrm{xi})$ \\
\hline 5 & 5 & 5 & 0 & 0 \\
\hline 5 & 5 & 5 & 0 & 0 \\
\hline 5 & 5 & 5 & 0 & 0 \\
\hline
\end{tabular}

Sabe-se que é praticamente impossivel alinhar os três sensores perfeitamente, considere agora, a mesma situação anterior mas com os sensores ligeiramente desalinhados. As leituras de cada sensor serão constantes durante a medição mas cada sensor medirá um valor, já que não estão alinhados.

Tabela 6.2: Leitura dos sensores A, B e C em sistema sem desvios geométricos e com sensores desalinhados

\begin{tabular}{|c|c|c|c|c|c|c|}
\hline Posição & A & B & C & A-2B+C & $\begin{array}{c}\text { Z com erro } \\
\text { quadrático }\end{array}$ & $\begin{array}{c}\text { Z sem erro } \\
\text { quadrático }\end{array}$ \\
\hline 0 & 5 & 4 & 1 & -2 & -2 & -2 \\
\hline 1 & 5 & 4 & 1 & -2 & -6 & -5 \\
\hline 2 & 5 & 4 & 1 & -2 & -12 & -8 \\
\hline 3 & 5 & 4 & 1 & -2 & -20 & -11 \\
\hline 4 & 5 & 4 & 1 & -2 & -30 & -14 \\
\hline 5 & 5 & 4 & 1 & -2 & -42 & -17 \\
\hline 6 & 5 & 4 & 1 & -2 & -56 & -20 \\
\hline
\end{tabular}

A última coluna da Tabela 6.2 apresenta o erro de retilineidade do mensurando calculado de acordo com a equação 6.5, propostas por Gao et al,2002. O Gráfico 6.5 mostra que a superficie medida apresenta inclinação mas que pode ser perfeitamente representado por uma reta. Com isso verifica-se que o método apresenta resultados coerentes para dados simulados. No entanto, quando são analisados dados experimentais 
verifica-se que um desalinhamento entre os sensores de $10 \mathrm{~nm}$ é suficiente para acrescentar um erro de perfil parabólico nos resultados de medição, tornando inviável a utilização do método para aplicações práticas.

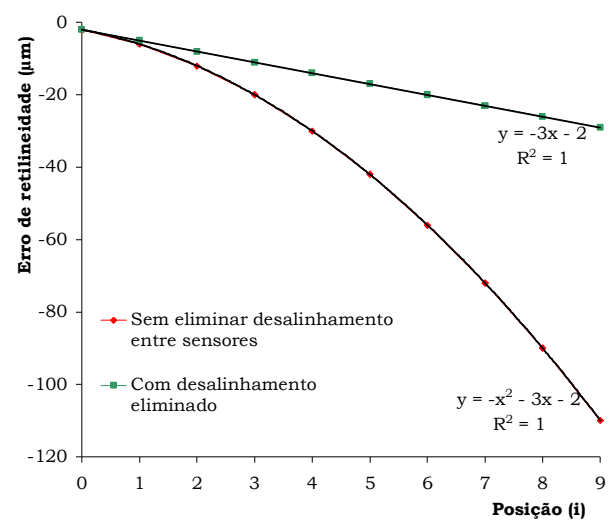

Gráfico 6.5: Resultados do desvio de retilineidade da superficie idealizada

O gráfico 6.6 apresenta o erro de retlineidade da régua de aço. Comparando com os resultados obtidos através do método da reversão os resultados podem ser considerados bons. O desvio de retilineidade com o método proposto por GAO et al,2002 foi de $48 \mu \mathrm{m}$. Quando o desvio de retilineidade é calculado através do método da reversão o valor encontrado é de $42 \mu \mathrm{m}$. No entando, quando são realizadas inúmeras medições verifica-se que este método não apresenta repetibilidade. O item 6.1.5 descreve o experimento realizado para verificar a repetibilidade dos métodos.

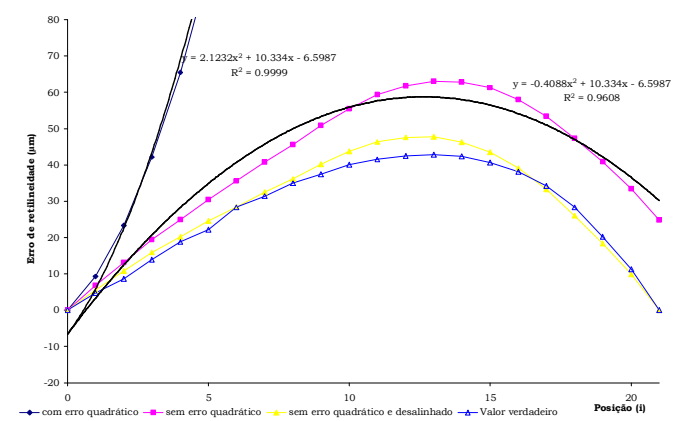

Gráfico 6.6: Erro de retilineidade régua de aço calculado com método proposto por GAO et al,2002. 


\subsubsection{Resultados Obtidos com o método "Sequencial-Three- POINTS"(STRP)}

Os Gráficos 6.7 a- e b- apresentam o erro de retilineidade das réguas de aço e de granito determinado a partir do método "Sequencial-ThreePoints"(STRP). Percebe-se que o método não calcula o resultado corretamente para a régua de granito adicionando tendência parabólica no resultado, enquanto que para a régua de aço os resultados se aproximam em 95\% do valor verdadeiro. No entanto, o método não apresenta repetibilidade como descrito no item 6.1.5.

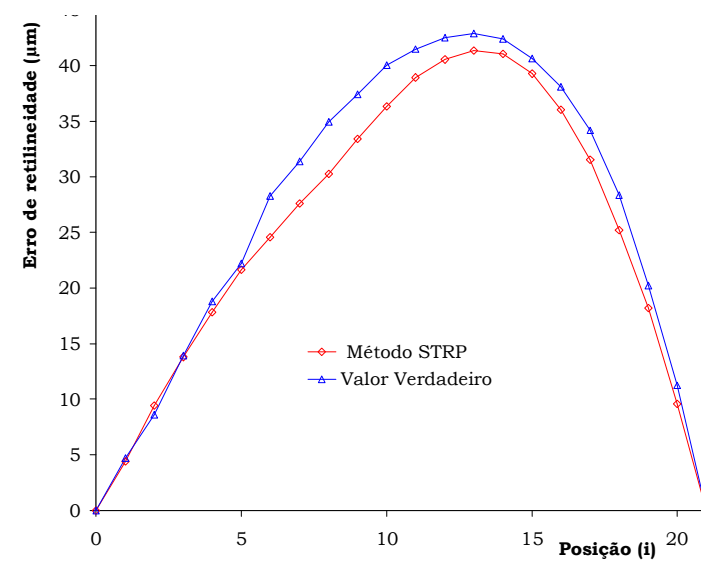

a- Régua de aço

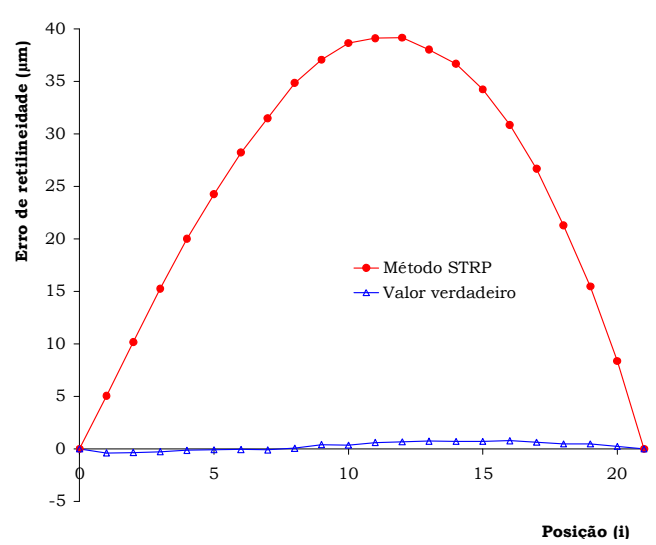

b- Régua de granito

Gráfico 6.7: Desvio de retilineidade determinados através do método STRP

\subsubsection{Resultados obtidos Com O MÉtodo 'SEQuencial-Two-Points" (TSP)}

Como esse método exige apenas dois sensores, os três sensores foram combinados dois a dois e a equação proposta por Tozawa no ano de 1982 foi aplicada. A tabela 6.3 apresenta as equações utilizadas para cada uma das combinações. 
Tabela 6.3: Equações usadas para separação de erros com método de TSP

\begin{tabular}{|c|c|}
\hline COMBINAÇÃO & EQUAÇÃO \\
\hline \multirow{2}{*}{ A e B } & $X_{K}^{C}=X_{K-1}^{C}+D_{K-1, B}-D_{K, A} ; \Delta=\frac{X_{N}^{C}}{N}=\frac{X_{22}^{C}}{22} ; X_{0}^{C}=0 ;$ \\
& $Y_{K}=X_{K}^{T}+D_{K, B}-D_{0, B}$ \\
\hline B e C & $X_{K}^{C}=X_{K-1}^{C}+D_{K-1, B}-D_{K, C} ; \Delta=\frac{X_{N}^{C}}{N}=\frac{X_{22}^{C}}{22} ; X_{0}^{C}=0 ;$ \\
& $Y_{K}=X_{K}^{T}+D_{K, C}-D_{0, C}$ \\
\hline A e C & $X_{K}^{C}=X_{K-1}^{C}+D_{K-1, A}-D_{K, C} ; \Delta=\frac{X_{N}^{C}}{N}=\frac{X_{22}^{C}}{22} ; X_{0}^{C}=0 ;$ \\
& $Y_{K}=X_{K}^{T}+D_{K, C}-D_{0, C}$ \\
\hline
\end{tabular}

Os gráficos 6.8-a e 6.8-b apresentam o erro de retilineidade da régua de granito. Assim como nos resultados calculados pela equação de Gao, os resultados obtidos para cada uma das combinações foram diferentes. Como já constatado, a diferença pode ser justificada pela presença de erros angulares nos eixos da MM3C com mesma grandeza que o erro do mensurando. Inviabilizando que o método seja utilizado para medição de superficies com desvio de retilineidade da mesma ordem que o desvio de da referência adotada. Desta forma, o sistema proposto foi utilizado abaixo dos seus limites de resolução na medição da régua de granito.

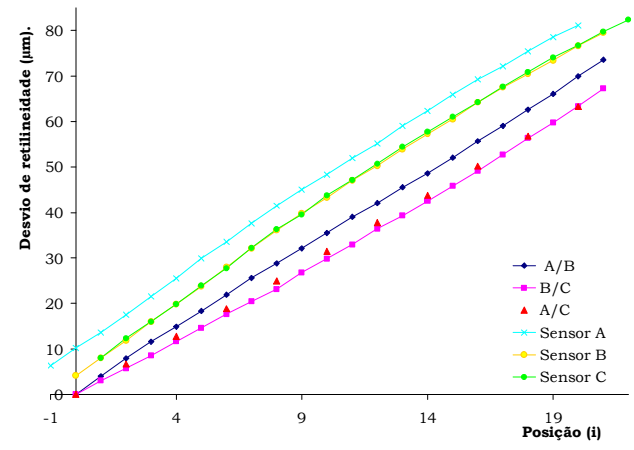

a- com desalinhamento

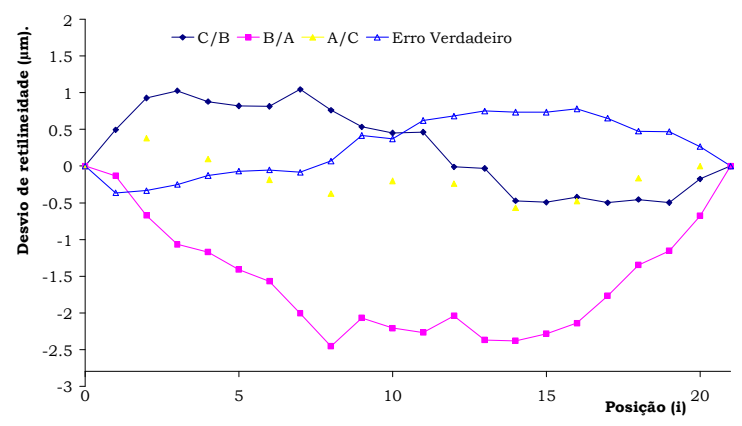

b- sem desalinhamento

Gráfico 6.8: Desvio de retilineidade régua de granito usando método TSP 
O erro de retilineidade da régua de aço também foi calculado utilizando as equações da Tabela 6.3. Os resultados são apresentados nos Gráficos 6.9-a e 6.9-b.

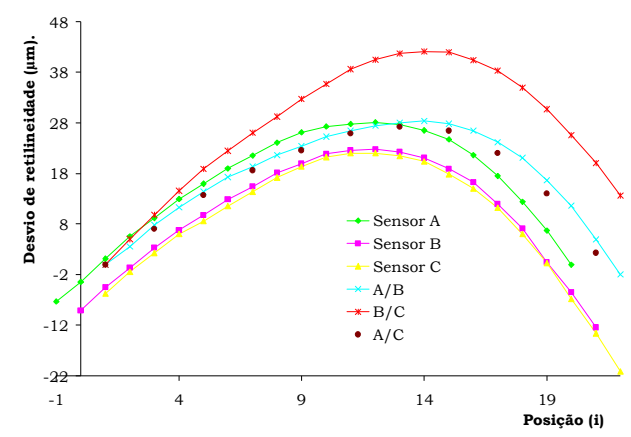

a- com desalinhamento

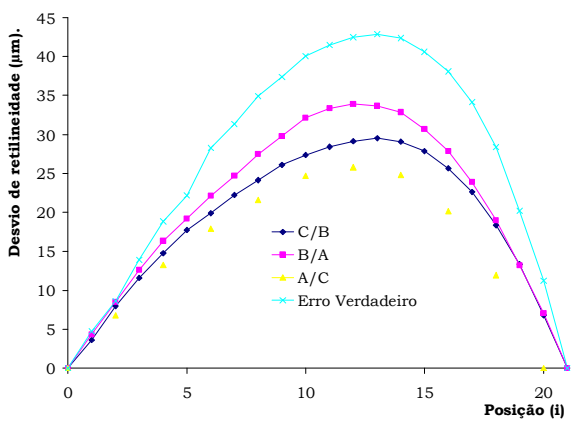

b-sem desalinhamento

Gráfico 6.9: Desvio de retilineidade régua de aço usando método TSP

As diferenças entre os resultados de cada um das combinações na medição da régua com maior desvio de retilineidade é pequena quando comparadas aos resultados da medição da régua de granito. Os resultados para essa medição também são próximos aos valores verdadeiros do desvio de retilineidade, calculados através do método da reversão. O valor verdadeiro do desvio de retilineidade é de $43 \mu \mathrm{m}$. O maior resultado calculado pelo método de separação de erros resulta em $35 \mu \mathrm{m}$, equivalente a $81 \%$ do valor verdadeiro. Enquanto, o menor resultado foi de $25 \mu \mathrm{m}$, equivalente a $56 \%$ do valor valor verdadeiro.

\subsubsection{VERIFICAÇÃO DA REPETIBILIDADE DOS MÉTODOS DE SEPARAÇÃO DE ERROS}

Para verificar e repetibilidade dos métodos uma sequência de quatro experimentos foram realizados. Em cada um do experimentos, a régua de aço foi medida três vezes seguidas. Entre os experimentos, os sensores foram reajustados e o mesmo processo de medição foi realizado. Os gráficos abaixo apresentam o resultado para cada um dos métodos. 


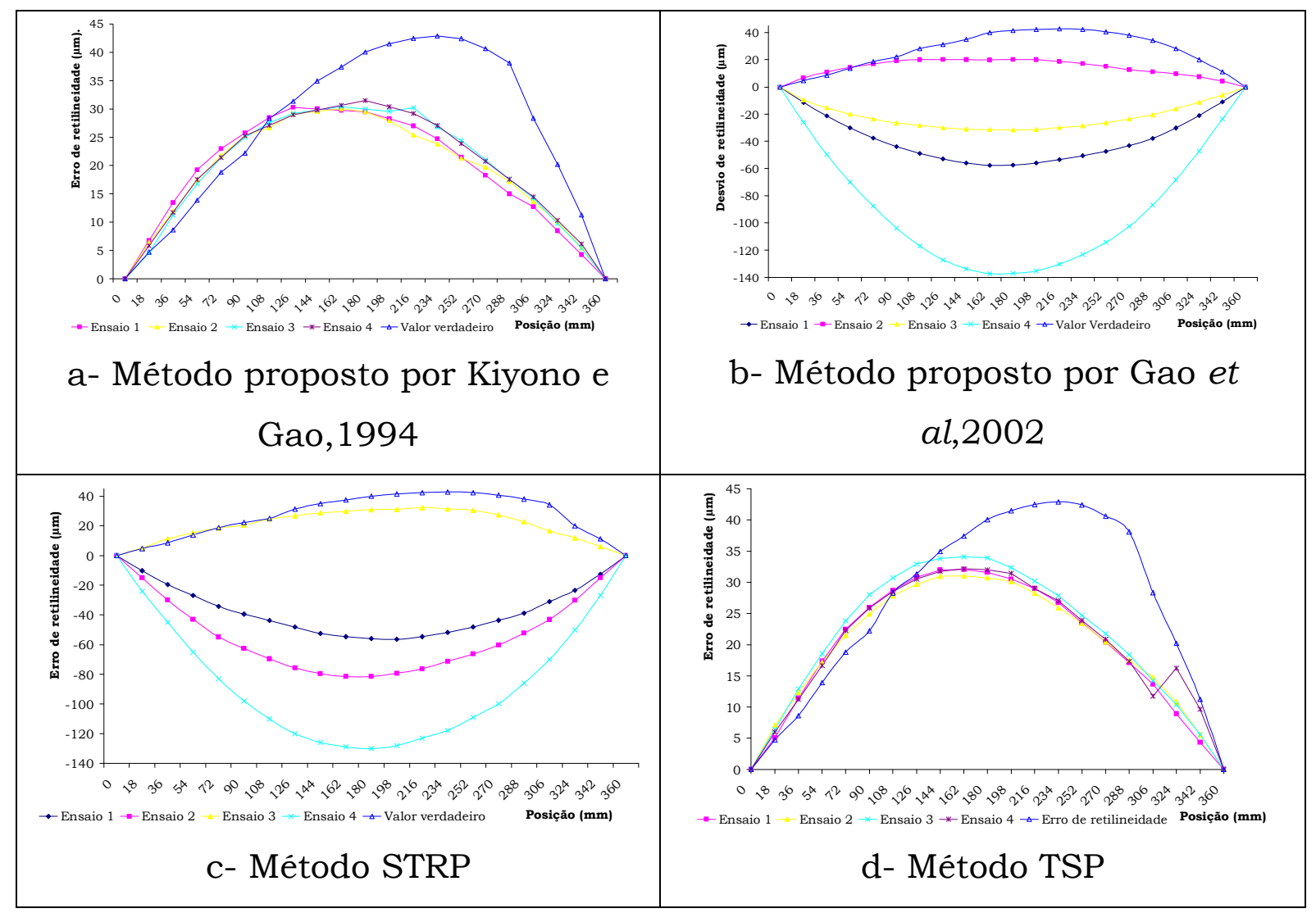

Gráfico 6.10: Resultado do experimentos realizados para verificar repetibilidade dos métodos de separação de erros

Como pode ser observado nos gráficos, os métodos que utilizam três sensores não apresentam repetibilidade. Esses métodos são influenciados pela diferença das leituras dos sensores no primeiro ponto de medição. Como em cada um dos ensaios, os sensores foram reajustados, o desalinhamento entre os sensores em cada um dos ensaios foi diferente e portanto a variável $\alpha$ é diferente para cada um dos ensaios. Nesse, estudo, não foi encontrada uma relação entre o valor de $\alpha$ e o resultado da medição. PAZIANI, F. T. (2005) propôs um modelo que resolve esse problema.

Os métodos que utilizam dois sensores apresentaram maior repetibilidade e resultados próximos ao valor verdadeiro de desvio de retilineidade. Ocálculo do desvio de planicidade foi realizado através do método proposto por Kiyono e Gao, 1994. 


\subsection{MEdiÇÃO DE ERRO DE PLANICIDAdE}

O desvio de planicidade de uma superficie foi medido para verificar a eficiência do algorítmo de separação de erros na medição de desvio de planicidade. O desvio de planicidade dessa superficie também foi medido utilizando interferômetro a laser e nível eletrônico. Em seguida, os três resultados foram comparados.

Os gráficos 6.11 apresentam os valores dos desvios medidos utilizando o sistema proposto, o nivel eletrônico e o interferômetro a laser.

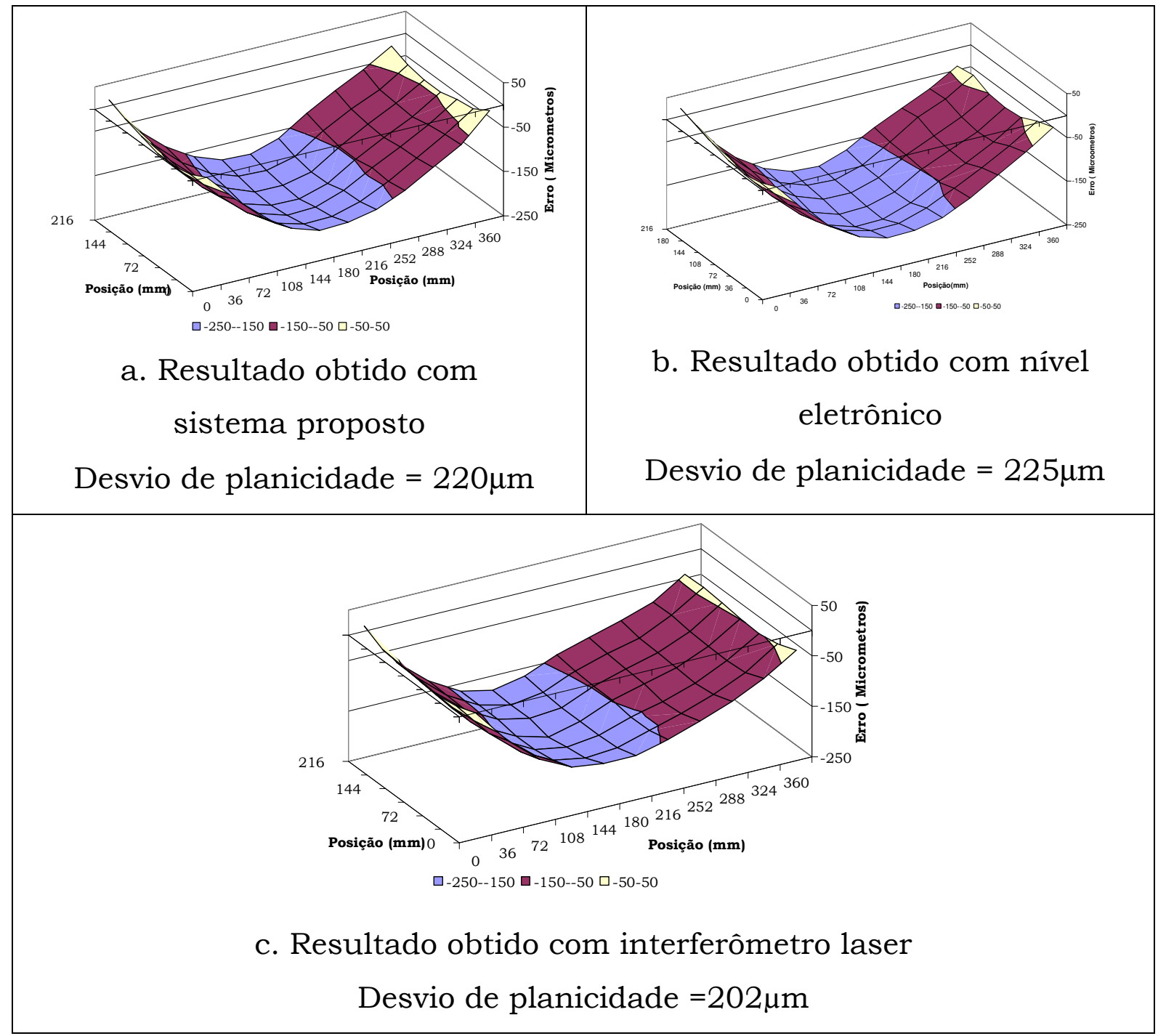

Gráfico 6.11: Erros de planicidade medidos utilizando diferentes sistemas de medição 
De modo geral, pode-se dizer que os valores de desvio de planicidade encontrados são próximos aos valores medidos com o interferômetro a laser e com o nível eletrônico. O desvio de planicidade calculado com o método de separação de erros foi de $220 \mu \mathrm{m}$. Esse valor corresponde a um percentual de 97\% quando comparado ao nível eletrônico e a um percentual de $92 \%$ quando comparado ao interferômetro a laser.

Além da avaliação qualitativa, o sistema de medição deve ser avaliado quanto ao custo e tempo para realizar medição. Por isso, o tempo de medição de cada um dos experimentos realizados foi medido. O interferômetro a laser foi o mais demorado visto que as ópticas devem ser alinhadas para a medição de cada uma das linhas. A medição com o nivel eletrônico foi simples e rápida, já que o instrumento foi conectado a um microcomputador preparado com programa computacional para cálculo do desvio de planicidade. A medição com sistema proposto foi facilitada devido às réguas ópticas da MM3C estarem conectadas com programa computacional que verifica a posição do eixo da MM3C e guarda a leitura dos transdutores na posição pré-determinada pelo operador. Outro fato facilitador é que este mesmo programa computacional possuía algoritmo para separação de erros e para cálculo do desvio de planicidade.

O custo do sistema interferométrico a laser é de aproximadamente U\$30.000,00 enquanto o nível eletrônico custa em torno de U\$15.000,00. Desconsiderando o preço da MM3C o sistema proposto tem custo da ordem de U\$3.000,00. A Tabela 6.4 apresenta uma comparação entre os três sistemas.

Tabela 6.4: Comparação entre sistemas de medição

\begin{tabular}{c|c|c|c}
\hline Instrumento & Tempo $(\mathrm{min})$ & Erro $(\mu \mathrm{m})$ & Custo (U\$) \\
\hline Nivel eletrônico & 7 & 225 & $15.000,00$ \\
\hline Sistema proposto & 11 & 220 & $3.000,00$ \\
\hline Laser & 60 & 251 & $30.000,00$ \\
\hline
\end{tabular}




\subsection{CÁlCulo da INCERTEZA de MEdiçÃo}

A seguir são apresentados os cálculos realizados para determinar a incerteza de medição do resultado do erro de planicidade utilizando o sistema proposto.

\subsubsection{CÁlCULO DA INCERTEZA RELATIVA Às ALTURAS Z MEDIDAS}

Quando as equações do método de separação de erros propostas por Tanaka e Sato (1986) são utilizadas para determinar os valores das alturas $Z$, a altura $Z$ de um ponto i é calculada a partir do valor $Z$ do ponto anterior (i-1). Portanto, a incerteza relativa à altura $Z$ de um ponto depende de sua posição i, conforme apresentado no Capítulo 5.

A coordenada do ponto em que se tem máxima distância até o plano de MMQ, Min(dist), é $(\mathrm{x}=180, \mathrm{y}=108, \mathrm{z}=-0,876)$. Como esse ponto encontra-se na linha $\mathrm{x}=180$ e a distância entre cada ponto de medição é $38 \mathrm{~mm}$, o valor do índice i usado na equação de separação de erros e na equação para determinação da incerteza de medição, $\mathrm{U}^{2}(Z)$, será 5 . A coordenada do ponto em que se tem Máx(dist) é ( $\mathrm{x}=0, \mathrm{y}=216, \mathrm{z}=0.132)$ e o valor do índice i é zero.

A incerteza relativa à leitura dos transdutores é dada por:

$$
u\left(D_{i-1, B}\right)=u\left(D_{i, A}\right)=\sqrt{\frac{\left(\operatorname{Re} s_{L V D T}\right)^{2}}{6}}=\sqrt{\frac{0.1^{2}}{6}}=1.6 \times 10^{-3} \mu \mathrm{m}
$$

Sendo que $\operatorname{Re} s_{L V D T}$ é a resolução dos transdutores utilizados.

Através da equação (5.33), determina-se o valor de $u_{c}\left(Z_{\text {Max (dist) }}\right)$ e de $u_{c}\left(Z_{\text {Min }(\text { dist })}\right): u_{c}\left(Z_{\text {Min (dist })}\right)=0,16 \mu \mathrm{m}$ e $u_{c}\left(Z_{\text {Max (dist })}\right)=0,05 \mu \mathrm{m}$.

\subsubsection{CÁlCULO de $\mathbf{u}^{2}\left(\beta_{0}\right), u^{2}\left(\beta_{1}\right)$ e $\mathbf{u}^{2}\left(\beta_{2}\right)$}

Utilizando as equações 5.34 e 5.35 determina-se os valores de $u^{2}\left(\beta_{0}\right), u^{2}\left(\beta_{1}\right)$ e $u^{2}\left(\beta_{2}\right)$.

A incerteza relativa às leituras das escalas ópticas da MM3C é dada por: 
$u(y)=u(x)=\frac{\operatorname{Re} s_{M M 3 C}}{\sqrt{3}}=\frac{2}{\sqrt{3}}=1,15 \mu \mathrm{m}$.

As Tabelas 6.5, 6.6 e 6.7 apresentam os resultados das incertezas relativas a $\beta_{0}, \beta_{1}$ e $\beta_{2}$.

Tabela 6.5: Incerteza no cálculo de $\beta_{0}, \mathrm{u}\left(\beta_{0}\right)$

\begin{tabular}{|c|c|c|c|}
\hline $\begin{array}{c}\text { Componente } \\
\text { de incerteza } \\
\mathrm{u}\left(\mathrm{x}_{\mathrm{i}}\right)\end{array}$ & $\begin{array}{c}\text { Incerteza } \\
\text { Padronizada } \\
(\mu \mathrm{m})\end{array}$ & $\begin{array}{c}\text { Coeficiente de } \\
\text { Sensibilidade }\end{array}$ & $\left(\frac{\partial f}{\partial x_{i}}\right)^{2} u^{2}\left(x_{i}\right)$ \\
\hline $\mathrm{U}(\mathrm{z})$ & 0,16 & $-4,67$ & 0,56 \\
\hline $\mathrm{U}(\mathrm{x})$ & 1,15 & $-1,17$ & 1,81 \\
\hline $\mathrm{U}(\mathrm{y})$ & 1,15 & $2,4 \times 10^{-3}$ & $7,62 \times 10^{-6}$ \\
\hline
\end{tabular}

Tabela 6.6: Incerteza no cálculo de $\beta_{1}, \mathrm{u}\left(\beta_{1}\right)$

\begin{tabular}{|c|c|c|c|}
\hline $\begin{array}{c}\text { Componente } \\
\text { de incerteza } \\
\mathrm{u}\left(\mathrm{x}_{\mathrm{i}}\right)\end{array}$ & $\begin{array}{c}\text { Incerteza } \\
\text { Padronizada } \\
(\mu \mathrm{m})\end{array}$ & $\begin{array}{c}\text { Coeficiente de } \\
\text { Sensibilidade }\end{array}$ & $\left(\frac{\partial f}{\partial x_{i}}\right)^{2} u^{2}\left(x_{i}\right)$ \\
\hline $\mathrm{U}(\mathrm{z})$ & 0,16 & $1,37 \times 10^{-5}$ & $4,8 \times 10^{-12}$ \\
\hline $\mathrm{U}(\mathrm{x})$ & 1,15 & $6,5 \times 10^{-4}$ & $0,56 \times 10^{-6}$ \\
\hline $\mathrm{U}(\mathrm{y})$ & 1,15 & $4,27 \times 10^{-10}$ & $2,4 \times 10^{-19}$ \\
\hline & & $\sqrt{\text { Soma }}$ & $0,75 \times 10^{-3} \mu \mathrm{m}$ \\
\hline
\end{tabular}

Tabela 6.7: Incerteza no cálculo de $\beta_{2}, \mathrm{u}\left(\beta_{2}\right)$

\begin{tabular}{|c|c|c|c|}
\hline $\begin{array}{c}\text { Componente } \\
\text { de incerteza } \\
\mathrm{u}\left(\mathrm{x}_{\mathrm{i}}\right)\end{array}$ & $\begin{array}{c}\text { Incerteza } \\
\text { Padronizada } \\
(\mu \mathrm{m})\end{array}$ & $\begin{array}{c}\text { Coeficiente de } \\
\text { Sensibilidade }\end{array}$ & $\left(\frac{\partial f}{\partial x_{i}}\right)^{2} u^{2}\left(x_{i}\right)$ \\
\hline $\mathrm{U}(\mathrm{z})$ & 0,16 & $3,6 \times 10^{-6}$ & $3,31 \times 10^{-13}$ \\
\hline $\mathrm{U}(\mathrm{x})$ & 1,15 & $-1,1 \times 10^{-3}$ & $1,60 \times 10^{-6}$ \\
\hline $\mathrm{u}(\mathrm{y})$ & 1,15 & $8,0 \times 10^{-10}$ & $8.46 \times 10^{-19}$ \\
\hline & & $\sqrt{\text { Soma }}$ & $1,29 \times 10^{-3} \mu \mathrm{m}$ \\
\hline
\end{tabular}




\subsubsection{CÁlCULo DE U²(MÁx(DIST)) E U²(Mín(DIST))}

A equação (5.13) pode ser utilizada para determinação de $u^{2}$ (Máx(dist)) e $u^{2}(\operatorname{Min}(d i s t))$, os resultados são apresentados nas Tabela 6.8 e 6.9.

Tabela 6.8: Incerteza no cálculo de Máx(dist), $u$ (Máx(dist))

\begin{tabular}{|c|c|c|c|}
\hline $\begin{array}{c}\text { Componente } \\
\text { de incerteza } \\
\mathrm{u}\left(\mathrm{x}_{\mathrm{i}}\right)\end{array}$ & $\begin{array}{c}\text { Incerteza } \\
\text { Padronizada } \\
(\mu \mathrm{m})\end{array}$ & $\begin{array}{c}\text { Coeficiente } \\
\text { de } \\
\text { Sensibilidade }\end{array}$ & $\left(\frac{\partial f}{\partial x_{i}}\right)^{2} u^{2}\left(x_{i}\right)$ \\
\hline $\mathrm{U}(\mathrm{z})$ & $5,7 \times 10^{-2}$ & 1 & $3,2 \times 10^{-3}$ \\
\hline $\mathrm{U}\left(\beta_{1}\right)$ & $7,5 \times 10^{-4}$ & $2,9 \times 10^{-4}$ & $4,73 \times 10^{-14}$ \\
\hline $\mathrm{U}\left(\beta_{2}\right)$ & $1,3 \times 10^{-3}$ & $-215,9$ & $7,87 \times 10^{-2}$ \\
\hline $\mathrm{U}\left(\beta_{0}\right)$ & 1,53 & $-0,99$ & 2,29 \\
\hline $\mathrm{U}(\mathrm{x})$ & 1,15 & $2,1 \times 10^{-3}$ & $5,8 \times 10^{-6}$ \\
\hline $\mathrm{U}(\mathrm{y})$ & 1,15 & $3,58 \times 10^{-5}$ & $1,69 \times 10^{-9}$ \\
\hline & & $\sqrt{\text { Soma }}$ & $1,53 \mu \mathrm{m}$ \\
\cline { 3 - 4 } & & &
\end{tabular}

Tabela 6. 9: Incerteza no cálculo de $\operatorname{Min}($ dist $), u(\operatorname{Min}(d i s t))$

\begin{tabular}{|c|c|c|c|}
\hline $\begin{array}{c}\text { Componente } \\
\text { de incerteza } \\
\mathrm{u}\left(\mathrm{x}_{\mathrm{i}}\right)\end{array}$ & $\begin{array}{c}\text { Incerteza } \\
\text { Padronizada } \\
(\mu \mathrm{m})\end{array}$ & $\begin{array}{c}\text { Coeficiente } \\
\text { de } \\
\text { Sensibilidade }\end{array}$ & $\left(\frac{\partial f}{\partial x_{i}}\right)^{2} u^{2}\left(x_{i}\right)$ \\
\hline $\mathrm{U}(\mathrm{z})$ & 0,16 & 1 & 0,025 \\
\hline $\mathrm{U}\left(\beta_{1}\right)$ & $7,5 \times 10^{-4}$ & -180 & $1,82 \times 10^{-2}$ \\
\hline $\mathrm{U}\left(\beta_{2}\right)$ & $1,3 \times 10^{-3}$ & $-107,99$ & $1,97 \times 10-2$ \\
\hline $\mathrm{U}\left(\beta_{0}\right)$ & 1,53 & $-0,99$ & 2,29 \\
\hline $\mathrm{u}(\mathrm{x})$ & 1,15 & $2,1 \times 10^{-3}$ & $5,83 \times 10^{-6}$ \\
\hline $\mathrm{u}(\mathrm{y})$ & 1,15 & $3,58 \times 10^{-5}$ & $1,69 \times 10^{-9}$ \\
\hline & & $\sqrt{\text { Soma }}$ & $1.52 \mu \mathrm{m}$ \\
\hline
\end{tabular}


Utilizando os resultados anteriores os valores de $u(\operatorname{Máx}(d i s t))$ e $u(\operatorname{Min}(d i s t))$ são respectivamente $1,53 \mu \mathrm{m}$ e $1,52 \mu \mathrm{m}$. Através da equação (5.49) determinase que o valor de $u($ Erro $)$ é $2,15 \mu \mathrm{m}$.

Tabela 6. 10: Incerteza do resultado da medição de desvio de planicidade

\begin{tabular}{|l|c|c|c|}
\hline $\begin{array}{c}\text { Componente } \\
\text { de incerteza } \\
\mathrm{u}\left(\mathrm{x}_{\mathrm{i}}\right)\end{array}$ & $\begin{array}{c}\text { Incerteza } \\
\text { Padronizada }(\mu \mathrm{m})\end{array}$ & $\begin{array}{c}\text { Coeficiente de } \\
\text { sensibilidade }\end{array}$ & $\left(\frac{\partial f}{\partial x_{i}}\right)^{2} u^{2}\left(x_{i}\right)$ \\
\hline$u($ Máx(dist $))$ & 1,53 & 1 & 2,34 \\
\hline$u($ Mín(dist $))$ & 1,52 & 1 & 2,31 \\
\hline \multicolumn{1}{l|}{} & $\sqrt{\text { Soma }}$ & $2,15 \mu \mathrm{m}$ \\
\cline { 2 - 4 }
\end{tabular}




\section{CAPÍTULO 7}

\section{CONCLUSÕES E SUGESTÕES PARA TRABALHOS FUTUROS}

Planicidade é um parâmetro crítico na fabricação de diversos componentes da indústria mecânica. Para avaliar apropriadamente a planicidade de superfícies, fabricadas com tolerâncias cada vez mais apertadas, intrumentos de alta acuracidade e alta velocidade de medição devem ser desenvolvidos. O que sigmifica um grande desafio para os especialistas em metrologia mecânica dimensional.

O objetivo desse trabalho foi desenvolver um sistema que utiliza a medição de desvio de retilineidade para determinar o desvio de planicidade de uma superfície. Para tanto, foi feita uma ampla revisão bibliográfica sobre métodos de medição de planicidade e sobre técnicas de separação de erros aplicadas na medição do desvio de retilineidade.

A literatura sobre técnicas de separação de erros, destacou a necessidade de resultados experimentais que permitam comprovar a 
aplicabilidade das referidas técnicas. A maioria dos artigos consultados neste trabalho apresentaram os resultados através de dados simulados, o que não pode ser utilizado para retirar conclusões práticas já que um experimento está imune a diversas fontes de erros.

O sistema de medição envolveu programação computacional, interfaceamento eletrônico entre instrumentos de medição e microcomputador e a realização de ensaios cuidadosamente planejados.

Foram realizados experimentos para medição de retilineidade com dois e três sensores na garra de medição. Com isso, pôde-se verificar a eficiência das técnicas que propõem a utilização de dois e três sensores para separação de erros. Em seguida, as técnicas de separação de erros foram utilizadas na medição de desvio de planicidade.

Do desenvolvimento do sistema para medição de desvio de planicidade as seguintes conclusões foram obtidas:

As equações para separação de erros propostas por Tanaka \& Sato (1986) e GAO et al (2002) utilizando três sensores não apresentam repetibilidade nos resultados;

$\checkmark$ As equações de separação de erros que utilizam dois sensores de medição podem ser aplicadas desde que o desvio de retilineidade da referência adotada seja uma ordem de grandeza menor que o desvio do mensurando;

$\mathrm{Na}$ medição de retilineidade os resultados obtidos com as técnicas de separação de erros se aproximam em 90\% do valor verdadeiro, calculado utilizando método da reversão;

$\checkmark$ As técnicas de separação de erros para medição de erro de retilineidade podem ser aplicadas na medição de desvio de planicidade; 
$\checkmark \mathrm{Na}$ medição de desvio de planicidade os resultados obtidos com o sistema proposto se aproximam em 97\% do valor obtido com o nível eletrônico e em $92 \%$ do valor obtido com o interferômetro a laser;

$\checkmark$ O tempo de medição com o sistema proposto é $88 \%$ menor que quando se utiliza interferômetro a laser;

$\checkmark$ O tempo de medição com o sistema proposto é comparável ao tempo de medição com o nível eletrônico;

Durante o desenvolvimento deste trabalho diferentes propostas para trabalhos futuros surgiram. São elas:

$\checkmark$ Utilização de uma mesa x-y para a substituição da MM3C no processo de medição;

$\checkmark$ Desenvolvimento de modelos para sepação de erros que eliminem os erros de movimentação da referência de medição mesmo quando a referência possua erros da mesma ordem dos erros do mensurando;

$\checkmark$ Automatização do processo de medição através da utilização de um robô para deslocar a garra de medição;

$\checkmark$ Desenvolvimento de sonda com sensores de medição sem contato. 


\section{Referências Bibliográficas}

ANSI/ASME B89.4.1. Methods for performance evaluation of coordinate measuring machines. (1997).

ASSOCIAÇÃO BRASILEIRA DE NORMAS TÉCNICAS (1980).

BRITISH STANDARTS INSTITUTION (1998).

BS 6808 Part 1-3: British Standard - Coordinate Measuring Machines (1989).

BUSCH T. (1988). Fundamentals of Dimensional Metrology.

CAMPBELL, A. (1995). Measurement of lathe Z-axis straightness and parallelism using a flat land. Precision Engineering v17 p207-210.

CARR K.; FERREIRA P. (1995). Verification of form tolerances Part 1: Basic issues, flatness, and straightness. Precision Engineering v.17 p131-143.

CHERAGHI, S.H. et al (1996). Straightness and flatness tolerance evaluation: an optimization approach. Precision Engineering v18 p3037. 
DAY P. E.; MARPLES V. (1972). A technique for measuring the flatness errors of machined surfaces. Apparatus and techniques, p1151-1153.

DECKER, J.E. AND PEKELSKY, J.R. (1999). Gauge Block Calibration and the expression of associated measurement uncertainties, Anais III Seminário de Metrologia Aeroespacial, Julho, pp 1-10

DEW, G.D. (1966). The measurement of optical flatness. J. SCI. INSTRUM. V43 p 409-415.

DICKINSON C. S. (1968). A method of flatness control in optical polishing. J. Sci. Instrum. V1 p 365-366.

Di Giacomo, B.; Magalhães, R. C. A.; Paziani, F. T. (2003). Reversal technique applied to the measurement of straightness errors. COBEM 2003.

EVANS, J.B.; HOCKEN, R.J.; ESTLER,W.T. (1996). Self-calibration: reversal, redundancy, error separation and "absolute testing". CIRP $\mathrm{v} 45 / 2$

FAN, K.C.; SHIOU, F.J. (1997). An optical flatness measurement system for medium-sized surface plates. Precision Engineering V21 p 102-112. 
GALE B.; WILSON L. (1962). A simple machine for testing flatness using air gauging. J. Sci. Instrum. V39 p 638-639.

GALYER,J.; SHOTBOLT,C. (1981). Metrology for Engineers.

GAO, W. et al (2002). A compact and sensitive two-dimensional angle probe for flatness measurement of large silicon wafers. Precision Engineering v26 p396-404.

GAO, W. et al (2002). Precision measurement of cylinder straightness using a scanning multi-probe system. Precision Engineering v26 p279-288.

GARCIA,D. F. et al (1999). Real-time flatness inspection system for steel strip production lines. Real-Time Imaging V5 p35-47.

HEKMAN, K.A.; LIANG, S.Y. (1997). Flatness control in grinding by depth of cut manipulation. Mechatronics v8 p323-335.

HEWLETT-PACKARD (1988). Laser Measurement System 5528A User's Guide.

HOWICK,E.F. et al (2003). Automaton of a 1960s Hilger gauge block interferometer. Metrologia v40 p139-145.

HUANG, S.T. et al (1993). A new minimum zone method for evaluating flatness errors. Precision Engineering v15 p25-32. 
HUANG,S.T.; FAN,K.C.; WU,J.H. (1993). A new minimum zone metho for evaluating flatness errors. Precision Engineering v15 p25-32.

ISO TAG 4/WG 3: Guide to the Expression of Uncertainty in measurement. (1993).

JAPANESE STANDARTS ASSOCIATION (1993).

KIYONO,S.; GAO,W. (1994). Profile measurement of machined surface with a new differential method. Precision Engineering v16 p212-218.

MARQUES, A. (2003). Uma Interface Eletrônica e Computacional Para Medições A Três Coordenadas, Tese de Doutorado, EESC-USP.

PAAKKARI, J.; AILISTO,H.; KOPOLA,H. (1998). Flatness and dimensional control of planar objects with a novel modular moiré system. J. Opt. v29 p174-178.

PAVAGEAU,S. et al (2003). High-accuracy optical measurement of flatness for large objects. Meas. Sci. Technol. v14 p2121-2126.

PAZIANI, F. T. (2005). Desenvolvimento de um sistema automatizado e dedicado de medição, Tese de Doutorado, EESC-USP. 
PHILLIPS, S.D. (1995). Performance Evaluations, in: BOSCH, J. A. Coordinate Measuring Machines and Systems.

PIRATElli, A. F. (1997). Método para Avaliação do desempenho de máquinas de medir a três coordenadas através de planejamento de Experimento, Tese de Doutorado, EESC-USP.

SARDINÃS, H. (1986). Metrologia Dimensional.

SLOCUM, A.H. (1992). Precision Machine Design.

STRÖBELE, S. (2001). A new machine for planarity measurement of CCDs and mosaics of CCDs. Experimental Astronomy v11 p151-156.

TANAKA, H.; SATO,H. (1986). Extensive analysis and development of straightness measurement by sequential-two-points method. Journal of Engineering for Industry v108 p176-182.

THE AMERICAN SOCIETY FOR MECHANICAL ENGINEERS (1998).

THOMAS, G.G. (1974). Engineering Metrology

TOZAWA, K. et al (1982). A new method for the measurement of the straightness of machine tools and machined work. Journal of Mechanical Design v104 p587-592. 
TRABAND,M.T. et al (1989). Evaluation of straightness and flatness tolerances using the minimum zone. Manufacturing Review v2 p189193.

WEBER et al (2002). A unified approach to form error evaluation. Precision Engineering v26 p269-278. 